\title{
Return on services : empirical studies on the financial consequences of customer service evaluations
}

Citation for published version (APA):

Streukens, A. C. P. (2005). Return on services : empirical studies on the financial consequences of customer service evaluations. [Doctoral Thesis, Maastricht University]. Universiteit Maastricht. https://doi.org/10.26481/dis.20050121as

Document status and date:

Published: 01/01/2005

DOI:

10.26481/dis.20050121as

Document Version:

Publisher's PDF, also known as Version of record

\section{Please check the document version of this publication:}

- A submitted manuscript is the version of the article upon submission and before peer-review. There can be important differences between the submitted version and the official published version of record.

People interested in the research are advised to contact the author for the final version of the publication, or visit the DOI to the publisher's website.

- The final author version and the galley proof are versions of the publication after peer review.

- The final published version features the final layout of the paper including the volume, issue and page numbers.

Link to publication

\footnotetext{
General rights rights.

- You may freely distribute the URL identifying the publication in the public portal. please follow below link for the End User Agreement:

www.umlib.nl/taverne-license

Take down policy

If you believe that this document breaches copyright please contact us at:

repository@maastrichtuniversity.nl

providing details and we will investigate your claim.
}

Copyright and moral rights for the publications made accessible in the public portal are retained by the authors and/or other copyright owners and it is a condition of accessing publications that users recognise and abide by the legal requirements associated with these

- Users may download and print one copy of any publication from the public portal for the purpose of private study or research.

- You may not further distribute the material or use it for any profit-making activity or commercial gain

If the publication is distributed under the terms of Article $25 \mathrm{fa}$ of the Dutch Copyright Act, indicated by the "Taverne" license above, 


\section{Return on Services}

Empirical Studies on the Financial Consequences

of Customer Service Evaluations 
C 2004, Sandra Streukens, Maastricht.

All rights reserved. No part of this publication may be reprinted or utilized in any form by any electronic, mechanical or other means, now known, or hereafter invented, including photocopying and recording, or in any information storage or retrieval system, without permission from the copyright owner.

Printed by DATAWYSE Maastricht ISBN 90-9018903-3 


\title{
Return on Services
}

\section{Empirical Studies on the Financial Consequences \\ of Customer Service Evaluations}

\section{PROEFSCHRIFT}

\author{
ter verkrijging van de graad doctor \\ aan de Universiteit Maastricht, \\ op gezag van de Rector Magnificus, Prof. Mr. G.P.M.F. Mols, \\ volgens het besluit van het Collega van Decanen, \\ in het openbaar te verdedigen \\ op vrijdag 21 januari 2005 om 12.00 uur
} door Alexandra Christina Petronella Streukens 


\section{Promotoren}

Prof. Dr. J.C. de Ruyter

Prof. Dr. Ir. C.P.M. van Hoesel

\section{Beoordelingscommissie}

Prof. Dr. J.G.A.M. Lemmink (voorzitter)

Dr. T.W. Andreassen

Prof. Dr. R.H.G. Meuwissen RA 
Voor de 5 allerliefsten in mijn leven:

Papa, Mama, Mark, Bas, en Eric 



\section{Acknowledgements}


Zonder de hulp van velen zou dit proefschrift niet tot stand zijn gekomen. De meeste dank ben ik verschuldigd aan mijn promotor Ko de Ruyter. Vanaf het moment dat ik aan mijn proefschrift begon, heeft hij een enorme hoeveelheid ideeën geproduceerd dan wel geintroduceerd die zeer waardevol waren voor het tot stand komen van dit proefschrift en die mij uitermate inspireerden mijn wetenschappelijke grenzen te verkennen en te verleggen. Naast zijn excellente academische vaardigheden, dienen ook zijn dito sociale vaardigheden vermeld te worden. Onder leiding van Ko is er een gezellige en zeer gemotiveerde aio groep ontstaan die erg hard werkt, maar ook veel leuke dingen doet. Ko, bedankt voor de inspirerende en gezellige aio-tijd die ik onder jouw leiding heb mogen meemaken. Verder vind ik het een grote eer om samen met jouw aio's te mogen gaan begeleiden en hoop ik dat ik ook in de toekomst nog bij tal van sociale evenementen je chauffeuse zal zijn.

Verder wil ik ook mijn andere promotor Stan van Hoesel bedanken. Ondanks zijn vele andere werkzaamheden en zijn overvolle privé leven heeft hij altijd tijd voor me vrijgemaakt om mijn werk te lezen en van waardevol commentaar te voorzien. Verder wil ik Stan oprecht bedanken voor zijn geduld en hulp bij het uitvoeren en programmeren van de optimalisatie probiemen die in dit proefschrift aan bod komen.

I also would like to thank the members of my graduation committee, Prof. Dr. Jos Lemmink, Prof. Dr. Roger Meuwissen, and Dr. Tor Andreassen, for the time and effort they have put in reading my dissertation. I really appreciate your comments and I think the quality of my dissertation greatly benefited from your critique.

Een speciaal woord van dank wil ik ook richten aan mijn collega's van de vakgroep Marketing \& Marketing Research voor de prettige werksfeer van de afgelopen jaren. Mijn oud-kamer genoten, die ik toch echt wel eens mis nu ik een kamer voor mezelf heb, zijn daarbij bijzonder belangrijk geweest. Ad, Allard, Thorsten, Michel, Roger, Claudia, Mirella, en Sonja veel dank voor jullie gezelligheid en steun. Ook wil ik op deze plaats Caroline, Lisa, Carl, Boudewijn en Roger bedanken voor het proeflezen van de afzonderlijke hoofdstukken van deze dissertatie. Tevens wil ik Willemijn, Janjaap, Marcel, 
Veronica, Rita, Tor, Allard, Caroline, Jos en Ad bedanken voor de vruchtbare en prettige samenwerking die geresulteerd heeft in tal van publicaties.

Verder wil ik degenen bedanken aan wie ik dit proefschrift opdraag, zij zijn de allerbelangrijksten en allerliefsten in mijn leven. Mijn vader en moeder wil ik danken voor hun niet aflatende steun en vertrouwen in mij. Ik ben blij dat ze me steeds dat zetje in de rug gaven als ik weer eens twijfelde aan mijn eigen capaciteiten. Ik ben er trots op dat mijn broer Bas naast me zal staan tijdens de verdediging van mijn proefschrift, en ik hoop dat ik in de toekomst ook zijn paranimf kan zijn. Van de "kump good" mentaliteit mijn oudste broer Mark kan ik nog veel leren, en ik hoop dat ik het nog een beetje onder knie krijg voor 21 januari. Eric, het leven met jouw is heerlijk, "Love is strong, and you're so sweet.......we make a beautiful team". Lieve Eric, ik hou met heel mijn hart van jou!

Sandra Streukens Maastricht, November 2004

P.S. Mijn broer Bas vond na het lezen van dit dankwoord dat er wel wat meer zinnen aan hem gewijd mochten worden, het liefst ook met een stukje Rolling Stones tekst erbij. Bas, bij deze hoop ik dat "I have come to your emotional rescue". 

Table of Contents 


\section{Introduction}

1.1 Customer evaluative judgments as performance indicators 2

1.2 Return on services 3

1.3 Gaps in the empirical literature 6

1.4 Current trends in the service industry 7

1.5 Objectives 8

1.6 Outline of this dissertation 9

2 The service profit chain: Meta analysis and assessment of causal effects

$\begin{array}{lll}2.1 & \text { Introduction } & 14\end{array}$

2.2 The research domain 15

2.3 The employee part of the SPC 16

2.3.1 The employee-job interface 16

2.3.2 The employee-coworker-manager interface 18

2.3.3 The employee-organization interface 20

2.4 The employee-customer interface of the SPC 22

2.5 The customer part of the SPC 23

2.6 Potential moderators 24

$\begin{array}{lll}2.7 & \text { Methodology } & 25\end{array}$

2.7.1 Literature search and inclusion criteria 25

2.7.2 Analysis of pairwise relationships 25

2.7.3 Moderator analysis 26

2.7.4 Causal models $\quad 27$

2.8 Results 28

2.8.1 Analysis of pairwise relationships 28

2.8.2 Moderator analysis $\quad 35$

2.8.3 Causal models 38 
2.9 Discussion and conclusions

2.10 Implications, limitations, and suggestions for further research

3 Managing frontline employees in service organizations: Analysis and Optimization

3.1 Introduction $\quad 52$

3.2 Model development 54

3.2.1 The service profit chain 56

3.2.2 Optimization and evaluation of service investments 60

3.3 Methodology 63

3.3.1 Measures 63

3.3.2 Sampling and surveying $\quad 64$

3.3.3 Estimation procedure SPC 66

3.3.4 Estimation procedure optimization framework 67

3.4 Analytical results 68

3.4.1 Empirical results SPC estimation 68

3.4.2 Implementation mathematical framework $\quad 70$

3.4.2.1 Effort, profitability, and rate of return $\quad 70$

3.4.2.2 Allocation of effort 72

3.4.2.3 Robustness of the optimal solution 73

3.5 Discussion and conclusion $\quad 74$

3.6 Limitations and suggestions for further research 76

$4 \quad$ Reconsidering nonlinearity and asymmetry in customer satisfaction and loyalty models

$\begin{array}{lll}4.1 & \text { Introduction } & 80\end{array}$

4.2 Structural relationships among customer evaluative judgments 81

4.3 Asymmetry 82 
4.4 Nonlinearity 83

4.5 Methodology and analytical results $\quad 86$

4.5.1 Sample 86

4.5.2 Questionnaire design and measurement properties 86

$\begin{array}{ll}\text { 4.5.3 Analytical results } & 87\end{array}$

4.6 Discussion and conclusion 93

4.7 Limitations 95

4.8 Suggestions for further research 95

$\begin{array}{lll}4.9 & \text { Appendix } & 97\end{array}$

5 Managing customer relationships by the customer equity criterion: An expected value approach

5.1 Introduction 100

5.2 An expected value approach to customer equity 101

5.3 The probability of customer retention 103

5.3.1 Focal constructs 103

5.3.2 Hypotheses 104

5.3.3 Customer heterogeneity 106

5.4 Customer monetary value 107

$\begin{array}{ll}5.5 & \text { Data and methodology } \\ & 108\end{array}$

5.5.1 Sampling 108

5.5.2 Questionnaire design and measurement properties 109

5.5.3 System of equations and estimation procedure 111

5.6 Empirical findings 112

5.6.1 Customer retention probability 112

5.6.2 Customer monetary value 114

$\begin{array}{ll}5.7 \text { Maximizing customer equity } & 116\end{array}$

5.7.1 Model development 116

5.7.2 Model implementation 120 
5.8 Limitations and suggestions for further research

5.9 Managerial implications

6 Conclusion

$\begin{array}{lll}6.1 & \text { Synopsis } & 130\end{array}$

6.2 An integrated perspective 131

6.2.1 Service employees 132

6.2.2 Customer service evaluations 133

6.2.3 Return on services 133

$\begin{array}{lll}6.3 & \text { Suggestions for future research } & 136\end{array}$

\section{References}

Studies used in meta-analysis

Nederlandse samenvatting

Curriculum vitae 

Chapter 1

Introduction 


\section{Scire est mensurare (Johannes Kepler)}

In this chapter we first introduce and describe the field this dissertation has relevance to. Next, we discuss the motivation that drives this study and the specific objectives of the individual studies. We conclude this chapter with an outline of the remainder of this dissertation, indicating how the four individual research projects described in this thesis are variations on a common theme and how they are related to each other.

\subsection{Customer evaluative judgments as performance indicators}

Kepler's adagio that "measuring is knowing" is more true than ever in today's highly competitive and results-oriented service industry. In fact, service management's concern of the highest priority is to measure and maximize the relationship between customer service evaluations and financial outcomes of the service organization (Kamakura et al. 2002; Zeithaml 2000; Rust et al. 1995; Greising 1994). The strategically oriented use of customer evaluative judgments reflects the shift from product-centered to customer-centered thinking that characterizes recent evolutionary stages of the marketing field. Central to this customer-centered marketing paradigm is the notion that it is not the actual product or service that produces financial value to a company, but rather the customer who buys the service or product. The notion that a firm's relationships with a customer can be viewed as an asset is grounded in both the resource-based view of the firm (Barney 1991; Hunt and Morgan 1995) and the relationship-marketing paradigm (Dwyer 1997; Morgan and Hunt 1994).

Recent services research indeed reflects an accumulating body of evidence on the relationship between customers' service evaluations and financial performance. Loveman (1998) was one of the first to empirically demonstrate that various forms of customer retention are positively related to financial performance. Moreover, Anderson et al. (1994) provide empirical evidence for a positive relationship between customer satisfaction and return on investment (ROI). Similarly, Nelson et al. (1992) report that perceived service quality drives financial performance. Based on these and related studies, we 
conclude that satisfied and loyal customers provide a significant source of financial value to the service firm. As a result, a growing number of managers appreciate using customer evaluative judgments as a leading indicator of financial performance, rather than relying on hard but historic figures such as market share (cf. Anderson et al. 1994; Rust et al. 2001). However, to fully appreciate the financial consequences of customer service evaluations two necessary conditions need to be met. First, efforts to improve service evaluations should be made financially accountable. Second, it is necessary to understand and quantify the entire chain of effects relating service evaluations to enhanced financial performance.

\subsection{Return on services}

Although customer evaluative judgments like perceived service quality and satisfaction can be considered as important leading indicators of a service firm's financial performance, programs aimed at improving customer service evaluations have not always yielded the anticipated results (Anderson and Mittal 2000). Rust et al. (1995) illustrate this by providing examples of leading service firms that invested heavily in improving service delivery processes which could not be sustained by the firms resulting in bankruptcy or a sudden-death of the improvement actions. The examples offered by Rust et al. (1995) and research conducted by Anderson et al. (1994) and Fornell et al. (1996) illustrate that efforts aimed at improving customer service evaluations are frequently subject to diminishing returns. This in turn illustrates the inherent complexity of the relationship between customer service evaluations and its financial consequences.

In response to this, Rust et al. (1995) argue that rather than focusing on maximizing quality and satisfaction scores at all costs, the costs and revenues associated with service improvement initiatives aimed at improving customer evaluative judgments need to be balanced. This idea forms the basic premise of Rust et al.'s (1995) Return on Quality (ROQ) approach. The value of the ROQ approach lies in that fact that it forces to judge service improvement initiatives from a financially sound perspective and places the evaluation of these service improvement initiatives on an even footing with other 
investment opportunities. The ROQ approach is based on the principles that effort directed at improving customers' service quality evaluations (cf. Rust et al. 1995): (1) should be considered as an investment; (2) must be financially accountable; (3) are subject to diminishing returns; and (4) are not all equally valid.

In making service improvement initiatives financially accountable it is crucial to understand the complete chain of effects from resource allocation to customer evaluative judgments to enhanced financial performance (Rust and Zahorik 1993). The service profit chain (SPC) (Heskett et al. 1994) is an integration of research from several academic fields, including services marketing, human resources, and services operations and offers a comprehensive framework of the relationship among service employees, service customers, and the financial performance of service firms (Loveman 1998). In short, Heskett et al. (1994) posit that revenues are driven by customer service evaluations which in turn are determined by employee attitudes and behaviors.

The starting point of the SPC is the notion that employee perceptions concerning their job, organization, and colleagues drive employees' attitudes and behavior towards service delivery. The importance of service employees' attitudes and behaviors of service employees is underscored by many researchers. Czepiel (1990, p.13) states that "an encounter is the point on which both today's and tomorrow's business success hinges". Furthermore, the service as performed by the employee is often the service quality as perceived by the customer (Bitner 1990). In support of this notion ample empirical research is available. Hartline and Ferrell (1996) show that employee job satisfaction is a significant determinant of customer perceived service quality. A finding that is in line with Schneider (1980) who states that employee satisfaction is the primary reason to deliver quality service. Similarly, Peccei and Rosenthal (1997) find that the extent to which service employees are affectively committed also influences the customer service evaluations. In addition, Bell and Menguc (2002) demonstrate that employee citizenship behaviors have a substantial influence on customer evaluative judgments. 
The second half of the SPC describes the interrelationships among customer evaluative judgments and how these customer evaluative judgments translate into financial performance. This part of the SPC hypothesizes that customer perceived service quality leads to customer satisfaction, which in turn leads to customer loyalty. The final link of the service profit chain, the assumption that customer loyalty results into financial performance, forms the underlying premise in research on the financial accountability of customer service evaluations. Only when the strength and nature of the link between customers' perceptions of the service and actual repurchase behavior is understood, economic consequences of service quality investments can be estimated (Zahorik and Rust 1992).

In line with this last association entailed in the SPC, it becomes obvious that maintaining strong relationships with customers provides a tremendous source of financial value to a firm. From the firm's perspective, the financial value of a customer is reflected in the "life time value" of a customer. The customer lifetime value (CLV) is the sum of discounted net contribution margins over time of the customer, or the revenues provided to firm, minus the firm's cost associated with maintaining a relationship with a particular customer (Berger et al. 2002). The total of the discounted lifetime values of a firm's complete set of customers is referred to as a firm's customer equity (Rust et al. 2000; Berger and Nasr 1998). As a firm's customer equity has been shown to be a good indicator of a firm's financial value (Gupta et al. 2004), customer equity is probably the most effective criterion managers can use in determining their course of action.

Having explained the importance of quantifying the links between service evaluations and their financial consequences, we now outline several gaps in the empirical literature that need to be addressed in order to effectively manage service evaluations in terms of their financial consequences. These shortcomings in the empirical literature form the major theoretical rationale for undertaking our research. 


\subsection{Gaps in the empirical literature}

Despite the great academic and managerial interest in understanding the entire array of relationships entailed in the SPC, the preponderance of empirical studies available on the links suggested in the SPC focus only on discrete relationships (notable exceptions are Kamakura et al. 2002 and Loveman 1998). In order to obtain a more profound insight into the mechanisms underlying the SPC an integral multi-equation approach is needed for at least two reasons. First, a focus on discrete relationships of the SPC impedes the identification of causal and mediating processes (cf. Kamakura et al. 2002). Second, an exclusive focus on isolated links may lead to equivocal and mixed results due to omitted variable bias (cf. Wayne et al. 1997).

In explaining the formation of customer loyalty Heskett et al. (1994) focus on the relationship between service quality, satisfaction and purchase intentions. A shortcoming of models that only use service quality and satisfaction as antecedents of behavioral intentions is that the focus is solely on benefits associated with service or product use, whereas the sacrifices that are in involved are ignored (Patterson and Spreng 1997). Furthermore, drawing on recent advances in relationship marketing we believe that the extending the SPC to include customer relationship perceptions enhances our understanding of the formation of customer loyalty (e.g. Garbarino and Johnson 1999; Verhoef 2003).

Although there is great consensus concerning the importance of service employees in the formation of customer evaluations, the exact mechanism covering the influence of service employees' attitudes and behaviors on the formation of customer service judgments has remained unclear. Furthermore, research is needed to uncover factors that elicit the appropriate attitudes and behaviors from service employees.

With regard to their functional forms the true nature of the relationships put forward in the SPC remain unclear. Recently, researchers stated that the use of symmetric linear functional forms to capture the relationships put forward in the SPC leads to serious misspecification of these relationships (Anderson and Mittal 2000). Despite the fact that some studies indicate that asymmetric nonlinear functional forms indeed perform well in explaining the relationships 
among customer evaluative judgments (e.g. Mittal et al. 1998; Ngobo 1999; Otani et al. 2003), the question whether these asymmetric nonlinear functional forms indeed possess superior explanatory power compared to the often-used symmetric linear functional forms remains unaddressed.

In the spirit of the market concept, assessing customer service evaluations is only useful to the extent that it changes a firm's actions, in a way that enhances expected financial performance (Rust et al. 2000; Churchill 1995). Consequently, the most important implication of quantifying the link between customer service evaluation and financial performance is to connect customer service evaluations to decision making (Rust et al. 2000; Zeithaml 2000). In addition, one of the decision areas in services research which has attracted considerable attention is that of maximizing the financial consequences of service improvement initiatives (Zeithaml 2000; Berger et al. 2002; Bell et al. 2002; Berger and Nasr 1999). Although several researchers (e.g. Harker 1995; Rust and Metters 1996) underscore the prospective contribution of mathematical models to effective and efficient service management, the design and application of such models remains underdeveloped.

From a practical point of view, our research effort has also strongly been fueled by the dominance of the service industry in many Western economies and the changes taking place in both the national and international service environment that mark a new era in which there is a need for a much more results-oriented approach to service management. These issues will shortly be reviewed in the next paragraph.

\subsection{Current trends in the service industry}

In many Western economies, the majority of the GDP (Gross Domestic Product) is now accounted for by the services industry. Moreover, in these economies, substantially more than half of the total labor force is employed by the service industry. The vast number of service customers and service encounters implied by these figures demonstrate the value of an in-depth assessment of the financial consequences of customer service evaluations and how these customer service evaluations can be effectively managed. 
Furthermore, the need to adopt a more precise, efficient and accountable approach to service management is driven by several substantial changes in the both the national and international service environment. First, given the increased competition in the service industry, both nationally and internationally, service firms need to be increasingly results-oriented in order to survive. Second, faced with the overwhelming amount of customer information on attitudes and behavior service firms new approaches to effective strategic decision-making are both desired and necessary to stay ahead of the competition. Third, impelled by recent business scandals service firms and their managers are under growing pressure to be more open and accountable to shareholders. Fourth, as most developed service economies face slow growth, mature markets, customers become an increasingly scarce resource pursued by an increasing number of aggressive suppliers.

The importance of the research topic addressed in this dissertation is also underscored by the fact that leading service companies consider the need for a more results-oriented service management approach so important that the Marketing Science Institute has established its highest priority for 2002-2004 as "Assessing Marketing Productivity (Return on Marketing) and Marketing Metrics" (see also Rust et al. 2004).

\subsection{Objectives}

As can be concluded from the literature outlined in previous paragraphs there is a great need among both academics and practitioners to understand how customer service evaluations should be effectively managed in terms of financial consequences. This leads to the following overall objective guiding this dissertation:

\section{"To investigate how to effectively manage customer service evaluations in terms of financial consequences"}

In order to successfully fill the gaps in the empirical literature described above and to effectively address the overall objective of this dissertation from a 
variety of perspectives, we formulated four related research projects. These four research projects were guided by the following research objectives:

1. To conduct an integral test of the relationships put forward in the SPC

2. To understand what service employees' perceptions, attitudes, and behavior are relevant antecedents of customer service evaluations and how these employee constructs affect customer service evaluations

3. To understand what customer service evaluations contribute to the formation of customer loyalty and how these customer service evaluations are interrelated

4. To empirically test the true nature of the functional forms describing the relationships among customer evaluative judgments

5. To design a mathematical optimization framework that can be used for a formal and economically justified evaluation and optimization of the financial consequences of efforts directed at improving service evaluations.

In the next paragraph, we will elaborate on the contents of the remainder of this dissertation and how the various chapters are related to the research objectives outlined above.

\subsection{Outline of this dissertation}

This dissertation explores the relationship between customer service evaluations and their financial consequences. Consistent with this goal, the SPC framework, the ROQ approach, and customer equity approach play a fundamental role in the four studies of this dissertation. Despite sharing an obvious common theme, the different studies draw from and contribute to different literature streams and integrate different theoretical perspectives. Furthermore, the studies in this dissertation employ and link multiple data sources and apply a wide array of advanced statistical data analysis techniques. 
The studies conducted in chapters 2,3 , and 4 draw heavily on the relationships outlined in the SPC. Chapter 2 takes a very broad approach to the SPC as it aims to review and summarize the available literature so far. Following a meta-analytic approach, we synthesize the empirical information available on the separate links of the SPC into a multivariate integral test of the SPC. Furthermore, chapter 2 aims to provide insight into the processes that link employee and customer perceptions and the mechanisms that describe the sequence of effects among customer evaluative judgments. Chapter 3 also provides an integral test of the complete service profit chain, although we narrow down our focus by examining the influence of a specific set of employee constructs on customer evaluative judgments and their ultimate influence on service profitability. Chapter 3 builds on chapter 2 , in the sense that the results of our meta-analysis guided our selection of employee perceptions under study. From a theoretical perspective, chapter 3 relies heavily on boundary-spanning literature and insights from linkageresearch.

Whereas chapters 2 and 3 assess the entire gamut of relationships put forward in the SPC, chapter 4 only assesses that part of the SPC describing the relationships among the customer evaluative judgments. Another distinctive feature which sets the analysis of the SPC in chapter 4 apart from the studies described in chapters 2 and 3 , is that chapter 4 solely focuses on the nature of the relationships among customer evaluative judgments. Understanding the true nature of the relationships among key customer evaluative judgments is a necessary condition to correctly prioritize and evaluate the consequences of efforts aimed at improving customer service evaluations.

In chapter 5 we explore the financial consequences of customer evaluative judgments from a customer equity perspective. In line with the basic principles of relationship marketing we explore how customer relationship perceptions influence customer retention, which in turn is related to customer monetary value. Although not explicitly mentioned in the previous paragraph, elements of the SPC can be recognized in our model used to explain the formation of customer retention. 
In chapters 3 and 5 we take into account both the costs and revenues associated with service investments, allowing us to make the service investments financial accountable by applying the principles of the ROQ approach. In both chapters the ROQ approach is modeled as part of a mathematical framework. Besides evaluating the financial consequences of investments aimed at improving service perceptions, we also use these mathematical frameworks to determine investment strategies that optimize the financial consequences of service investments.

The data we explore in our four studies come from various sources. For the meta-analysis in chapter 2 we collected studies that contain correlation coefficients on the relationships put forward in the SPC. Chapter 3 links data from 3 different sources: employee data, customer data, company data on customer revenues. In chapter 3, aggregated employee data (per service team) were linked to individual customer data on service perceptions and revenues (cf. Allen and Grisaffe 2001, Kamakura et al. 2002).The unit of analysis in chapter 3 is the individual customer. For our analysis in chapter 4 we used survey data obtained from customers from four different retail settings. Chapter 5 links customer data to company data on customer usage. The data for chapters 3 and 5 were collected at an internationally operating company in office equipment.

Finally, chapter 6 presents a summary of the main conclusion that can be draw from our four studies and offers suggestions for future research. Tables 1.1 and 1.2 provide a summary of the outline of this dissertation.

Table 1.1 Overview of the research objectives addressed in the individual chapters

\begin{tabular}{lcccc}
\hline Research Objectives & Chapter 2 & Chapter 3 & Chapter 4 & Chapter 5 \\
\hline Integral test SPC & $\sqrt{ }$ & $\sqrt{ }$ & $\sqrt{ }$ \\
Employee constructs & $\sqrt{ }$ & $\sqrt{ }$ & $\sqrt{ }$ & $\sqrt{ }$ \\
Customer constructs & $\sqrt{ }$ & & $\sqrt{ }$ \\
Functional forms of relationships & & $\sqrt{ }$ & \\
Optimization & & $\sqrt{ }$ & \\
\hline
\end{tabular}

"Integral test of customer-side of SPC 
Table 1-2 Summany of the topics discussed in this dissertalion

\begin{tabular}{|c|c|c|c|c|}
\hline & Chappter 2 & Chapter 3 & Chapter $A$ & Chaprer 5 \\
\hline Subject & $\mathrm{SPC}: \mathrm{A}$ meta-analysts & $\begin{array}{l}\text { Service employees, service } \\
\text { customers, and profitabiliry }\end{array}$ & $\begin{array}{l}\text { Functional form and customer } \\
\text { service craluations }\end{array}$ & $\begin{array}{l}\text { Custome: relatonshap } \\
\text { management and profitability }\end{array}$ \\
\hline Key framework & $S P C_{-}^{-}$ & $S P C, R Q D$ & $S P C$ & Custonet equiry, $\triangle P C, R O Q$ \\
\hline Theoretical background & $\begin{array}{l}\text { Services marketing literature } \\
\text { Grgandartonal litenature } \\
\text { Linkage restarch }\end{array}$ & $\begin{array}{l}\text { Services marketing literature } \\
\text { Organizational literature } \\
\text { Boundary-spanning lizerature } \\
\text { Lankage research }\end{array}$ & Serwices marketing literature & $\begin{array}{l}\text { Services marketmg literature } \\
\text { Relationship marketing literature }\end{array}$ \\
\hline Data sourcey & Published studies & $\begin{array}{l}\text { Employee survey } \\
\text { Customer sarvey } \\
\text { Company data }\end{array}$ & Customer survey & $\begin{array}{l}\text { Customer survey } \\
\text { Company data }\end{array}$ \\
\hline Service setting & Various & Office equipment & Four diffezent retal services & Otfice cquipment \\
\hline Analysis tcelıniçuc & $\begin{array}{l}\text { Meta-analysis } \\
\text { Regression analysis (SUR) }\end{array}$ & $\begin{array}{l}\text { Regression anaiysis (PLS) } \\
\text { Nonilintar programming }\end{array}$ & $\begin{array}{l}\text { Regression analysis (OLS) } \\
\text { Steiger's test }\end{array}$ & $\begin{array}{l}\text { Regression analysis (SLR, PCR) } \\
\text { Time series analysis } \\
\text { Nonlinear programming }\end{array}$ \\
\hline
\end{tabular}




\title{
Chapter 2
}

\section{The Service Profit Chain: Meta-Analysis and Assessment of Causal Effects}

\begin{abstract}
In this study we review more than 300 studies concerning the relationships put forward in the service profit chain (SPC). These studies form the basis for a three-phase, quantitative investigation of the relationships proposed in the SPC. First, the strength and magnitude of pairwise relationships are assessed by means of a meta-analysis. Second, study characteristics coded as moderator variables are used to account for variability in effect sizes. Third, weighted mean correlations resulting from the analysis of pairwise relationships are used to evaluate three causal models that describe the chain of effects underlying the SPC. In general, the individual pairwise relationships as well as the causal models offer support for the relationships in the SPC. Furthermore, systematic moderating effects of measurement level, type of service offering, and service industry are found.
\end{abstract}




\subsection{Introduction}

During the past decades services research has become a major research domain in the leading marketing journals. This research attention is well justified, considering that the service sector accounts for the large majority of total employment and gross national product in most parts of the world. Furthermore, a focus on service excellence has become an important competitive cornerstone for companies across many industries (Rust et al. 1995). Well-performing service employees and systems aimed at delivering quality service generate high levels of customer satisfaction. Satisfied customers are likely to be loyal and, in turn, loyalty is a key driver of financial performance. This simple logic is the basis for the so-called service profit chain (SPC) (Heskett et al. 1994). One of the unique characteristics of the SPC is its use of customer satisfaction and loyalty as leading indicators of financial performance, rather than focusing on hard and historic figures, such as market share. Furthermore, in combination with Rust et al.'s (1995) Return on Quality approach, the SPC can be used for evaluating the economic returns of service quality investments (see for example Kamakura et al. 2002).

As the SPC integrates various research streams, including services marketing, human resources, and service operations (Loveman 1998) a vast amount of empirical research is available with regard to the individual relationships that constitute the SPC. However, the strength, significance, and generalizability of the relationships put forward in the SPC have not yet been established by integrating empirical results across multiple research streams. Given the academic and managerial interest and need for understanding the relationships put forward in the SPC, a meta-analytic assessment of the relationships in the SPC across various service contexts seems necessary. Besides assessing the generalizability of the individual links that make up the chain, a meta-analytic review of the correlations among the various constructs in the SPC also enables us to estimate a series of path models that describe the chain of effects underlying the SPC. Moreover, a meta-analysis can provide fresh insights into a research area by sometimes producing surprising and unanticipated results (Brown and Peterson 1993). In the tradition of metaanalytic research the objectives of our study are (1) to assess the strength and 
consistency of all pairwise relationships put forward in the SPC. (2) to account for variance in these relationships by using study characteristics as moderator variables and (3) to estimate and evaluate causal models that describe the mechanisms underlying the SPC.

\subsection{The research domain}

With a number of notable exceptions (Loveman, 1998; Kamakura et al. 2002), the literature is scarce in comprehensive empirical tests of the SPC that take into account the entire gamut of the relationships proposed by Heskett et al. (1994). Many studies have been devoted to empirically assessing parts of the chain. Hence, meta-analysis allows us to integrate and unite these study findings resulting in an overview of the complete SPC.

To systematically discuss the constructs and relationships relevant to the SPC, we divide the SPC into three parts; (1) the employee part that describes how service employees perceive their working environment and how these perceptions build attitudinal and behavioral responses, (2) the linkage part (c.f., Schneider et al. 1992) that focuses on the interaction between employees and customers and finally, (3) the customer part, that is used to describe how customers' perceptions of service quality translate into satisfaction, loyalty and ultimately enhanced financial performance. $A$ thorough review of the services marketing literature as well as the literature of related fields reveals that many constructs have been proposed to understand various relationships put forward in the SPC. A synthesis of all these constructs and relationships leads to the research model presented in figure 2-1. We discuss all associations proposed in the research model in subsequent paragraphs. 
Figure 2-1 The service profit chain

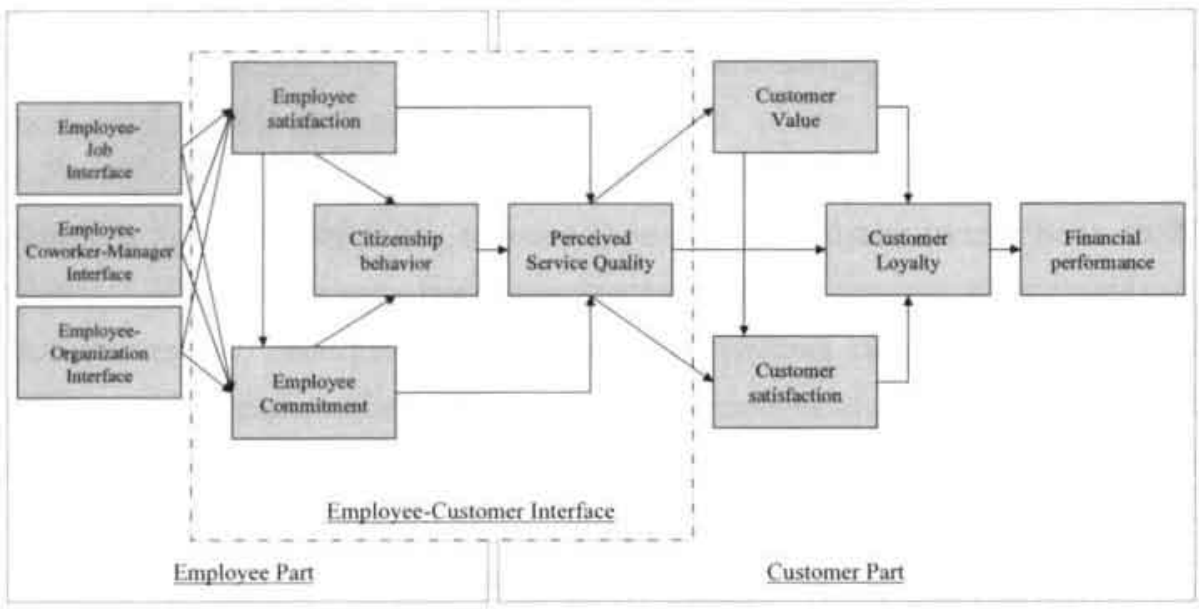

\subsection{The employee part of the SPC}

To a large extent, customers' perceptions of service quality depend significantly on the behaviors and attitudes of the employees delivering the service (Bettencourt and Brown 2003; Schneider and Bowen 1995). Therefore, service firms must find ways to effectively manage their customer-contact employees to help ensure that their attitudes and behaviors are conducive to the delivery of quality service (Hartline and Ferrell 1996). According to Heskett et al.'s (1994) definition of internal service quality, employees' perceptions of their job, colleagues, and organization are believed to influence their service attitudes and behaviors. Employee satisfaction, commitment, and organizational citizenship behavior (OCB) are among the most studied employee attitudes and behaviors in services research. In the next paragraphs, we discuss various antecedents to these attitudes and behaviors.

\subsubsection{The Employee-job interface}

Peccei and Rosenthal (2001) point out that appropriate job design is relevant to elicit the desired behavior of employees to customers. A wide variety of job 
conditions such as role stressors and task characteristics, have been studied in relation to employee attitudes like job satisfaction and commitment and employee behaviors like OCB. Below, we summarize aspects of the employeejob interface that emerge from the literature.

Role Stressors. Kahn et al (1964) conceptualize role stress as a composite construct consisting of the so-called role stressors of role conflict and role ambiguity. While role conflict refers to the perceived incompatibility among role expectations and demands that impinge on employee role performance, role ambiguity occurs when an employee lacks the information needed to effectively enact his role (Rizzo et al. 1970). It has been shown that role stressors are negatively related to job satisfaction (Grant et al. 2001), commitment (Singh 2000), and OCB (MacKenzie et al. 2001). As service employees commonly occupy boundary-spanning positions, the influence of role stressors is particularly relevant in a services context (Hartline and Ferrell 1996).

Task Characteristics. Hackman and Lawler (1971) propose that there are four "core dimensions" of job characteristics that are related to employees" reactions to their jobs. These four characteristics include task variety, task autonomy, task identity, and task feedback. Task variety refers to the degree to which a job requires a variety of different activities in carrying out the work, which involve the use of a number of different skills and talents of the employee. Task autonomy is described as the extent to which the job provides substantial freedom, independence, and discretion to the employee in scheduling the work and in determining the working procedures. Task identity denotes the degree to which an employee does an entire or whole piece of work and can clearly identify the results of his/her efforts. Task feedback is the degree to which an employee receives information about his/her work performance. Empirically, these task characteristics have shown to positively affect employee attitudes and behavior (Dubinsky and Skinner 1984; Glisson and Durick 1988; Law and Wong 1999). As the task characteristics outlined above capture the flexibility, initiative, and individualized care entailed in the 
concept of service quality (Peccei and Rosenthal 1997), these variables are relevant to our meta-analysis of the service profit chain.

\subsubsection{The employee-coworker-management interface}

It has been suggested that customer contact employees treat customers the way they are treated by management (Berkley and Gupta 1995). Moreover, according to Thompson (1996), the presence of a supportive and involved leader is critical to the development of employee attitudes that contribute to organizational success. Furthermore, it is well known that elements of the social context have an impact on the attitude and behavior of employees. Perhaps the most prominent social context for an individual employee is his/her immediate workgroup (Kidwell et al. 1997).

Leader Consideration. Leader consideration is the degree to which a supervisor creates an atmosphere of affective support and socio-emotional concern for the well being of subordinates (Jackson and Schuler 1985). According to Sager (1994), the positive association between leader consideration and job satisfaction can be explained by the notion that an employee who sees that the manager is concerned with the well-being of employees should be more satisfied with the job overall. Likewise, employees who believe their managers are supportive tend to be more committed to their organizations than those who do not perceive their managers to be supportive (Johnston et al. 1990). The direct positive relationship between leadership consideration and OCB in services settings is less pronounced, as can be concluded from the empirical results reported by Podsakoff et al. (1993) and Netemeyer et al. (1997).

Leader Initiating Structure. Leader initiating structure relates to the way in which a supervisor guides service employees, provides a psychological framework that clarifies roles, monitors subordinates' activities, and stimulates them to display better service performance (Wetzels et al. 1999). On a bivariate level of analysis many studies report a significant positive correlation between leader initiating structure and employee attitudes (e.g. Hampton et al. 1986; Teas et al. 1983). However, on a multivariate level of analysis, evidence for a 
significant positive relationship between leader initiating structure and employee attitudes is mixed in services research.

Participative Leadership. Several empirical studies found that participation in decision- making has a significant influence on the behavioral and psychological outcomes of employees (Teas 1983; Parker et al. 1995; Singh 1998). According to Singh (1998), this relationship can be explained by the idea that provision of a high level of participation in a job enhances the experienced meaningfulness of work, thereby leading to a high level of intrinsic motivation.

Leader-Member Exchange (LMX). Leader-member exchange is defined as the quality of the relationship between a supervisor and an employee (Graen and Scandura 1987). In line with social exchange theory, which is the most important basis for LMX theory, it is expected that LMX will be positively related to commitment and OCB (Wayne et al. 1997; Liden et al. 2000). Following the Leadership Making Model (Graen and Uhl-Bien 1991), subordinates who engage in constructive interaction and exchange with their supervisors (i.e. score high on LMX) report higher levels of job satisfaction. In a services context a positive relationship between LMX and job satisfaction is evidenced by Liden et al. (2000) and Law and Wong (1999).

Workgroup Cobesiveness. Cohesiveness describes group members' affinity for one another and their desire to remain part of the group. In cohesive workgroups individuals tend to be more sensitive to others and are more willing to aid and assist them (Kidwell et al. 1997). Several studies (e.g. Podsakoff et al. 1993; Kidwell et al. 1997) show that workgroup cohesiveness is significantly correlated with job satisfaction, affective commitment, and OCB in a services setting. Griffeth (1988) states that cohesive workgroups can provide emotional support for individuals and be a direct source of satisfaction. According to Van Dyne et al. (1995) workgroup cohesiveness is an important antecedent to favorable employee responses, as highly cohesive 
groups engender a strong social identity that can enhance members' desires to help one another.

\subsubsection{The employee-organization interface}

Organizational management shapes the organizational culture and sets a tone that influences how service employees feel about both the organization and their customers and, subsequently, how service employees treat customers (Allen and Grisaffe 2001; Bell and Menguc 2002). In addition, Morrison (1996) states that the employee-organization relationship is likely to have implications for employees' service-oriented attitudes and behaviors.

Perceived Fairness. Perceived Fairness refers to employee perceptions of the "rightness" of outcomes, procedures, and interactions with the firm (Greenberg 1990). Fairness is a fundamental characteristic of effective exchange relationships since it assures employees that they will receive their deserved reward for the effort and contributions to the organization (Organ 1990). One type of fairness that is particularly relevant to the study of employment relationships is "distributive justice" or "fairness in rewards allocation" (Netemeyer et al. 1997). Maxham and Netemeyer (2003) define distributive justice as the degree to which employees believe that they have been fairly rewarded for the performance, effort, experience, and stress associated with their job. Equity theory, social exchange theory, and the notion of reciprocity suggest that fairness (or justice) is positively associated with employee attitudes and behaviors (Netemeyer et al. 1997). In a services context, distributive justice has been shown to positively influence job satisfaction (Pillai et al. 1999), affective commitment (Ko et al. 1997), and organizational citizenship behaviors (Aryee et al. 2002).

Perceived Organizational Support. Perceived organizational support (POS) is the global belief that employees form concerning the extent to which the organization values their contributions and cares about their well-being (Eisenberger et al. 1986). As such, POS represents an attitudinal response to the organization as a whole. As high levels of POS are thought to create 
obligations within individuals to repay the organization, it can be expected that POS positively influences affective commitment and organizational citizenships behaviors (Rhoades and Eisenberger 2002). Furthermore, POS should contribute to job satisfaction by meeting socio-emotional needs, increasing performance-reward expectancies, and signaling the availability of aid when needed (Rhoades and Eisenberger 2002). Empirically, it has been shown that POS enhances job satisfaction (Allen et al. 2003), commitment (Rhoades et al. 2001), and citizenship behaviors (Shore and Wayne 1993) in services contexts.

Besides an understanding of how employee service attitudes and behaviors are affected by employee perceptions of the various interfaces in which employees are involved, it is also crucial to understand the nomological network among the service attitudes and behaviors themselves. Organizational behavioral scientists have shown that job satisfaction positively influences citizenship behaviors (e.g. Smith et al. 1983; Organ and Ryan 1995; Netemeyer et al. 1997). According to MacKenzie et al. (1998) employees who are satisfied with their jobs are more likely to engage in OCB out of gratitude to the organization or a desire to reciprocate the feeling of satisfaction they experience. Several theoretical explanations have been offered for this relationship, including social exchange theory and psychological contract theory (Netemeyer et al. 1997).

The hypothesized positive relationship between affective commitment and OCB is more complex. From a theoretical point of view, many explanations have been put forward concerning the relationship between commitment and OCB (e.g. Meyer and Herscovitch 2001; Mowday et al. 1982; Morrison 1994). Despite several appealing theoretical explanations proposing a positive link between affective commitment and $\mathrm{OCB}$, empirical evidence regarding this hypothesized positive relationship is mixed. Although several studies report significant positive relationship among commitment and OCB (e.g. Organ and Ryan 1995), this positive relationship often reduces to zero in multivariate analyses (e.g. Williams and Anderson 1991; MacKenzie et al. 1998). Finally, the management literature is almost unanimous in their finding that job 
satisfaction has a positive influence on commitment (e.g. Brown and Peterson 1993; MacKenzie et al. 1998).

\subsection{The employee-customer interface of the SPC}

Few things are as important to service firms as contact employees' attitudes and behaviors towards customers (Hartline and Ferrell 1996; Bell and Menguc 2002; Yoon and Suh 2003). Following our course of action set in the previous paragraph, we will proceed by discussing the influence of satisfaction, commitment, and OCB on customer service evaluations.

Several reasons have been advanced for explaining why OCB is expected to relate positively to customers' perceptions of service. First of all, Morrison (1996) suggests that the dimensions of OCB capture many of the discretionary behaviors alluded to in the services literature that are deemed essential for the delivery of superior service quality. Second, based on socialization theory, employees who exhibit higher OCBs towards coworkers or their firm will be more active in the fulfillment of customer needs in the customers' best interest, which will be reflected in the service quality evaluations (Yoon and Suh 2003). Third, from an internal organization perspective it is expected that $\mathrm{OCB}$ has a positive influence on service quality as OCBs enhance co-worker productivity, communication among employees, and build an esprit de corp among work colleagues (Bell and Menguc 2002).

The so-called "satisfaction mirror" suggests that satisfied employees contribute to satisfied customers (Heskett et al. 1994). According to Schneider (1980) and Schneider and Bowen (1985) job satisfaction is the primary reason that employees provide good service. Moreover, Churchill et al (1985) state that job satisfaction is closely related to employees' behavioral performance. As employee behavior often is the service as perceived by customers, Hartline and Ferrell (1996) suggest that especially in a service context job satisfaction will be positively related to customers' perceived service quality.

Schlesinger and Heskett (1991) note that the absence of the commitment to providing service quality accounts for more than fifty percent of customer defection in service industries. Employees with high levels of affective commitment, cannot only be expected to identify more fully with the 
organization and its core values, but also to exhibit a greater willingness to exert effort on its behalf (Mathieu and Zajac 1990) Thus, ceteris paribus, organizationally committed individuals can be expected to show a greater propensity to work hard and try to provide high-quality services, particularly if they perceive the organization as placing a strong value on this kind of behavior (Peccei and Rosenthal 1997).

\subsection{The Customer Part of the SPC}

In discussions concerning customer loyalty formation constructs like perceived service quality, perceived customer value, and overall satisfaction have taken center stage (Cronin et al. 2000). Although there appears to be a general consensus regarding the positive associations between service quality, customer satisfaction, perceived value and customer loyalty (Cronin et al. 2000; Nijssen et al. 2003; Streukens and De Ruyter 2004), there is at least one issue that is subject to considerable debate. This debate involves the order of the relationships among quality, satisfaction, and behavioral intentions. Dabholkar et al. (2000) suggest that satisfaction completely mediates the influence of perceived service quality on behavioral intentions. In contrast, Cronin et al (2000) and Mittal et al. (1998) suggest that in addition to the impact mediated by satisfaction, service quality also has a direct influence on behavioral intentions. A path-analysis using meta-analytic data provides an excellent opportunity to shed some light on this issue.

The final link of the service profit chain, the assumption that customer loyalty results in financial performance, forms the underlying premise in research on the financial accountability of service quality. Only when the strength and nature of the link between customers' perceptions of the service and actual repurchase behavior is understood, economic consequences of service quality investments can be estimated (Zahorik and Rust 1992). Several studies (Kamakura et al. 2002; Loveman 1998; Hallowell 1996) indicate that there is indeed a positive relationship between customers' evaluation of the service and financial performance. 


\subsection{Potential Moderators}

A more profound understanding of the strength and variability of pairwise relationships put forward in the SPC can be gained by considering potential moderating effects. For each of the three parts of the SPC we propose different moderators, which will be outlined below.

In line with Rhoades and Eisenberger (2002) and Brown (1996), we believe the relationships in the employee part and the employee-customer interface of the SPC may differ depending on the type of service industry for which an employee works, as the organizational context influences employee expectations and attitudes.

Regarding the customer part of the SPC we propose two potential moderators, which are related to the work of Szymanski and Henard (2001). First of all, we believe that the type of service offering may have an effect on the magnitude and variability of the effect sizes. In contrast to Szymanski and Henard (2001) who discern between services and products, we investigate the moderating effect of pure services as opposed to product-related services. Given the large inherent differences between services and products, we believe that the differences in satisfaction and loyalty formation as observed when comparing goods to services (see Szymanski and Henard 2001) can be extrapolated to a situation in which we compare pure services to productrelated services. Second, we believe that the magnitude of effect sizes may depend on the measurement level. By measurement level, we refer to whether satisfaction is captured through an aggregate or attribute level of measurement. Although aggregate measurement subsumes the attribute measurements, studies have shown that the two measures are likely to deviate from each other (Mittal et al. 1998). According to Szymanski and Henard (2001) this divergence occurs in particular when customers engage in partial information processing and partial satisfaction assessment or when consumers disproportionately weight the attributes incorporated into the overall service evaluation.

This concludes our review of the literature. In the next section we will report the meta-analytic study. 


\subsection{Methodology}

\subsubsection{Literature search and inclusion criteria}

Studies for inclusion in the meta-analysis were identified by means of a computer search of the PsycINFO and EBSCO databases'. In addition, we searched the references lists of leading meta-analyses ${ }^{2}$ associated with the relationships put forward in the SPC.

We used the following 3 criteria for selecting empirical relationships to be used in our meta-analysis. First, we only included relationships that are assessed by means of scientifically validated scales. Second, as our main research interest concerns the SPC, only relationships studies in a service setting were included in our design. Third, only relationships for which the zero-order Pearson product-moment correlation was available are included. Ultimately, 316 studies, containing 827 study effects, were identified that could be included in the analyses.

\subsubsection{Analysis of pairwise relationships}

The analyses were conducted using the procedures suggested by Hunter and Schmidt (1990). We corrected each correlation for attenuation using the scale reliabilities reported in each study. For studies that did not report reliabilities, correction for attenuation was accomplished by substituting the mean reliabilities from the meta-analysis for each variable (cf. Brown 1996). Furthermore, in cases where reliabilities were reported for separate subscales (e.g. OCB dimensions) but not for all items combined, we estimated the desired overall reliability using Nunnally and Bernstein's (1994) procedure for the correlation of linear combinations. For studies that contained more than one measure of the same subcategory, we followed the procedure outlined in Rhoades and Eisenberger (2002) in order to preserve the assumption of independent sampling.

Homogeneity estimates $(Q)$ were calculated for each relationship. Whenever outliers were removed to reduce heterogeneity of variance, the findings are 
reported both with outliers included and without outliers. In order to assess whether potential publication bias could seriously threaten the results of our meta-analysis, we calculated fail-safe Ns. This statistic provides the number of nonsignificant effect sizes that would need to be included to alter the determination that a relationship exists (Rosenthal 1991).

Statistics reported for each analysis include $k$ (number of samples in each analysis), $N$ (total number of participants in the analysis), $r_{\text {. (average weighted }}$ correlation) and its corresponding significance level, $r_{c-}$ (average weighted correlation corrected for attenuation) and the corresponding significance level, fail-safe $\mathrm{N}\left(F S N_{0.05}\right)$ and $Q$ (heterogeneity of effect sizes). The magnitudes of the corrected mean correlations are discussed using the guidelines suggested by Cohen (1988). According to these guidelines, corrected correlations less than 0.24 are considered small effects; those between 0.24 and 0.37 medium effects; and those larger than 0.37 are considered large effects.

\subsubsection{Moderator analysis}

Statistically significant $Q$ values suggest that other variables are moderating the observed relationship (Rhoades and Eisenberger 2002). For nonhomogeneous relationships, if elimination of a single outlier did not result in homogeneity and at least 10 study effects were available, moderator analysis was conducted to account for the variance in the effect sizes (cf. Brown and Peterson 1993).

In order to examine the potential moderator effects systematically we follow the procedure outlined by Lipsey and Wilson (2001). According to this procedure the total variability $(Q)$ is portioned into the portion of variance explained by the moderator $\left(Q_{b}\right)$ and the remaining variance $\left(Q_{w}\right)$. A significant value for $Q_{b}$ indicates that the mean effect sizes across categories differ by more than sampling error. It should be noted that $Q_{b}$ follows a Chisquare distribution with $j-1$ degrees of freedom; where $j$ denotes the number of categories. In case $j>2$, detection of a significant value for $Q_{b}$ is followed by significance tests of differences among the various subgroups using Rosenthal's (1991) formula. 


\subsubsection{Causal models}

Expecting a significant bivariate correlation between variables does not necessarily imply that a significant path should be specified between the same two variables in a structural model. Structural equation modeling is a multivariate technique in which the explanatory power of each variable is pitted against that of the other variables in the model (Wayne et al. 1997). In order to obtain a more profound insight into the mechanisms underlying the SPC, we test structural models for the three main parts of the SPC using the effect sizes obtained from the meta-analysis (cf. Viswesvaran and Ones 1995). The causal models are estimated using Seemingly Unrelated Regression (SUR). Opting for SUR allows us to take into account interrelationships among the various relationships and avoids identification problems as the degrees of freedom are based on the sample size in the analysis and not on the number of unique elements in the correlation matrix.

\subsection{Results}

\subsubsection{Analysis of pairwise relationships}

Table 2-1 summarizes the effect internal service quality has on employee attitudes and employee behavior. Based on the findings presented in table 2-1, we conclude that all internal service quality variables defined, significantly influence the formation of employees' attitudes. Regarding the creation of employee citizenship behavior the availability of empirical evidence was lacking for many variables. In case where empirical evidence was available regarding the development of citizenship behavior, we found significant relationships.

All three categories of internal service quality are strongly related to job satisfaction; organizational fairness and support $\left(r_{c,}=0.51\right)$, job conditions $\left(r_{c .}=0.43\right)$, and coworker-management perceptions $\left(r_{c *}=0.43\right)$. A similar pattern can be found for affective commitment which is mostly affected by organizational fairness and support $\left(r_{c_{*}}=0.69\right)$ followed by coworkermanager perceptions $\left(r_{c}=0.42\right)$ and job conditions $\left(r_{c}=0.40\right)$. Finally, 
concerning the formation of citizenship behavior we can state in particularly variables reflecting organizational and management characteristics have a substantial influence $\left(0.24 \leq r_{c *} \leq 0.36\right)$. Moreover, both role stressors only marginally seem to influence citizenship behavior (for both role stressors $r_{c-}=$ $-0.12)$.

Regarding the interrelationship among employee attitudes and behaviors, we can conclude that there is a medium effect size between satisfaction and citizenship behavior $\left(r_{c *}=0.21\right)$, whereas the relationship between commitment and citizenship behaviors is characterized by a large effect size $\left(r_{s}=0.38\right)$. Finally, we found a large mean effect size for the relationship between satisfaction and commitment $\left(r_{c *}=0.65\right)$.

Although little empirical evidence is available regarding the influence of employee attitudes and behaviors on the formation of customer attitudes, we did find support for the notion that employee attitudes affect the perceptions and attitudes of customer. We found customers' perceptions of service quality are moderately related to employees' job satisfaction $\left(r_{c *}=0.34\right)$ and commitment $\left(r_{c-}=0.28\right)$. Moreover, we find as strong relationship between employees' citizenship behaviors and perceived service quality $\left(r_{c-}=0.46\right)$. Details concerning the meta-analysis of the employee-customer interface are outlined in table 2-2. 
Table 2-1 Meta analytic correlations pairwise relationships employee part

\begin{tabular}{|c|c|c|c|c|c|c|c|}
\hline Relanonshipx & $N$ & $k$ & $r$ & $r_{c-}$ & $S D$ & $Q$ & $F S N_{0.05}$ \\
\hline E-J Interface - Satisfaction & 93804 & 187 & 0,33 & 0.43 & & & \\
\hline Role Ambugury & 15165 & 65 & $039^{\circ}$ & $0.47^{\circ}$ & 0.18 & $\operatorname{Kat} 22^{\circ}$ & 65002 \\
\hline Role Conflict & $166+4$ & 63 & $0.37^{\circ}$ & $0.45^{\circ}$ & 0.17 & $9727^{*}$ & 67560 \\
\hline Task Vancty & 15006 & 13 & ax" & $0 w^{*}$ & $a(n)$ & $196.85^{\circ}$ & 7062 \\
\hline Task Idenuty & 7658 & 9 & $027^{\circ}$ & $1032^{\circ}$ & 0,07 & $6621^{\circ}$ & 2 visi \\
\hline Task Siguificance & 14151 & III & $1128^{\circ}$ & $0.40^{\circ}$ & ar & $114.21^{\circ}$ & 5463 \\
\hline Task Fesubach & 9274 & 11 & $1131^{\circ}$ & $0.40^{\circ}$ & 200, & $6245^{\circ}$ & 4606 \\
\hline Task Iutonomy & 15906 & 16 & $036^{\circ}$ & $649^{\circ}$ & 0.12 & +43.27 & 14042 \\
\hline E-C-M Interface - Satisfaction & 14346 & 47 & 0.38 & 0.43 & & & \\
\hline Isadership Suppors & $43(0)$ & 20 & $1 .+7^{*}$ & $0.54^{*}$ & 0,14 & $217,2^{-\cdots}$ & $61+9$ \\
\hline Ieadesshup Inutuang Structure. & 1372 & y & $026^{\circ}$ & $0.30^{\circ}$ & 015 & $3+, 96^{\circ}$ & 309 \\
\hline Participative lesadenhip & 3019 & 7 & $0.34^{\circ}$ & $0 . w^{*}$ & 068 & $37.74^{*}$ & 1161 \\
\hline ISI & 1876 & 5 & $0+42^{\circ}$ & $0.49^{\circ}$ & $0(n)$ & $20,08^{\circ}$ & 725 \\
\hline Cohesiveness & 379 & 6 & $0, \pi 2^{\circ}$ & $6.38^{\circ}$ & 013 & $166,93^{\circ}$ & 1167 \\
\hline E-O Interface - Satisfaction & 8826 & 27 & $0.45^{\circ}$ & 0.51 & & & \\
\hline Percened Organizatsmal Support & 5195 & 15 & $0.55^{\circ}$ & $0.63^{\circ}$ & 10.16 & $3511.4^{\circ}$ & 9381 \\
\hline Destributuse fusuce & 3586 & 12 & $0.33^{*}$ & $0.34^{\circ}$ & $\alpha 19$ & $190.82^{\circ}$ & 20041 \\
\hline E-J Interface - Affective commitment & 30913 & 100 & 0.33 & $0 .+0$ & & & \\
\hline Role Ambeguity & 10073 & 38 & $40.7^{\circ}$ & $0.44^{*}$ & 0.16 & $494.41^{\circ}$ & 26787 \\
\hline Roke Conflict & 12949 & 42 & $0.33^{\circ}$ & $0.39^{\circ}$ & 0.17 & $710.05^{\circ}$ & $275 \times$ \\
\hline Task Vancty & 1392 & 5 & $0.26^{\circ}$ & $03 t^{\circ}$ & 0.11 & $2404^{\circ}$ & 237 \\
\hline Task Identry & 435 & 2 & $0,23^{\circ}$ & $0.31^{\circ}$ & 012 & $9.05^{\circ}$ & 22 \\
\hline Task Fecdtack & $29+4$ & 6 & $0,3^{\circ}$ & $0.39^{\circ}$ & $a w$ & $35.86^{\circ}$ & 667 \\
\hline Task Jutonomy & 2231 & 7 & $1123^{\circ}$ & $028^{\circ}$ & $0(n)$ & $27,45^{\circ}$ & 457 \\
\hline E.C-M Interface - Affective commitment & 11176 & M & 0.37 & 0,42 & & & \\
\hline Leadershup Suppon & $34 \geq 2$ & 12 & $1136^{*}$ & $0+00^{\circ}$ & 013 & $31.18^{\circ}$ & Mants \\
\hline Ieadership Iturtafing Structure & 638 & 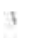 & $0.40^{*}$ & $0.46^{\circ}$ & $0 \times 2$ & $364 t$ & 13 \\
\hline Particpatuse / exdenhip & 6301 & 2 & $12+1^{*}$ & $0+6^{\circ}$ & sinis & 6011 & 94 \\
\hline ISIX & $24 \%$ & 8 & $10.40^{*}$ & $0,46^{\circ}$ & 0.110 & $124.78^{\circ}$ & 1532 \\
\hline ISMX audler momert & $23+4$ & 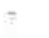 & $1138^{\circ}$ & $a+4^{\circ}$ & $<0001$ & 1184t & $105 k$ \\
\hline folvesiveness & $+1 k_{1}$ & 7 & $115^{\circ}$ & $0.43^{\circ}$ & $\operatorname{lin}(\sin )$ & $\operatorname{arcs} 6^{\circ}$ & $1 \times 15$ \\
\hline E-O Interface - Affective commitment & 12348 & 32 & 0.61 & 0.69 & & & \\
\hline Pefcerdol (Organizational Support & 0538 & 23 & $1265^{\circ}$ & $074^{\circ}$ & 0.11 & $493.03^{\circ}$ & $\operatorname{man} 2 \%$ \\
\hline Distnbutse lustce & 2710 & i) & $11+5^{\circ}$ & $0.51^{\circ}$ & 0,13 & $20134^{\circ}$ & $3 m$ \\
\hline \multicolumn{8}{|l|}{ Antecedents - Citizenship behavior } \\
\hline Roile Imbigain & 25013 & 7 & $2010^{\circ}$ & $4012^{*}$ & 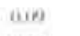 & $29+4^{\circ}$ & 114 \\
\hline Role Conflec & $|\mathrm{x}|_{2}$ & 5 & $111^{\circ}$ & $1012^{\circ}$ & 014 & $x \boldsymbol{F}^{*}$ & in \\
\hline Leaderifup support & fo4) & 5 & $1126^{\circ}$ & $1133^{*}$ & 6.111 & $19.6^{*}$ & 16. \\
\hline $1 \mathrm{MX}$ & 376 & 2 & $1031^{\circ}$ & $036^{\circ}$ & $\log$ & $3 \times 41$ & 35 \\
\hline Ciahesicness & 1766 & 3 & $1016^{\circ}$ & $10.1^{-*}$ & $<01011$ & $11 \times 4+$ & 4) \\
\hline Percesvad Cryamizational Support & 3291 & 11 & $023^{\circ}$ & $026^{\circ}$ & 06 & $2704^{\circ}$ & 601 \\
\hline Distributive lustice & $23 \times 8$ & 9 & $030^{\circ}$ & $1124^{\circ}$ & 0.14 & $616.5^{\circ}$ & +42 \\
\hline Jolo sansfactoon - Iffectwe commetment. & $\ln x+4$ & 96 & $0.55^{\circ}$ & $0.65^{\circ}$ & 0.12 & $22+13^{\circ}$ & 4K81K4 \\
\hline Joh sansfaction - Citizinship behasuer & $1032 x$ & 36. & 1127 & $032^{\circ}$ & 012 & $2+422^{\circ}$ & $1217 \mathrm{~K}$ \\
\hline Iffectire commeirment - Ciozenshup behaveer & 10274 & 30 & $0.31^{\circ}$ & $1038^{\circ}$ & o.ty & $716.73^{\circ}$ & $127 \%$ \\
\hline
\end{tabular}

- $p<0.01+p \geq 0.05$ 


\section{Chapter 2}

Table 2-3 summarizes the meta-analytic correlations among customer evaluative judgments. Based on these figures, we can conclude that all customer evaluative judgments are strongly related to each other. More specifically, we can see that perceived service quality is strongly related to perceived value $\left(r_{c t}=0.57\right)$, customer satisfaction $\left(r_{c *}=0.63\right)$, and intention to remain loyal $\left(r_{c+}=0.64\right)$. Furthermore, intentions to remain loyal are strongly related to both perceived value $\left(r_{c *}=0.63\right)$ and customer satisfaction $\left(r_{c *}=\right.$ $0.70)$. Finally, we can conclude that perceived value and customer satisfaction are strongly connected to each other $\left(r_{c+}=0.67\right)$.

Table 2-2 Meta-analytic correlations pairwise relationships employee-customer interface

\begin{tabular}{|c|c|c|c|c|c|c|c|}
\hline Relationship & $N$ & $k$ & $r$ & $r_{c+}$ & $S D$ & $Q$ & $F S N_{0.05}$ \\
\hline Job satisfaction $\rightarrow$ Service quality & 596 & 3 & $0.29^{\circ}$ & $0.34^{\circ}$ & 0.02 & 3,71 & 75 \\
\hline Affective commitment $\rightarrow$ Service quality & 135 & 2 & $0.24^{\circ}$ & $0.28^{\circ}$ & $<0.001$ & $8.17^{\circ}$ & 5 \\
\hline Citizenship behavior $\rightarrow$ Service quality & 408 & 2 & $0.40^{\circ}$ & $0.46^{\circ}$ & 0.17 & $21.76^{\circ}$ & 62 \\
\hline
\end{tabular}

Table 2-3 Meta-analytic correlations pairwise relationships customer part

\begin{tabular}{llllllll}
\hline Relationship & $N$ & $k$ & $r$ & $r_{c *}$ & $S D$ & $Q$ & $F S N_{0.05}$ \\
& & & & & & & \\
\hline Service Quality $\rightarrow$ Value & 4191 & 11 & $0.49^{\circ}$ & $0.57^{\circ}$ & 0.22 & $856.59^{\circ}$ & 5668 \\
Service Quality $\rightarrow$ Satisfaction & 25843 & 35 & $0.58^{\circ}$ & $0.63^{\circ}$ & 0.15 & $3180.98^{\circ}$ & 97522 \\
Service Quality $\rightarrow$ Loyalty intentions & 6699 & 18 & $0.57^{\circ}$ & $0.64^{\circ}$ & 0.08 & $160.13^{\circ}$ & 15109 \\
Value $\rightarrow$ Sattisfaction & 3977 & 10 & $0.60^{\circ}$ & $0.67^{\circ}$ & 0.07 & $210.99^{\circ}$ & 5179 \\
Value $\rightarrow$ Loyalty intentions & 4402 & 12 & $0.53^{\circ}$ & $0.63^{\circ}$ & 0.14 & $487.81^{\circ}$ & 6592 \\
Satisfaction $\rightarrow$ Loyalty intentions & 12303 & 42 & $0.62^{\circ}$ & $0.70^{\circ}$ & 0.15 & $1132.20^{\circ}$ & 78836 \\
\hline & & & & & & &
\end{tabular}

We found 19 studies (containing 65 study effects) that examined the relationship between customers' service evaluations and financial performance/actual purchase behavior. Given the great variety in both aspects of service evaluations and performance measures used in these 
studies, the above-mentioned set of 19 studies is not suitable for conventional meta-analytical procedures. Based on a thorough inspection of the studies, which are summarized in table 2-4, we can conclude that of the 65 study effects 41 times $(62.08 \%)$ a significant positive relationship was found between customer service evaluations and business performance. The remaining study effects ( 24 study effects or $36.92 \%$ ), fail to provide evidence of a significant relationship between customer service evaluations and financial performance. Finally, none of the 65 study effects indicated a significant negative relationship between customer service evaluations and performance.

Table 2-4 The effect of customer service evaluations on financial performance

\begin{tabular}{|c|c|c|}
\hline Study & Support & Finding and details of the study \\
\hline Hallourll (1996) & + & $\begin{array}{l}\text { Finds support for a positive relarionship between customer loyalty and profitability. } \\
\text { - Seven out of eight regression statistically significant } \\
\text { - } \mathrm{R}^{2} \text { ranges from } 0.168 \text { to } 0.398 \\
\text { - Customer loyalry measured in terms of length and depth } \\
\text { - Profitability is measured as NIE/Rev and } \mathrm{ROA} \\
\text { - Retail bank / Analysis at the aggregated level }(\mathrm{n}=59) \\
\text { - Control variables: houschold income, primary bank of elient }\end{array}$ \\
\hline $\begin{array}{l}\text { Kamateania at al. } \\
\text { (200)2) }\end{array}$ & + & $\begin{array}{l}\text { Find support for a positive relationship between customer retention and profitability } \\
\text { - Path coefticient }=0.13 \text {; } t \text {-value }=6.74(\mathrm{p}<0.01) \\
\text { - Customer retention measured by multiple measures (share of wallet, } \# \text { transaction / month; } \\
\text { tenure } \\
\text { - Profitability is defined as the monthly average profits generated by customers } \\
\text { - Retail bank / Analysis at the individual level }(n=3489)\end{array}$ \\
\hline $\begin{array}{l}\text { Anderson at al. } \\
\text { (1994) }\end{array}$ & + & $\begin{array}{l}\text { Find support for a positive relanonship berween customer satisfaction and ROI } \\
\text { - Elasticity berween customer satisfaction and ROI equals } 0.40 \\
\text { - Customer satisfaction is assessed by means of the SCSB } \\
\text { - ROI figures are collected at the business level } \\
\text { - Sample contains multiple industries; analysis at the aggregated level }(\mathrm{n}=77) \\
\text { - Control variables trend and past ROI }\end{array}$ \\
\hline Andermen at al. & + & Find support for a positive relationship between customer satisfaction and ROI \\
\hline
\end{tabular}




\begin{tabular}{|c|c|c|}
\hline (1997) & & $\begin{array}{l}\text { - Regression coefficient }=0.17 \text { (standard error }=0.09 \text { ) } \\
\text { - Customer satisfaction is assessed by means of the SCSB } \\
\text { - ROI figures are collected at the business level } \\
\text { - Sample contains multiple industries; analysis at the aggregated level ( } \mathrm{n}=126 \text { ) } \\
\text { - Control variables: productiviry and various interaction effects }\end{array}$ \\
\hline Lotrmain (1998) & + & $\begin{array}{l}\text { Finds support for a positive relationship berween customer loyalty and financial performance } \\
\text { - Customer loyalty is assessed by means of multiple measures (checking retention: } \\
\text { retention; average investable assets; cross selling) } \\
\text { - Financial performance is defined as the revenue per household } \\
\text { - Cross-selling } \rightarrow \text { Financial performance: regression coefficient }=162.8 \text { (st. ertor }=67.0 \text { ) } \\
\text { - Retention } \rightarrow \text { Financial performance: regression coefficient }=132.8 \text { (st. error }=20.1 \text { ) } \\
\text { - Investable assets } \rightarrow \text { Financial performance: not significant } \\
\text { - Retail bank; analysis at the individual level ( } n=955 \text { ) } \\
\text { - Control variables: various customer characteristics }\end{array}$ \\
\hline Ryan et al (t996) & 0 & $\begin{array}{l}\text { Fails to find to support for relation between customer satisfaction and business performance } \\
\text { - Customer satisfaction: } \% \text { of customer who are completely or very satisfied (single item) } \\
\text { - Business performance; total dollar profit; market share; volume } \\
\text { - Automobile finance company; analysis at aggregated level ( } \mathrm{n}=142 \text { ); rwo waves of data } \\
\text { - Control variables: branch size }\end{array}$ \\
\hline Koys (200I) & + & $\begin{array}{l}\text { Finds support for a positive (lagged) correlation between customer satisfaction and profitability } \\
\text { - Customer satisfaction: four items (e.g, "this is a great place to have a meal) } \\
\text { - Profitability" profits after deduction of controllable expenses, profits as " of total sales } \\
\text { - Profitability: Correlation coefficient }=0.33(\mathrm{p}<0.10) \\
\text { - Profitability as "o of sales: Correlation coefticient }=0.44(\mathrm{p}<0.05) \\
\text { - Regional restaurant chain, analysis at branch level }(\mathrm{n}=24)\end{array}$ \\
\hline
\end{tabular}

Miagnan et al, (t999)

Siempie $I$

Simple 2
Fail to find support for a relationship berween customer loyalty and business performance Finds support for a positive relationship berween customer lovalty and business performance

- Customer loyalty: scale developed for this study, 6 irems

- Business performance: scale designed by Samice and Roth (1992)

- Constructs evaluared from managers' perspective

- Marketing managers cmployed in various (service) settings ( $n_{1}=210, n_{2}=154$ ); the analysis was condueted at the individual level

- Correlation coefficient sample 1: not sugnificant

- Correlation coefficient sample 2:0.50 ( p < 0.05$)$

I irtherf ef al (2002)

Rrlationship I
Find support for a positive telationship between affective commitment and number of purchases Fail to find support for a relanonship between sansfaction and number of purchases

- Affective commitment: adapted from Anderson and Weitz (1992). Garbarino and fohnson (1999), and Kumar et al (1995). The items contains a strong loyalty component 
Nisison te al. (1992)

thaker atd Javion

(1994)

Bembuarit et al.

(2000)

Miagl (2003)

Rulation 1

Relation 2

I'inborf (2003)

Relation $!$

Relation 2
- Customer satisfaction: Singh $(1990)$ and 4 new items

- Affective commitment $\rightarrow$ \# purchases: Regression coefficent $=0.06(\mathrm{t}$-value $=2.59)$

- Customers from an insurance company ( $n=1946)$; analysis at individual level

- Control variables: income, number of cars, and relationship length

Find support for a positive relationship between service quality and financial performance

- Perceived service quality: various diserete dimensions

- Financial performance: earnings; net revenuc; return on assets

- Service quality dimensions are related to all 3 performance measures, $R^{2}$ value range from 0,16 to 0.27 (all $\mathrm{p}<0.05$ )

- Hospital setting, analysis conducted at aggregated level $(\mathrm{n}=51)$

Find support for a positive relationship between (service) quality and stock retums

- Quality perceptions: composite measure of quality, awareness, satisfaction, and loyalty

- Stock returns based on dividend distributions and chance of market value of stock

- Data available on 100 brands in 33 categories; analysis at aggregated level ( $n=83$ )

- Regression coefficient $=0.757$ (s.c. $=0.259$ )

- Control variables; advertising expenditures, ROI, salience, cconomy-wide factors

Find support for a positive (lagged) relation between $\Delta$ cust. satisfaction and $\Delta$ profitability / sales

- Customer satisfaction: single item

- Restaurant chain, analysis at aggregated level $(n=432)$

- $\Delta \mathrm{SAT} \rightarrow \Delta$ Profitability $/$ Sales $=0.42(\mathrm{p}<0.05)$

Finds support for a positive relationship between customer sansfaction and share of purchase Finds support for a positive relationship berween customer satisfaction and share of volume

- Customer satisfaction: approach used by Swedish and American Satisfaction Index

- Share of purchase / Share of volume: customers' diary data

- Customer satisfaction $\rightarrow$ SOP: regression coefficient $=0.013$ ( $\mathrm{t}-\mathrm{valuc}=3.57)$

- Customer satisfaction $\rightarrow$ SOV: regression coefficient $=0,016(\mathrm{t} \cdot$ value $=2.52)$

- Data concerned customers' grocery shopping, analysis at individual level ( $\mathrm{n}=643$ )

- Control variables: various customer characteristics

Fails to find support for a relatonship berween satisfacrion and Customer share development (CSD) Finds support for a positive relationshup between affective commitment and CSD

- CSD: amount of service purchased from supplier $X$ as percentage of total amount

- Customer satisfaction: Singh (1990) and four new items

- Affective commitment: adapted from Anderson and Wetz (1992), Garbanno and Johnson (1999), and Kumar et al. (1995). The items contains a strong loyalty component

- Affective commitment $\rightarrow$ CSD: Regression coefficient $=0.03(t$-value $=2.58)$

- Customers of financial service company, analysis at individual level ( $n=918$ )

- Control variables: Past customer share, relanonshup age, type of service purchased in past 


\begin{tabular}{|c|c|c|}
\hline Kimen (1999) & + & $\begin{array}{l}\text { Finds support for a positive telationship berween quality and revenues per available botel room } \\
\text { - Qualiry items are centered around relevant service delivery areas } \\
\text { - REVPAR = occupancy } \% \text { * average daily room rate } \\
\text { - Hotels, analysis at hotel level ( } \mathrm{n}=1135 \text { ) } \\
\text { - The average REVPAR is } \$ 3 \text { higher for hotels that have zeto quality defects }\end{array}$ \\
\hline Dell wif et at (2001) & + & $\begin{array}{l}\text { Find support for a positive relationship berween relationship quality and purchase behaviot } \\
\text { - Relanonship quality perceptions of relationship sarisfaction, trust, and commitment } \\
\text { - Purchase behavior: thiree items all related to share of purchase / share of wallet } \\
\text { - } 6 \text { samples; for } 2 \text { setrings (food, apparel) } 3 \text { countries (US, Belgium. The Netherlands) sample } \\
\text { size ranges from } 231 \text { to } 338 \text {; analysis ar individual level } \\
\text { - For all } 6 \text { samples the above finding holds; } R^{2} \text { range from } 0.04 \text { to } 0.21\end{array}$ \\
\hline $\begin{array}{l}\text { Kondupiliciei at ath } \\
\text { (1993) }\end{array}$ & + & $\begin{array}{l}\text { Find support for a positive relationship between overall service quality and market share } \\
\text { - Overall service quality: aggregated measure of various service components (e.g. repair) } \\
\text { - Data is collected from AT\&T customers } \\
\text { - No exact figures are given }\end{array}$ \\
\hline $\begin{array}{l}\text { Ittrer and Lanker } \\
\text { (1998) }\end{array}$ & & $\begin{array}{l}\text { Find support for a positive relationship between customer satisfaction and financial performance } \\
\text { - Customer satisfaction: } 3 \text { (weighted) items }\end{array}$ \\
\hline Indinzidual lesv? & + & $\begin{array}{l}\text { - Financial performance: Retention, Revenues, } \Delta \text { Revenues } \\
\text { - Customer of retail bank; analysis at individual level }(n=2491) \\
\text { - Custemer sarisfaction is significantly related to all three performance measures; } R^{2} \text { values range } \\
\text { - from } 0.013 \text { to } 0.049 \text { (all } p<0.05 \text { ) } \\
\text { - Control variables: relationshup age and size (rotal revenue) of customer }\end{array}$ \\
\hline Bunese letrl & Mixed & $\begin{array}{l}5 \text { analyses support a positive telationship berween customer satisfaction and performance; } 13 \text { analyses } \\
\text { find no support for a relarionship berween customer sarisfaction and performance } \\
\text { - Customer sarisfacnon: } 20 \text { irems } \\
\text { - } 6 \text { performance measures: revenues, expenses, margin, retum on sales, number of retail } \\
\text { customers, number of business and professional customers } \\
\text { - Retal bank branches; analysts at branch level ( } \mathrm{n}=73 \text { ) } \\
\text { - For the significant relationships } \mathrm{R} 2 \text { adj, }=0.11 \text {. } \\
\text { - Control vanables; past performance and company size }\end{array}$ \\
\hline Cupoen it al. (1990) & + & $\begin{array}{l}\text { Based on theit meta analytic study Capon et al. conclude that financial performance of companies is } \\
\text { posinively related to produet and service quality. }\end{array}$ \\
\hline
\end{tabular}

The average number of nonsignificant effects that would need to be added to the pairwise relationships to change statistically significant relationships to nonsignificance equals 22489. Furthermore, all pairwise relationships, except 
the relationship between affective commitment and perceived service quality, pass the 5k+10 guideline (Hedges and Olkin 1985; Rosenthal 1991), which states that the fail-safe $\mathrm{N}$ should be larger than 5 times the number of studies included in the meta-analysis plus 10 . Based on these figures we therefore conclude that publication bias is very unlikely to influence our meta-analytic findings.

\subsubsection{Moderator analysis}

Concerning the employee part of the SPC we found that type of service industry indeed has a significant influence on the magnitude of the relationships between model constructs. The relevant moderator effects concerning the employee side of the SPC are summarized below in table 2-5. With regard to the moderating effects of service industry, we found that negative effects of role ambiguity are most profound in an educational setting, whereas the negative consequences of role conflict on employee attitudes appear to be larger in retail contexts. Furthermore, we find that the associations between attitudes and behavior are largest in educational settings. In contrast, the link between job satisfaction and affective commitment is least strong in an educational setting.

The significant moderator effects for the customer side of the SPC are summarized in table 2-6. 
Table 2-5 Moderator effects service industry type

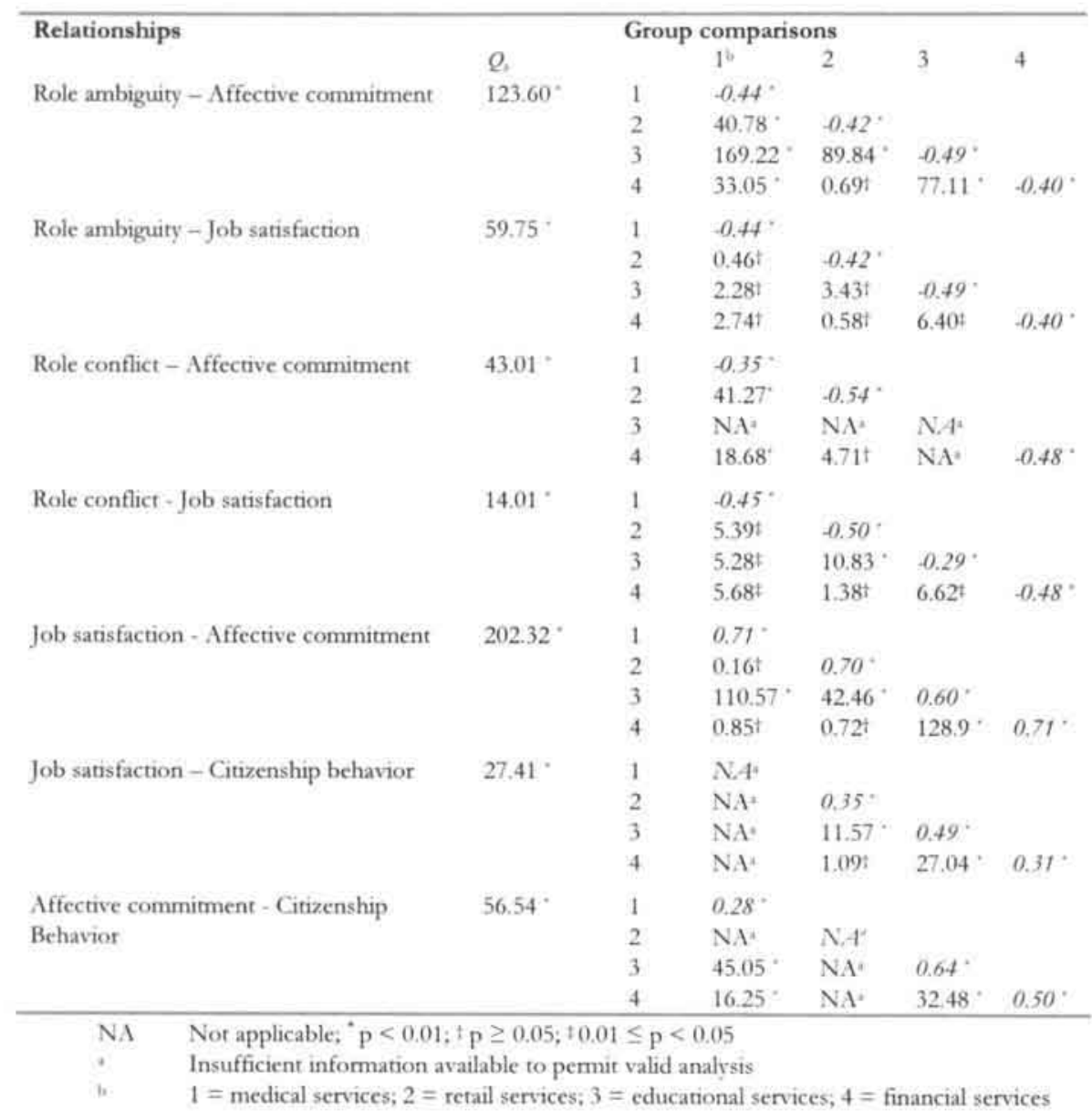


Table 2-6 Results moderator analysis customer side

\begin{tabular}{|c|c|c|c|}
\hline Relationships & $\begin{array}{l}\text { Quality measurement } \\
\text { (overall vs, attribute) }\end{array}$ & $\begin{array}{l}\text { Satisfaction } \\
\text { measurement } \\
\text { (overall vs. attribute) }\end{array}$ & $\begin{array}{l}\text { Type of Offering } \\
\text { (pure vs. product rel.) }\end{array}$ \\
\hline Quality - Value & $\begin{array}{l}\mathrm{Q}_{\mathrm{b}}=165.62^{\circ} \\
\left(0.80^{\circ} \text { r5. } 0.55^{\circ}\right)\end{array}$ & $\mathrm{NA}$ & $\mathrm{NA}^{*}$ \\
\hline Quality - Satisfaction & $\begin{array}{l}\mathrm{Q}_{b}=201.52^{\circ} \\
\left(0.82^{*}+5.0 .65^{*}\right)\end{array}$ & $\begin{array}{l}\mathrm{Q}_{\mathrm{b}}=114.12^{\circ} \\
\left(0.77^{\circ} \text { rs. } 0.64^{\circ}\right)\end{array}$ & $\begin{array}{l}\mathrm{Q}_{u}=274.09^{\circ} \\
\left(0.77^{\circ} \text { r. } 0.63^{\circ}\right)\end{array}$ \\
\hline Value - Sarisfaction & $\mathrm{NAs}$ & $\begin{array}{l}\mathrm{Q}_{\mathrm{b}}=36.17^{\circ} \\
\left(0.7 T^{\circ} \text { vs. } 0.66^{\circ}\right)\end{array}$ & NA \\
\hline Quality - Loyalty & $\begin{array}{l}\mathrm{Q}_{0}=1.78 \mathrm{t} \\
\text { (No differnice) }\end{array}$ & $\mathrm{NA}$ & $\begin{array}{l}Q_{0}=35.93^{\circ} \\
\left(0.77^{*} \text {, } 5.0 .58^{\circ}\right)\end{array}$ \\
\hline Satisfaction - Loyalty & $\mathrm{NA}^{-}$ & $\begin{array}{l}\mathrm{Q}_{\mathrm{b}}=183.71^{\circ} \\
\left(0.62^{\circ} \text { rs. } 0.77^{\circ}\right)\end{array}$ & $\begin{array}{l}Q_{10}=23.13^{\circ} \\
\left(0.73^{\circ} \text { 18. } 0.65^{\circ}\right)\end{array}$ \\
\hline Value - Loyalty & $\mathrm{NA}^{c}$ & $\mathrm{NA}^{i}$ & $\mathrm{NA}^{*}$ \\
\hline
\end{tabular}

NA Not applicable: ${ }^{\circ} \mathrm{p}<0.01 ;{ }^{\dagger} \mathrm{p} \geq 0.05$

Insufficient information to permit meaningful analysis.

Proposed moderator effect is not relevant for association between these vanables.

As can be seen in table $2-6$, the relationships among quality, value, and satisfaction are significantly more pronounced when at least one of the variables is measured on an aggregate level. Furthermore, we see that this phenomenon does not occur for the association between service evaluation and customer loyalty. More specifically, the association between quality and loyalty does not depend at all on the measurement level, while the relationship between satisfaction and loyalty is stronger when satisfaction is measured on an attribute level. Finally, similar to Szymanski and Henard (2001), we found larger effects in the customer part of the SPC when the research focus is on pure services compared to product-related services. 


\subsubsection{Causal models}

\section{Table 2-7 contains the path coefficients and model performance statistics of the three models describing various parts of the SPC.}

Table 2-7 Estimation Results Causal Models

\begin{tabular}{|c|c|c|c|c|c|}
\hline Relationship & $\beta$ & t-valued & p-value & $\mathbf{F}$ & $\mathbf{R}^{2}$ (adj) \\
\hline Employee-Job interface $\rightarrow$ Job satisfaction & 0.29 & 35.69 & $<0,0001$ & 2288.40 & 0.40 \\
\hline Employec-Cowork-Mngr interface $\rightarrow$ Job satisfaction & 0.19 & 21.63 & $<0.0001$ & & \\
\hline Employee-Organization interface $\rightarrow$ Job satisfaction & 0.38 & 46.06 & $<0.0001$ & & \\
\hline Employec-Job interface $\rightarrow$ Affective commitment & 0.15 & 21.78 & $<0.0001$ & 4188.49 & 0.62 \\
\hline Employee-Cowork-Mngr interface $\rightarrow$ Affective commitment & 0.05 & 7.08 & $<0.0001$ & & \\
\hline Employce-Organization interface $\rightarrow$ Affective commitment & 0.48 & 65.99 & $<0.0001$ & & \\
\hline Job satisfaction $\rightarrow$ Affective commitment & 0,32 & 40.89 & $<0.0001$ & & \\
\hline Job satisfaction $\rightarrow$ Affective commitment & 0.65 & $86.60^{\circ}$ & $<0.0001$ & 7534.03 & 0.42 \\
\hline Job satisfaction $\rightarrow$ Citizenship behavior & 0.13 & 10.60 & $<0.0001$ & 934.52 & 0.15 \\
\hline Affective commitment $\rightarrow$ Citizenship behavior & 0.30 & 24.96 & $<0,0001$ & & \\
\hline Job sarisfaction $\rightarrow$ Service quality & 0.22 & 19.86 & $<0.0001$ & 1163.23 & 0.25 \\
\hline Affectuve commitment $\rightarrow$ Service quality & n.s. & n.s. & & & \\
\hline Citizenship behavior $\rightarrow$ Service quality & 0.39 & 42.58 & $<0.0001$ & & \\
\hline Service quality $\rightarrow$ Value & 0.57 & 51.67 & $<0.0001$ & 2670.04 & 0.32 \\
\hline Service quality $\rightarrow$ Satisfaction & 0.37 & 33.16 & $<0.0001$ & 3256.86 & 0.54 \\
\hline Value $\rightarrow$ Satisfaction & 0.46 & 45.55 & $<0,0001$ & & \\
\hline Service quality $\rightarrow$ Loyalty intentions & 0.28 & 23.85 & $<0.0001$ & 2554.12 & 0.58 \\
\hline Value $\rightarrow$ Loyalty intentions & 0.22 & 17.97 & $<0.0001$ & & \\
\hline Satisfaction $\rightarrow$ Loyalty intentions & 0.38 & 29.60 & $<0.0001$ & & \\
\hline
\end{tabular}

To test the significance of the coefficients the median of all relevant sample sizes was used. This leads to the following sample size: model 1: 10328; model 2: 10271; model 3: 5550.

- Concerning our second causal model, the coefficient between job satisfaction and affective commitment is largely overestimated both in terms of magnitude and significance. This occurred due to the omission of the internal service quality predictors in our second causal model. Consequently. we refer to our first causal model for a valid estimation of the relationship between job satisfaction and affective commiment. 
Our analysis indicates that the three general categories of internal service quality indeed have a positive and significant effect on service employees' attitudes (system weighted $R^{2}=0.53$ ). Employee perceptions concerning the organization have the largest impact on both employee satisfaction $(\beta=0.38$; $\mathrm{t}$-value $=46.06)$ and commitment $(\beta=0.48 ; \mathrm{t}$-value $=65.99)$, followed by job perceptions (satisfaction: $\beta=0.29$; $\mathrm{t}$-value $=35.69$; commitment: $\beta=$ $0.15 ; \mathrm{t}$-value $=21.78$ ) and the coworker-manager perceptions (satisfaction: $\beta$ $=0.19 ; \mathrm{t}$-value $=21.63 ;$ commitment: $\beta=0.05 ; \mathrm{t}$-value $=7.08)$. In line with previous meta-analytic path analyses (e.g. Brown and Peterson 1993), we also found a strong positive relationship between job satisfaction and affective commitment $(\beta=0.32 ; \mathrm{t}$-value $=40.98)$. Given the scarcity of correlation coefficients reported between internal service quality variables and OCB, these relationships were not included in the previously discussed causal model. Turning to our second model, which describes the interaction between service employees and customers, we see that employee service attitudes indeed significantly influence citizenship behavior (satisfaction: $\beta=0.13$; $\mathrm{t}$-value $=$ 10.60; commitment; $\beta=0.30 ; t$-value $=24.96$ ). Furthermore, we can conclude that there is indeed significant empirical evidence for the notion that employee attitudes and behavior have a positive influence on customers' perceptions of service quality. First, we can state that employee citizenship behavior has direct positive influence on customers' perceptions of service quality $(\beta=0.39$; $\mathrm{t}$-value $=42.58)$. Second, employees' job satisfaction has both a positive direct $(\beta=0.22 ; \mathrm{t}$-value $=19.86)$ and indirect (Sobel's $\mathrm{t}=$ 10.29) effect on customers' quality perceptions. Third, affective commitment only influences perceived service quality indirectly (Sobel's $t=21.53$ ). Based on our analysis we can conclude that employee attitudes and behaviors are 
relevant predictors for customers' perceptions of service quality (system weighted $\left.\mathrm{R}^{2}=29\right)$.

Regarding our third causal model, which describes the interrelationships among customer evaluative judgments, we can state that the relationships put forward in the model are very well supported (system weighted $\mathrm{R}^{2}=0.50$ ). Furthermore, all hypothesized relationships are statistically significant (minimum t-value $=17.97)$. Focusing on the individual coefficients the following conclusions can be drawn. First, perceived service quality has a significant direct effect on the formation of loyalty intentions, thus providing strong empirical support for this much-debated relationship (c.f., Cronin et al. 2000; Dabholkar et al. 2000). Second, in the formation of customer loyalty, constructs like service quality and satisfaction play a larger role than perceived value.

\subsection{Discussion and conclusions}

The SPC supposes that capable employees enthusiastic about delivering great service generate high levels of customer satisfaction, which in turn leads to improved financial performance of the service company (Loveman 1998). Despite the enormous academic and managerial interest in understanding the entire chain of effects outlined in the SPC and the generalisability of these effects, only a few studies investigated the entire SPC (e.g. Loveman 1998; Kamakura et al. 2002). For our meta-analysis we analyzed research results from 316 studies on various relationships proposed in the SPC and synthesized these study results into a series of causal models, providing an integral test of the SPC. Overall, our meta-analysis provided support for the basic notion of the SPC, namely that employee attitudes and behaviors have a 
positive influence on customer evaluations of the service, which in turn are positively related to financial performance.

With respect to the employee part of the SPC, three general categories of antecedents (interfaces) were examined. Of these interfaces, the employeeorganization interface has the highest impact on job satisfaction and affective commitment. Based on inspection of the meta-analytic correlations of the pairwise relationships (summarized in table 2-1), it can be stated that particularly POS influences the formation of employee attitudes. These findings suggest that if the development of proper employee service attitudes is an important goal, steps to increase the degree of POS may have the largest impact.

Our analysis of the pairwise relationships as well as our analysis of causal effects indicates that employee attitudes are also influenced by employees' perceptions of job conditions, coworkers and managers. The results in table 21 appear to suggest that within the employee-job conditions interface reduction of role stress in particular has a positive effect on both job satisfaction and affective commitment. Furthermore, task characteristics have a large effect on employee attitudes. More specifically, task autonomy is in particular strongly related to job satisfaction, whereas affective commitment is strongly influenced by the amount of task feedback employees perceive. Of all three interfaces, the employee-coworker-manager interface appears to be the least effective in influencing employee attitudes, although the influence of this interface can still be considered as strong, according to the guidelines suggested by Cohen (1988). Concerning the impact of the employeecoworker-manager interface on job satisfaction, inspection of the pairwise correlations reveals that the impact of LMX and the degree of leadership support are particularly important. Turning to the impact of the employee- 
coworker-manager interface on affective commitment, we see that the various individual variables have a strong and almost equal influence on commitment. Our meta-analysis also shows that employee attitudes translate into employee service behavior. The discussion of the relationships between employee attitudes and employee behavior will be based on the results that stem from our causal analysis, as this analysis provides the most comprehensive picture. Our results indicate that both job satisfaction and affective commitment have a positive direct effect on citizenship behavior. In addition, job satisfaction also has a significant indirect effect on OCB (Sobel's $t=20.50$ ). These results concerning the creation of citizenship behavior are particularly interesting as individual studies provided mixed results concerning the influence of affective commitment on organizational citizenship behavior, when controlling for job satisfaction. Consequently, our findings seem to reflect Morrison's (1994) conclusion that affectively committed employees view their jobs as encompassing a wider range of behaviors (including the so-called extra role behaviors) than those who were not affectively committed. Furthermore, this finding supports Peccei and Rosenthal's (1997) point of view that affective commitment is a prerequisite for behaviors aimed at delivering quality services.

One of the basic assumptions of the SPC involves the belief that employee attitudes and behaviors are positively related to customers' evaluations of the service. Taking into consideration the complexity and expenses involved in conducting linkage research, it is hardly surprising that only a limited amount of studies is available on the interplay between employee attitudes and behaviors and customer attitudes. Therefore, we suggest that the path model describing the interaction between employees and customers should be interpreted with caution. A detailed look at the results of our path model 
describing the employee-customer interface reveals an intricate pattern of relationships between the employee part and customer part of the service encounter. Both job satisfaction and citizenship behavior have a positive direct relationship on the customers' service quality perceptions. Although affective commitment is not directly related to perceived service quality, it has a significant indirect effect on customers' service quality perceptions via citizenship behaviors (Sobel's $t=21.53$ ). In addition to its direct positive effect on perceived quality, job satisfaction also influences perceived service quality via citizenship behavior (Sobel's $t=10.29$ ). In general, our results provide empirical support for the notion that employee attitudes and behavior are crucial determinants of customers' evaluations of the service.

With regard to the customer part of the SPC, we find positive and significant relationships among key customer evaluative judgments. Although these findings are perfectly in line with existing work, two findings merit special attention. First, the results of our meta-analytic path model suggest a direct relationship between perceived service quality and customer loyalty. So far, there has been considerable disagreement concerning the causal order among the three evaluative judgments. The debate concentrated around three possible models: a direct effects model, a fully mediated model, and a partially mediated model (Dabholkar et al 2000; Cronin et al. 2000). Our results provide substantial empirical evidence that customer satisfaction is only a partial mediator in the relationship between quality and loyalty. Second, although customer service evaluations are often described only in terms of quality, satisfaction, and loyalty, we must consider value as a vital construct of the SPC. Given the highly statistically significant paths concerning perceived customer value, we may consider value as a vital construct of the SPC. Failing to take perceived customer value into account may lead to serious omitted 
variable bias, which damages the validity of models describing customers' service evaluations.

The proposed relationship between customer service evaluation and financial performance is one of the basic principles for making service quality investments financially accountable. Without support for this relationship the whole concept of the SPC would lose ground. A review of 65 study effects concerning the association between customer service evaluation and financial performance provides strong evidence that customer loyalty is indeed related to financial performance of service companies. This finding reflects the thought of using predictive and customer oriented measures like customer service evaluations as leading indicators of financial performance, rather than relying on hard but historic figures like market share (Pitt et al. 2000).

Furthermore, our analyses suggest that the four coded study effects (type of service industry, measurement level of perceived quality, measurement level of satisfaction, and type of offering) have systematic moderating effects on the observed effect sizes. With regard to the employee side of the SPC we found that the effects of role ambiguity on employee attitudes are especially strong for service employees in medical and educational settings. On the other hand, the association between role conflict and employee attitudes was larger in retail and financial services contexts. A possible explanation for this result may be found in the different types of customers and boundary spanning activities across the service industries investigated. Given the nature of employee-customer interaction in retail and financial service settings, boundary spanning service employees may in these instances especially be confronted with customer demands, which they cannot fulfill due to a lack of authority, thereby explaining the larger impact of role conflict on the formation of employee attitudes. We find a relatively stronger effect of role 
ambiguity on employee attitudes in medical and educational service settings. This may be attributable to the relative importance of information or the impact of lack thereof in these contexts. Furthermore, the relationship among satisfaction, commitment, and citizenship behavior also depend on the type of service industry for which one is employed. First of all, the association between job satisfaction and affective commitment is significantly weaker for employees in an educational setting. Second, the relationship between employee attitudes and behaviors is significantly stronger for employees in educational settings. One explanation could be that the intrinsic motivation (giving direction to others, the importance of education) for working in such jobs maybe higher and that this influences the relationship between attitude and behavior.

Measurement of perceived service quality and customer satisfaction by means of measures that assess an overall service evaluation (single item) rather than using attribute based measures (multiple items), produced larger effect sizes for the links between perceived service quality, value, and satisfaction. A possible explanation for this finding may be the lack of discriminant validity between the single item measures of the various customer evaluative judgments (Yi 1990), thereby artificially inflating the effect sizes among these constructs. In contrast to the previously discussed finding, we found that the relationship between satisfaction and customer loyalty intentions is lower when satisfaction is measured on an aggregate measurement level. A possible explanation for this finding might be that an attribute-based measure of customer satisfaction may tap the domain of satisfaction more comprehensively (Yi 1990) and hence be less subject to attenuation of effects than the overall satisfaction measure. Overall, these findings echo Oliver's 
(1997) notion that attribute-based and overall service evaluations do not converge.

Finally, our moderator analysis results point out that distinction between pure services and product-related services is important when estimating the relationships in the customer part of the SPC. More specifically, our findings indicate that the effects in the customer part of the SPC are larger in pure service settings compared to product-related service settings. This finding reflects Szymanski and Henard (2001) notion that satisfaction and outcome assessments are different when people are in a tangible versus an intangible processing mode. Drawing upon Tavassoli's (1998) work, Szymanski and Henard (2001) suggest that intangible feelings of satisfaction and perceived service quality play a stronger role in the purchase decision for pure services (intangibles).

\subsection{Implications, limitations, and suggestions for further research}

Our meta-analytic assessment of the SPC has a number of managerial implications for service firms. First, it may assist managers to set priorities when designing strategies to influence employee attitudes and behaviors in order to enhance customer loyalty. Second, when developing initiatives to influence customer behavior through alteration of the service offering, our analysis provides insights into how alternative courses of action (e.g. a tradeoff between increasing quality and value) work out in terms of financial performance. Third, our analysis supports the idea that delivering quality services pays of in terms of financial service, thereby emphasizing the need to treat service quality initiatives as investments and make them financially accountable. 
Our study also has several limitations. Although we undertook a comprehensive survey of the literature on the relationships put forward in the SPC, we could not include all studies in the analysis because in some the effects were not reported in usable form (i.e. correlation coefficients), could not be transformed to a usable format, or could not be obtained from the respective researchers. However, we do not expect the omission of these papers to have a substantial effect on our results given the high fail-safe $\mathrm{N}$ values. Furthermore, for some of the moderator variables under study only relatively small cell sizes were available. Therefore, caution in interpreting the results is warranted. Moreover, combining multiple moderator variables into one multivariate statistical analysis was not possible due to the limited amount of information that was available on many study effects. Finally, due to the wide variety of financial performance measures employed, we were not able to conduct a formal metric meta-analysis on the relationship between customer service evaluation and financial performance.

While our meta-analysis advances the understanding of the process and consequences of service delivery, several issues need to be examined in more detail. Our meta-analysis starts with employee perceptions of internal service quality, which are supposed to initiate the chain of effects proposed in the SPC. In order to design strategies to improve performance, more insight is needed on how to influence these employee perceptions of internal service quality. Only then, service quality initiatives can be made truly financial accountable. Moreover, although we synthesized findings of many studies into three causal models describing the SPC, there is clearly a need for more integral tests of the SPC using employee and customer data from a single company. In addition, two types of relationships in the SPC, the employeecustomer interface and the relationship between customer service evaluations 


\section{Chapter 2}

and financial performance, particularly need to be examined systematically in order to obtain comprehensive understanding of these relationships. Finally, the results of the moderator analyses offer promising avenues for further research. For instance, concerning the systematic changes in effect size attributable to one of more moderator variables, more research is needed to probe more deeply into the processes that cause these differences. In a similar fashion, after accounting for the moderator variables outlined in our study, a significant amount of within-group variance remained, reflecting the potential moderators unaccounted for so far. 


\section{Footnotes}

${ }^{1}$ In order to preserve the quality of the studies included in our meta-analysis our computer search was restricted to the following leading journals: Journal of Marketing, Journal of Marketing Researt, Journal of the Academy of Marketing Science, Journal of Consumer Research, Journal of Retailing, Marketing Science, Management Science, European Journal of Marketing, Journal of Service Research, Journal of Business Research, Journal of Service Industry Management, Journal of Economic Psychology, Journal of Applied Psychology, Personnel Psychology, Journal of Onganizational Bebavior; Journal of Vocational Bebavior, Academy of Management Journal, Journal of Management, Administrative Science Quarterly, and Organizational Bebavior and Human Decision Processes.

${ }^{2}$ We examined the reference lists of the following existing meta-analysis. Brown and Peterson (1993), Rboades and Eisenberger (2002), Organ and Ryan (1995), Symanski and Henard (2001), Tett and Meyer (1993), LePine, Erez, and Johnson (2002), Podsakoff, MacKenzie, Paine, and Bachrach (2000), and Tubre and Collins (2000). 



\section{Chapter 3}

\section{Managing Frontline Employees in Service Organizations: Analysis and Optimization}

As employee behavior significantly influences customer service evaluations, which in turn lead to service revenues, a key decision area is to ensure appropriate behaviors from front-line service employees. Fueled by the need for an economically justified decision-making approach to service investments, this study develops and empirically assesses a comprehensive model that allows for an explicit evaluation and optimization of service profitability by combining the principles of the Service Profit Chain (SPC) and the Return on Quality (ROQ) approach. Our study makes the following theoretical contributions: (1) we extend and integrally test the SPC to explore how employee perceptions ultimately result in financial performance; (2) we develop a mathematical framework that assists decision makers in optimizing financial performance from a customer-oriented standpoint. The practical decision-making value of our study lies in the explicitly assessment of the following three issues: (1) evaluation and optimization of the profitability and rate of return stemming from service investment strategies, (2) the allocation of investment efforts to optimize financial performance, (3) robustness of the proposed optimal solution to assess the impact of uncertainty. 


\subsection{Introduction}

The so-called Service Profit Chain (SPC) suggests that employee perceptions drive employee service attitudes and behavior, which in turn impact customer service evaluations that ultimately translate into revenues (Heskett et al. 1994; Kamakura et al. 2002). Consequently, a key problem for managers is to ensure appropriate employee behaviors (Peccei and Rosenthal 2001). It has been shown that an effective way to elicit apposite service employee actions is through efforts aimed at improving job design characteristics (Spector and Jex 1991; Singh 1998; Dubinsky and Skinner 1984). With regard to service employees, Singh (1998) shows that variety, participation, autonomy, and feedback are relevant job design characteristics. According to Peccei and Rosenthal (1997) appropriate job design is crucial in service contexts in order to capture the flexibility, initiative, and individualized care entailed in the concept of service quality. According to the SPC, investments aimed at improving employees' perceptions of job characteristics are likely to yield financial returns. For example, Swain et al. (2004) argue that the implementation of an "off-the-shelf" 360-degree online feedback system improves employee behavior and performance at relatively low costs.

However, as today's service environment becomes more competitive and results-oriented, a financially rigorous decision analysis to assist decisionmakers in evaluating and optimizing service improvement initiatives becomes increasingly important. Although the SPC provides a comprehensive diagnosis of how financial performance can be enhanced, the costs associated with these service improvements are not taken into account. In contrast, the Return on Quality (ROQ) model (Rust, Zahorik, and Keiningham 1995) focuses on both the positive (e.g., the increase in revenues due to the implementation of a 360-degree feedback system) and negative (e.g., the annual costs of the feedback system license) impact of service quality investments on profitability, thereby making service quality investments financially accountable (Rust et al. 1995).

In this study, we propose a model based on an integration of the SPC and ROQ approach to allow for an explicit evaluation and optimization of the financial impact of investments in services. In our case, job characteristics are 
chosen as the object of decision-making. Our model consists of two separate, but closely interrelated parts. First, we develop an SPC model that describes how changes in employees' perceptions of job characteristics are related to revenues. Second, we develop a mathematical framework that takes into account the revenues as well as the costs associated with proposed investment efforts. This framework allows us to optimize the financial consequences of our investments in job design and to evaluate different alternative investment schemes.

This paper attempts to make the following contributions. First, we conceptually and empirically explore how employees' perceptions regarding job design relate to customer service evaluations and financial performance. In order to fully appreciate the consequences of job design we propose an extended version of Heskett et al.'s (1994) SPC which will be subjected to a rigorous integral empirical test. Second, we propose a mathematical optimization framework that allows for the maximization of profitability stemming from service investments in job design and that provides guidance on how to optimally allocate investment efforts. This mathematical optimization framework is, to our best knowledge, one of the first attempts to optimize financial performance taking into account the complete set of relationships of the SPC from an external customer-oriented service markering perspective rather than from an efficiency internal operations-based approach (Rust and Metters 1996). From a managerial point of view, the value of our optimization model lies in the versatility of relevant decision-making issues that can be addressed by the model, such as determination of total investment level, resource allocation, and assessment of the impact of uncertainty.

In order to achieve these objectives, we start with a detailed description of our model. Next, we estimate the various components of the model and implement the optimization model to the situation under study. Finally, we discuss the implications and limitations of our study. 


\subsection{Model development}

An overview of the proposed core model is presented in figure 3-1.

Figure 3-1 Core model

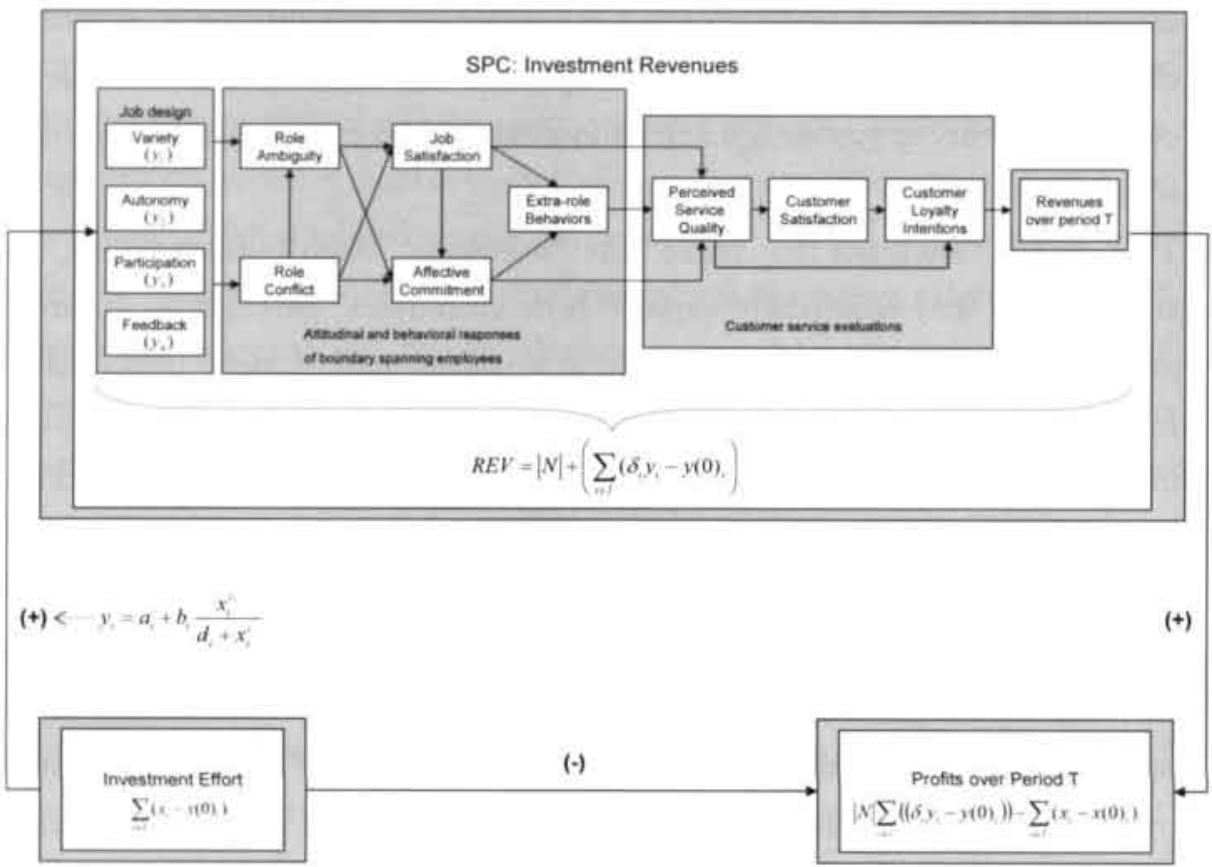

Essentially, our model represents Rust et al.'s (1995) ROQ approach, which presumes that service quality efforts can be made financially accountable when the revenues and costs resulting from service initiatives are considered simultaneously. The SPC framework, originally proposed by Heskett et al. (1994), postulates that revenues from service investments are driven by customer service perceptions, which in turn are driven by employee attitudes and perceptions. Combining the SPC and the ROQ framework enables us to track the revenues generated by service quality investments in detail, thereby providing diagnostic value in evaluating the consequences that stem from service quality initiatives.

Drawing from Hackman and Oldham's (1976) job characteristics model, Singh (1998) proposes the following four dimensions to capture the relevant 
aspects of job design for boundary-spanning employees: variety, autonomy, participation, and feedback. Variety refers to the degree to which a job requires a variety of different activities in carrying out the work, which involve the use of a number of different skills and talents of the employee (Singh 1998). Autonomy is described as the extent to which the job provides substantial freedom, independence, and discretion to the employee in scheduling the work and in determining the procedures to be used in carrying it out (Singh 1998; Dubinsky and Skinner 1984). Participation refers to the degree to which an employee can influence decisions about his or her job (Singh 1998). Feedback is the degree to which an employee receives information while working, regarding how well he or she is performing. Feedback may be inherent in the job or provided by outside sources (Singh 1998; Dubinsky and Skinner 1984). In order to evaluate the revenues stemming from the proposed investments in job design, the measures that we use to assess employees' perceptions regarding job characteristics must meet the following conditions: (1) the measures must be open to objectification, (2) the measures must be significant antecedents to relevant employee service delivery attitudes and behaviors, and (3) it should be possible to connect the measures to expenditure categories or drivers. We believe that the job characteristics outlined above meet these conditions. First of all, the work of Spector and Jex (1991) provides support for the notion that the Hackman and Oldham (1976) job characteristics are indeed objective. Concerning the second condition, we show that ample research is available that job design is an important determinant of attitudes and behaviors in boundary spanning situations (e.g. Brown and Peterson 1993; Fahr et al. 1990). Finally, several empirical studies (e.g. Greene 1981) demonstrate that the job redesign programs can be linked to and quantified in terms of employee perceptions.

In order to capture the financial consequences of investments in job design as veraciously as possible, we broaden Heskett et al.'s (1994) notion that customer service evaluations are mainly determined by employee satisfaction in the following two ways. First, as most customer-contact employees act as "boundary spanners" between the firm and the customer, role stress is very likely to influence employees' attitudes and behaviors. According to Boles and 
Babin (1996) and Goolsby (1992) role conflict and role ambiguity are hypothesized as key 'boundary role stimuli" that need to be coped with or else deleterious organizational outcomes may occur. Second, as the inclusion of constructs that assess extra-role service behaviors and the affective commitment to provide quality services have been proven to add to the understanding of employee-customer interfaces in services marketing (Bell and Menguc 2002; Kelley and Hoffman 1997; Peccei and Rosenthal 1997), we extend Heskett et al.'s (1994) model by including these constructs to augment our understanding of the processes that connect employee and customer service perceptions.

The following two paragraphs outline the development of the two separate but interrelated models needed to implement our core model presented in figure 1. First, we develop a SPC model that describes the entire chain of effects from job design perceptions to revenues. Second, we develop a mathematical optimization framework that takes into account the complete set of relationships outlined in our core model, including our detailed SPC model.

\subsubsection{The Service Profit Chain}

In order to maintain quality customer interactions and thus competitiveness, it is particularly important for service organizations to enact processes that reduce the amount of role stress that boundary spanning employees experience (cf. Stamper and Johlke 2003). Singh (2000), Dubinsky and Skinner (1986), and Teas (1983) show that the problems associated with high levels of role stress can be reduced significantly by appropriate job design. In the tradition of job enrichment theory, it is believed that variety reduces role stress as employees are afforded the opportunity to determine their own role expectations and to deal more freely with problems of role clarification (Dubinsky and Skinner 1984). As autonomy reflects the required flexibility and discretionary behavior for quality employee-customer interactions, it is believed that autonomy reduces role stress (De Ruyter et al. 2001). Teas (1983) finds empirical support for a negative relationship between participation and role stress. As participation in decision-making leads to 
increased clarity of ones role (cf. Teas et al. 1979), it therefore can be expected that participation reduces role stress. Several studies have reported a negative relationship between feedback and role stress for boundary spanners (Teas 1983, Dubinsky and Skinner 1984, Singh 1993). According to Singh (1993) feedback reduces role ambiguity because performance feedback helps boundary spanners learn their roles. In addition, Dubinsky and Skinner (1984) suggest that feedback reduces role conflict as employees use feedback information to reconcile various roles. Therefore, we state the following hypotheses:

\section{Hypothesis 1}

Service employee perceived role ambiguity $(R A)$ will be negatively influenced by (a) variety $(V A R),(b)$ participation $(P A R),(\mathrm{c})$ autonomy (AUT), and (d) feedback (FDB).

\section{Hypothesis 2}

Service employee perceived role conflict $\left(R C_{l}\right)$ will be negatively influenced by (a) variety (VAR), (b) participation (PAR), (c) autonomy (AUT), and (d) feedback (FDB).

Several researchers have provided empirical evidence that role stress has significant negative effects on the service employees' job satisfaction (Bettencourt and Brown 2003; Wetzels et al. 1999; Hartline and Ferrell 1996). With regard to the impact of role stress on affective organizational commitment in a service context, the literature reports divergent results. Some studies report a direct influence of role stress on commitment (e.g., MacKenzie et al. 1998) whereas other studies indicate that the impact of role stress on commitment is fully mediated by job satisfaction (e.g., Singh et al. 1996). Although often neglected in studies aimed at examining the consequences of role stress in service settings, we believe that role conflict has a positive direct influence on the degree of role ambiguity service employees experience. According to Hartline and Ferrell (1996) conflicting role expectations of the firm, manager, and customers increase the employees' uncertainty about how best to perform their jobs and prioritize their actions. 


\section{Chapter 3}

In a service context, this notion is supported by Wetzels et al. (1999) and Hartline and Ferrell (1996). Based on this discussion we hypothesize:

\section{Hypothesis 3}

Service employee job satisfaction (JS) will be negatively influenced by (a) perceived role ambiguity $(R A)$ and (b) perceived role conflict $(R C)$.

\section{Hypothesis 4}

Service employec affective commitment $(A C)$ will be negatively influenced by (a) perceived role ambiguity $(R A)$ and $(\mathrm{b})$ perceived role conflict $(R C)$.

\section{Hypothesis 5}

Service employee perceived role ambiguity $(R A)$ will be positively influenced by perceived role conflict $(R C)$.

Extra-role performance has been found to have a significant influence on customer service evaluations (Bettencourt and Brown 2003; Bell and Menguc 2002). The most relevant predictors of extra-role service behaviors include job satisfaction and affective commitment, which both have been shown to positively influence extra-role service performance (Bettencourt and Brown 2003; Netemeyer et al. 1997; MacKenzie et al. 1998). Moreover, the total effect of job satisfaction on extra-role service behaviors consists of a direct effect and an indirect effect through commitment. Furthermore, Bettencourt and Brown (2003) showed that the negative influence of role stress on extra role service behaviors is fully mediated by job satisfaction and commitment. Besides indirectly influencing customer service evaluations through extra-role performance, several authors argue that job satisfaction and affective commitment directly influence customer service evaluations. Hartline and Ferrell (1996) indicate that job satisfaction is naturally displayed during service delivery and subsequently reflected in customers' cognitive evaluations of service quality. According to Schneider (1980) and Schneider and Bowen (1985) job satisfaction is a primary reason that employees deliver good service. Empirically, the positive relationship between job satisfaction and service quality is supported by Hartline and Ferrell (1996), Wetzels et al. (1999), and 
Yoon et al. (2001). Allen and Grisaffe (2001) propose that there is a positive link between affective organizational commitment and perceived service quality. According to Allen and Grisaffe (2001) this link can be explained as follows; given that strongly committed employees have an interest in remaining with the organization, one might expect that they have a heightened interest in the maintenance of the company's customer base. Furthermore, organizationally committed employees can be expected to exhibit a greater willingness to exert effort on behalf of the organization (Mathieu and Zajac 1990). Although not tested in a multivariate context, some authors report significant correlations among affective commitment and customer service evaluations (e.g. Ko et al. 1997). The above discussion leads to the following hypothesized relationships:

\section{Hypothesis 6}

Service employee extra-role service behaviors (ERSB) will be positively influenced by (a) employee job satisfaction (JS) and (b) employee affective commitment $(A C)$.

\section{Hypothesis 7}

Service employee affective commitment $(A C)$ will be positively influenced by employec job satisfaction (JS).

\section{Hypothesis 8}

Customer perceived service quality (PSQ) will be positively influenced by (a) employee extra-role service behaviors (ERSB), (b) Employee job satisfaction (JS), and (c) Employee affective commitment $(A C)$.

Ample empirical support is available that service quality perceptions are positively related to customer satisfaction (Cronin et al. 2000; De Ruyter et al. 1997). Concerning the consequences of customer satisfaction, many researchers support the notion that one of the key benefits of customer satisfaction is increased loyalty for current customers (Anderson and Sullivan 1993; Bolton 1998; Loveman 1998). Furthermore, although subject to considerable debate, empirical evidence seems to indicate that perceived service quality also directly influences customers' loyalty intentions (Cronin et 
al. 2000; Mittal et al. 1998). In line with this literature review, we therefore state the following hypotheses:

\section{Hypothesis 9}

Customer satisfaction (SAT) will be positively influenced by the customer perceived service quality (PSQ).

\section{Hypothesis 10}

Customer loyalty intentions ( $L O Y$ ) will be a positively influenced by a) customer satisfaction (SAT) and b) customer perceived service quality (PSQ).

The final link of the service profit chain, the assumption that customer loyalty results in profit, forms the underlying premise in the research on the financial accountability of service quality. Only when the strength and nature of the link between behavioral intentions and actual repurchase behavior is understood, economic consequences of service quality investments can be estimated (Zahorik and Rust 1992). Several studies (Kamakura et al. 2002; Loveman 1998; Hallowell 1996) indicate that customer retention is indeed related to financial performance.

\section{Hypothesis 11}

Customer revenues $(R E V)$ will be positively influenced by current customer loyalty intentions $(L O Y)$.

\subsubsection{Optimization and evaluation of service investments}

In order to design a mathematical framework aimed at maximizing the profitability resulting from the investment efforts directed at job design, the relationships among revenues, profitability, and investment efforts need to be modeled explicitly. Below we describe how the various relationships in our core model play a role in the mathematical framework.

Our SPC framework captures the revenues associated with a particular investment, which in turn positively affect profitability. As the relationships in 
the SPC are modeled linearly, a linear relation exists between the job characteristics and the revenues. Consequently, the relationship between the revenues over the coming year and the input variables, as described in our SPC model, can be compactly expressed as:

$$
R E V=|N|\left(\sum_{i=l} \delta_{i}\left(y_{i}-y(0)_{i}\right)\right)
$$

In equation (1-1), the input variables or job characteristics are denoted by $y_{i}(i \in I)$ and $\delta_{i}(i \in I)$ reflect the total effect of the input variables and the relationships in our conceptualization of the SPC on the revenues. The term $y(0)_{i}$ reflects the current level of input variable $y_{i}(i \in I)$. Finally, $|\mathrm{N}|$ denotes the number of customers served by the company which are comparable to the customers used in our sample $(\mathrm{N}=10,000)$.

To capture the positive relationship between investment effort and employees' perceptions of job characteristics (and thus indirectly revenues), an estimate of the rating shift that will be produced by a particular investment effort is required. To link investment efforts to changes in the perceptions of the various job characteristics, we pursue a decision calculus approach (cf. Rust and Zahorik 1993). More specifically, we employ the response curve used in Little's (1970) ADBUDG model to estimate the link between expenditures and rating shift in the input variables. Consequently, the relationship between the level of the various input variables $y_{i}$ and investment effort $x_{i}$, is expressed as follows:

$$
y_{i}=a_{t}+\left(b_{i}-a_{i}\right) \frac{x_{i}^{c_{i}}}{d_{i}+x_{i}^{c_{i}}}
$$

Parameters $a_{i}$ and $b_{i}$ restrict the range of the $y_{i}$ to $\left[a_{i}, b_{i}\right]$. More specifically, $a_{i}$ represents the level of $y_{i}$ when $x_{i}=0 ; b_{i}$ represents the upper bound on $y_{i}$ when $x_{i} \rightarrow \infty$. Parameters $c_{i}$ and $d_{i}$ determine the shape of the relationship between $y_{i}$ and $x_{i}$. The parameters of the ADBUDG model have been 
calibrated in consultation with managers, thereby reflecting Blattberg and Hoch's (1990) notion that decision quality is best when both statistical and human input is combined. Details concerning the group interviews conducted with the managers are outlined in our methodology section.

As $x_{i}$ reflects the investment effort needed to influence the various levels of job characteristic $y_{i}$, the total investment effort associated with a particular investment strategy is defined as:

$$
\sum_{i \in l}\left(x_{i}-x(0)_{i}\right)
$$

In equation (1-3) the term $x(0)_{i}$ in the investment level needed to maintain the $y(0)$, level of the input variables (please note that this relationship is implied by equation (1-2)). Ultimately, we are interested in the optimization of the profitability resulting from our investment efforts. The direct positive effect of revenues on profitability, and the direct negative effects of the investment effort on profitability are reflected in the profit function, which is:

$$
\text { profit }=|N|\left(\sum_{i=1}\left(\delta_{i} y_{i}-y(0)_{i}\right)\right)-\sum_{i=1}\left(x_{i}-x(0)_{i}\right)
$$

The optimization of the profitability of service quality investments is subject to the following four constraints. First of all, we impose a budget constraint, $\sum_{i=1}\left(x_{i}-x(0)_{i}\right) \leq B U D G E T$ implying that the total investment effort cannot exceed a pre-set budget. The second constraint is a non-negativity constraint for $x_{i}$. The third constraint models the impact of investments on the level of the input variables. Our fourth and final constraint deals with the fact that the level of each of the variables we invest in $\left(y_{i}\right)$ should be at least equal to its starting value $y(0)_{i}$. The relationships and constraints described above are summarized in exhibit 1-1. 
Exhibit 1-1 Optimization framework

\begin{tabular}{|c|c|c|c|}
\hline $\max$ & profit & $=|N|\left(\sum_{i=l}\left(\delta_{i} y_{i}-y(0)_{i}\right)\right.$ & $-\sum_{i=1}\left(x_{i}-x(0)_{i}\right)$ \\
\hline \multirow[t]{4}{*}{ s.t. } & $\sum\left(x_{i}-x(0)_{i}\right)$ & $\leq \quad B U D G E T$ & \\
\hline & $x_{i}$ & 0 & $(i \in I)$ \\
\hline & $y_{i}$ & $=a_{i}+\left(b_{i}-a_{i}\right) \frac{x_{i}^{c_{i}}}{d_{i}+x_{i}^{c_{2}}}$ & $(i \in I)$ \\
\hline & $y_{i}$ & $y(0)$ & $(i \in I)$ \\
\hline
\end{tabular}

In the next sections we assess the relationships in our conceptual model (figure 1-1) empirically and use these results to develop an investment strategy, using the optimization framework outlined in exhibit 1-1, aimed at maximizing profitability. Furthermore, the usefulness and versatility of the framework in exhibit 1-1 in addressing various decision-making issues will be demonstrated when implementing the model.

\subsection{Methodology}

\subsubsection{Measures}

To remain consistent with previous research, the measures we used in this study were taken or adapted from previous studies in marketing, management, and organizational psychology (cf. Hartline and Ferrell 1996). A series of confirmatory factor analyses (cf. Steenkamp and Van Trijp 1991) was performed to validate the scales used in our study. Based on the results of these confirmatory factor analyses we can conclude that all scales possess favorable psychometric properties. Details of the scales used in our study can be found in table 1-1. 
Table 1-1 Scale properties

\begin{tabular}{|c|c|c|c|c|c|}
\hline Seale & Items & Searce & Reliability & Mean & SD \\
\hline Variety & 5 & Sims. Srilagyi and Keller (1976) (ef. Singh 1998). & 0.82 & 4.14 & 0.42 \\
\hline Participation & 4 & Inkson. Pugh, and Hickron (1970) (cf. Singh 1998). & 0.70 & 5.55 & 0.40 \\
\hline Autonomy & 5 & Hackman and Oldham (1976) (cf Singb 1998). & 0.71 & 4.14 & 0.38 \\
\hline Feedback & 3 & Hackman and Oldham (1976) (cf. Singh 1998). & 0.85 & 476 & 0.47 \\
\hline Role ambiguity & 7 & Rizzo, House, and Lirtzman (1970) & 0.89 & 2.66 & 0.38 \\
\hline Role conflict & 8 & Rizzo, Housc, and Lirtzman (1970) & 0.82 & 3.03 & 0.41 \\
\hline Job satisfaction & 8 & Churchill, Ford, and Walker (1976) & 0.79 & 4.92 & 0.34 \\
\hline Affective commitment & 6 & Mowday, Steers, and Porter (1979) & 0.94 & 5.30 & 0.40 \\
\hline Extra-role service behavior & 5 & Bettencourt and Bruxn (1997) & 0.83 & 5.01 & 0.36 \\
\hline Perceived service quality & 8 & $\begin{array}{l}\text { Instrutnent designed for this study } \\
\text { cf. Rust, Zahorik, and Keiningham (1995) }\end{array}$ & 0.97 & 6.02 & 1.03 \\
\hline Customer satisfaction & 1 & Anderson, Fornell, and Lehmann (1994) & na. & 6.48 & 1.15 \\
\hline Intention to remain loyal & 4 & Zeithaml. Berry, and Parasuraman (1996) & 0.80 & 5.79 & 1.19 \\
\hline Revenues: & 1 & $\begin{array}{l}\text { Internal reconds company. Measured } 1-12 \text { month } \\
\text { after the questionnaire. Average is taken over } \\
12 \text {-months period. }\end{array}$ & n.a. & 3003.94 & 2361.99 \\
\hline
\end{tabular}

\subsubsection{Sampling and Surveying}

Survey data were obtained from employees and business customers of a large internationally operating company that manufactures and sells office equipment such as copiers, printers, and faxes. The company has a dominant presence in medium and high volume segments and puts the maintenance of long-standing relationships with its customers on the basis of service excellence as a central element of the corporate mission.

The after-sales service business unit where we conducted our research employs 250 people, which are divided in 28 teams with an average size of 8 service-engineers. Due to the relatively limited amount of service employees we conducted a census. Paper-and-pencil questionnaires were given to team leaders who made sure that the questionnaires were distributed among the service employees. All service employees remained anonymous, only team codes were made available to us in order to link the employee data to the customer data. The employee census resulted in an effective sample size of 206.

Each team of service engineers serves customers in a certain region (regions are based on postal code). In order to be eligible for our study, customers had to meet the following three criteria. First, the customer has to operate in a 
retail environment. Second, the customer should have a relationship of at least 24 months with the company. Third, the customer should have contacted the service employees at least twice during the last 12 months. From this population 1500 customers were randomly selected, evenly spread over each region. The effective sample size for the customer survey consists of 556 usable respondents (minimum number of respondents per region is 11; maximum number of respondents per region is 19). The customer questionnaires were coded with client numbers we needed in order to merge the customer data with the employee and financial data.

In order to estimate the complete SPC, financial data at the customer level are required. For each customer that participated in our study, we had access to internal company records that contained the complete sales history (revenues) of each customer over the last year.

To estimate the relationships put forward in our SPC framework, the data of the employee sample and customer sample were merged. The client number of each individual customer and the team number of the employees provided us with sufficient data to link the employee data to the customer data. To construct the variance-covariance matrix needed to estimate the relationships in our model, the employee level scores were aggregated within each of the teams and then assigning the aggregate score to each client served by the team (cf. Jimmieson and Griffin 1998; Kamakura et al. 2002). Within-group reliability $r_{W G}$ (James et al. 1984) was used to determine whether it was suitable to aggregate the scales within each team. Given the minimum $r_{i v i}$ value of 0.78 for variety in one of the teams, we were confident with regard to our decision to aggregate the scales at the team level.

Furthermore, interviews with managers were needed to calibrate the relationship between investment effort $\left(x_{i}\right)$ and the level of the input variables $\left(y_{i}\right)$, as described in equation (2). To achieve this, we conducted two interview sessions with two separate groups of managers and employees. The first group of managers and employees $(n=8)$ was asked to brainstorm on actions that could be employed to improve employees' perceptions on the various job design variables. From this brainstorm-session, we selected for each of the 
four job design variables one improvement action that in our opinion could well be quantified. Examples of the output of this brainstorm session include: implementation of a job rotation program, division of work based on customers rather than task, bimonthly meetings with other teams, the implementation of an online feedback system, on-line customer surveys, and the use of more but smaller teams.

A second group of managers $(n=7)$ were interviewed to obtain estimates for the parameters $a_{i}, b_{i}, c_{i}$, and $d_{i}$ of the relationship put forward in equation (12). As the objective of parameters $a_{i}$ and $b_{i}$ is to restrict changes in $y_{i}$ to meaningful range, these parameters are implicitly determined by the range of measurement scales we employed to assess employee perceptions regarding job characteristics. Consequently, parameter $a_{i}$ is set to 1 (the lowest value of the measurement scale used) and parameter $b_{i}$ is set to 9 (the highest value of the measurement scale used). There was total consensus among the interviewed managers that investments aimed at improving job characteristics were subject to diminishing returns, implying that $c_{i}=1$ (see Little 1970). Furthermore, different values for $d_{i}$ were chosen for each input variable $y_{i}$ to account for differences in the shape of the function.

\subsubsection{Estimation procedure SPC}

The relationships underlying our conceptualization of the SPC are presented in exhibit 3-2. The system of equations presented in exhibit 3-2 is estimated by means of a Partial Least Squares (PLS) approach. Our choice for PLS is motivated by the following reasons. First, as least squares techniques, PLS ensure optimal prediction accuracy (Fornell and Cha 1994). Second, PLS makes no assumptions regarding the underlying distribution of the variables. Third, PLS estimates have been shown to be very robust against multicollinearity (Cassel et al. 2000). Fourth, PLS allows us to use model constructs with reflective and constructs with formative indicators in one single model. 
Exhibit 3-2 System of equations SPC

\begin{tabular}{|c|c|}
\hline$R C_{q}=f\left(V A R_{q}, P A R_{q}, A U T_{q}, F D B_{q}\right)$ & (3-5) \\
\hline$R A_{q}=f\left(V A R_{q}, P A R_{q}, A U T_{q}, F D B_{q}, R C_{q}\right)$ & $(3-6)$ \\
\hline$J S_{q}=f\left(R A_{q}, R C_{q}\right)$ & $(3-7)$ \\
\hline$A C_{q}=f\left(R A_{q}, R C_{q}, J S_{q}\right)$ & $(3-8)$ \\
\hline$E R S B_{q}=f\left(J S_{q}, A C_{q}\right)$ & $(3-9)$ \\
\hline$P S Q_{j q}=f\left(E R S B_{q}, J S_{q}, A C_{q}\right)$ & $(3-10)$ \\
\hline$S A T_{j q}=f\left(P S Q_{j q}\right)$ & $(3-11)$ \\
\hline$C L O Y_{j q}=f\left(P S Q_{j q}, S A T_{j q}\right)$ & $(3-12)$ \\
\hline$R E V_{j q}=f\left(C L O Y_{j q}\right)$ & $(3-13)$ \\
\hline
\end{tabular}

\subsubsection{Estimation procedure optimization framework}

One can view financial returns from service quality as arising from decreasing costs, increasing revenues by increasing customer satisfaction, or both at once (Rust, Moorman, Dickson 2002). Rust et al. (2002) conclude that, while no company can afford to ignore either revenues or costs, companies that emphasize revenues expansion more than cost reduction have better customer relationship outcomes and better financial outcomes, as measured by both self-reports and objective financial returns. This finding builds on Fornell, Anderson, and Rust's (1997) proposition that there is a trade-off between cost-cutting (standardization) and customer satisfaction (customization). Another issue faced with when making service quality investments, is whether to focus on attracting new customers (offensive effect) or retaining existing customers (defensive effect). Research has shown investing in lowering customer defection rates is an economically more feasible strategy than attracting new customers (Reicheld and Sasser 1990; Fornell and Wernerfelt 1987, 1988). Based on these findings, we seek an investment strategy that aims to optimize profitability based on increasing the revenue obtained from existing customers. 
Determining an investment strategy that leads to a maximum amount of profit consists of two interrelated but separate decisions (cf. Mantrala et al. 1992). The first decision relates to determining the amount of resources that leads to a maximum profitability level. The second decision deals with the allocation of the optimal amount of resources of the various variables. After having determined the optimal solutions, both in terms of investment effort and allocation scheme, we assess the robustness of the optimal solution. In order to address these issues, the framework in exhibit 3-1 was solved in AIMMS 1 using subgradient optimization for a various levels of investment effort.

\subsection{Analytical results}

\subsubsection{Empirical results SPC estimation}

Overall, we find strong support for our model describing the causal flow in the SPC (minimum goodness of fit value $\mathrm{F}=11.745(\mathrm{p}<0.0001)$ ). A detailed overview of the results of our statistical analysis is provided in table 3-2.

Based on the figures summarized in table 3-2 we conclude that the majority of the hypotheses are supported by the data. More important, the data provides support that the SPC is a chain, and that perceptions of job design indeed influence employee attitudes and behaviors, which in turn have an impact on customers' evaluations of the service provided, which ultimately is related to financial performance. The finding that employee perceptions of job design translate into financial performance is crucial for evaluating the consequences of investment effort directed at improving job design and for designing an investment scheme aimed at maximizing profitability.

Before turning to estimation of the complete core model some results stemming from our analysis of the SPC merit special attention and will be discussed explicitly. First, as indicated by the significant F-statistics job design appears to be an important determinant of the attitudes of service employees. It should be noted that a series of Lagrange Multiplier tests indicates that the influence of job design on attitudes like job satisfaction are fully mediated by the role stressors; a finding that is largely in line with the work of Teas (1983) and Dubinsky and Skinner (1984). 
Table 3-2 Estimation results SPC

\begin{tabular}{|c|c|c|c|c|c|}
\hline H & Relationship & Coefficient & t-value & p-value & Conclusion \\
\hline $\mathrm{H}_{4}$ & $V A R_{q} \rightarrow R A_{q}$ & $n s$ & ns & $n s$ & Reject $\mathrm{H}_{12}$ \\
\hline $\mathrm{H}_{1 \mathrm{~b}}$ & $P A R_{q} \rightarrow R A_{q}$ & -0.24 & 7.12 & $<0.0001$ & Fail to reject $\mathrm{H}_{1 \mathrm{~b}}$ \\
\hline $\mathrm{H}_{\mathrm{ic}}$ & $A U T_{q} \rightarrow R A_{q}$ & ns & ns & ns & Reject $\mathrm{H}_{1 \text { s }}$ \\
\hline $\mathrm{H}_{\text {id }}$ & $F D B_{q} \rightarrow R A_{q}$ & -0.44 & 10.71 & $<0.0001$ & Fail to reject $\mathrm{H}_{1 d}$ \\
\hline $\mathrm{H}_{2 \mathrm{i}}$ & $V A R_{q} \rightarrow R C_{q}$ & $n s$ & ns & $n s$ & Reject $\mathrm{H}_{2 a}$ \\
\hline $\mathrm{H}_{2 \mathrm{~h}}$ & $P A R_{q} \rightarrow R C_{q}$ & -0.19 & 4.07 & 0.0001 & Fail to reject $\mathrm{H}_{2}$ \\
\hline $\mathrm{H}_{2 c}$ & $A U T_{4} \rightarrow R C_{4}$ & -0.59 & 15.49 & $<0.0001$ & Fail to reject $\mathrm{H}_{2 \varepsilon}$ \\
\hline $\mathrm{H}_{24}$ & $F D B_{q} \rightarrow R C_{4}$ & -0.42 & 13.48 & $<0.0001$ & Fail to reject $\mathrm{H}_{24}$ \\
\hline $\mathrm{H}_{3 z}$ & $R A_{q} \rightarrow J S_{q}$ & -0.40 & 8.02 & $<0.0001$ & Fail to reject $\mathrm{H}_{30}$ \\
\hline $\mathrm{H}_{\text {sb }}$ & $R C_{q} \rightarrow J S_{q}$ & -0.37 & 6.84 & $<0.0001$ & Fail to reject $\mathrm{H}_{3 b}$ \\
\hline $\mathrm{H}_{4 \mathrm{a}}$ & $R A_{q} \rightarrow A C_{4}$ & $n s$ & ns & ns & Reject $\mathrm{H}_{4}$ \\
\hline $\mathrm{H}_{4 b}$ & $R C_{q} \rightarrow A C_{q}$ & $n s$ & ns & ns & Reject $\mathrm{H}_{4 b}$ \\
\hline $\mathrm{H}_{5}$ & $R C_{q} \rightarrow R A_{q}$ & 0.30 & 4.41 & $<0.0001$ & Fail to reject $\mathrm{H}$, \\
\hline $\mathrm{H}_{6 t}$ & $J S_{q} \rightarrow E_{R S B}$ & 0.67 & 24.49 & $<0.0001$ & Fail to reject $\mathrm{H}_{6 a}$ \\
\hline $\mathrm{H}_{6 \mathrm{~b}}$ & $A C_{q} \rightarrow E R S B_{q}$ & 0.08 & 3.62 & 0.0003 & Fail to reject $\mathrm{H}_{\mathrm{ot}}$ \\
\hline $\mathrm{H}_{7}$ & $J S_{q} \rightarrow A C_{q}$ & 0.36 & 5.51 & $<0.0001$ & Fail to reject $\mathrm{H}_{\text {, }}$ \\
\hline $\mathrm{H}_{\mathrm{si}}$ & $E R S B_{4} \rightarrow P S Q_{1 \psi}$ & 0.21 & 3.35 & 0.0009 & Fail to reject $\mathrm{H}_{\mathrm{L}}$ \\
\hline $\mathrm{H}_{\mathrm{sh}}$ & $J S_{4} \rightarrow P S Q_{\mu \varphi}$ & $n s$ & $n s$ & $n s$ & Reject $\mathrm{H}_{\mathrm{sb}}$ \\
\hline $\mathrm{H}_{\mathrm{sc}}$ & $A C_{q} \rightarrow P S Q_{A q}$ & ns & ns & ns & Reject $\mathrm{H}_{\mathrm{k}}$ \\
\hline $\mathrm{H}_{9}$ & $P S Q_{j q} \rightarrow S A T_{j \psi}$ & 0.52 & 15.08 & $<0.0001$ & Fail to reject $\mathrm{H}_{9}$ \\
\hline $\mathrm{H}_{109}$ & $S A T_{/ 4} \rightarrow L O Y_{N}$ & 0.32 & 7.54 & $<0.0001$ & Fail to reject $\mathrm{H}_{400}$ \\
\hline $\mathrm{H}_{10 \mathrm{~b}}$ & $P S Q_{\text {iq }} \rightarrow L O Y_{N}$ & 0.31 & 7.33 & $<0.0001$ & Fail to reject $\mathrm{H}_{10}$ \\
\hline $\mathrm{H}_{41}$ & $L O Y_{\rho q} \rightarrow R E V_{P Q}$ & 351.330 & 4.17 & $<0.0001$ & Fail to reject $\mathrm{H}_{11}$ \\
\hline
\end{tabular}

Second, introducing role stress as a mediator between job characteristics and employee attitudes like job satisfaction and affective commitment has shown to be a valuable contribution in terms of variance explained as evidenced by a 
Wald ${ }^{2}$ test $\left(J S_{q}: \mathrm{F}=49.991(\mathrm{p}<0.001)\right.$ and $\left.A C_{q}: \mathrm{F}=7.775(\mathrm{p}<0.001)\right)$. Third, we proposed to extend Heskett et al.'s (1994) conceptualization of the SPC by introducing constructs that assess the explicit behavioral commitment of boundary spanning employee to provide service quality. Based on a Wald ${ }^{2}$ test we can conclude that the inclusion of extra-role service behaviors adds significantly to our ability to understand the observed variance in customers' perceived service quality $(F=7.451(p=0.006))$. Fourth, although several researchers suggested that employee job satisfaction and affective commitment directly influence customer perceptions of service quality, our results indicate that the influence of these two attitudinal constructs on perceived service quality is fully mediated by employee extra-role service behaviors. As can be concluded from the Sobel test (Sobel 1982), job satisfaction and affective commitment do have a significant indirect effect on customer perceived service quality (job satisfaction: Sobel's $t=3.31(\mathrm{p}=$ 0.0009); affective commitment: Sobel's $t=2.46(p=0.0139)$.

Given the empirical support for the notion that changes in job design indeed translate into service revenues, we proceed by implementing our mathematical framework aimed at optimizing and evaluating the investments in job design in terms of profitability.

\subsubsection{Implementation mathematical framework}

\subsubsection{Effort, profitability, and rate of return}

Crucial to the evaluation and optimization of investments is the relationship between investment effort and financial consequences ${ }^{3}$. Figure 3-2 graphically presents the relationship among investment effort in job design, and respectively revenues and profitability for the situation at hand. 
Figure 3-2 Investment effort, profitability, and revenues

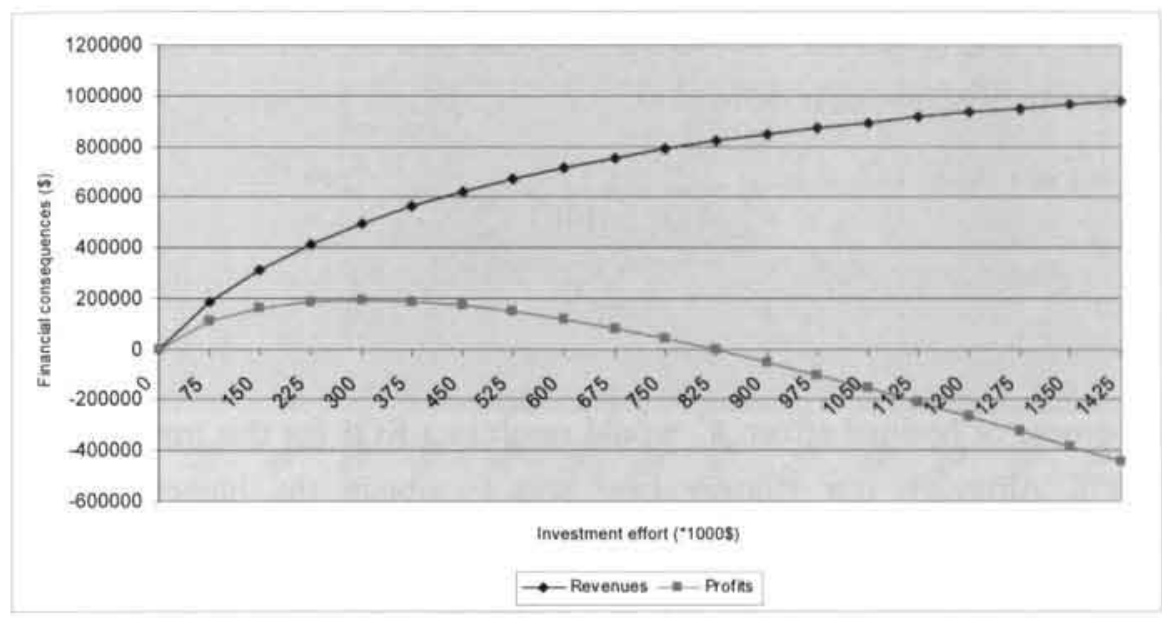

The concave shape of the relationship between investment effort and profitability implies that it is possible to spend too much, thereby stressing the need to carefully balance costs and benefits in deciding on service investments.

Concerning the determination of the total amount of effort that should be made to achieve an optimal objective ${ }^{3}$, the derivative of the profit function plays a pivotal role. The derivative of the profit function used in this study is defined as:

$$
\max _{i \in I}\left(\delta_{i} y_{i}\left(x_{i}\right)-x_{i}\right)^{\prime}=\max _{i \in I}\left\{\delta_{i} b_{i} c_{i} d_{i} \frac{x_{i}^{\varepsilon_{i}-1}}{\left(d_{i}+x_{i}^{c_{i}}\right)^{2}}-1\right\}
$$

Investments remain feasible as long as $\max _{i \in I}\left(\delta_{i} y_{i}\left(x_{i}\right)-x_{i}\right)>0$; the maximum amount of profit is obtained when $\max _{i \in I}\left(\delta_{t} y_{i}\left(x_{i}\right)-x_{i}\right)=0$.

For the situation under study, in which we aim to optimize investment effort in job design in terms of profitability, a total investment effort of $\$ 300,000$ 
leads to a maximum level of profitability (maximum profitability equals $\$ 193,310)$. In order to evaluate service investments on an even footing with competing investment opportunities an estimate of the rate of return is necessary. The return on investment (ROI) associated with the efforts aimed to improve profitability is defined as:

$$
R O I_{i}=\frac{\sum_{i=1} \delta_{i}\left(y_{i}-y(0)_{i}\right)-\sum_{i \in I} x_{i}}{\sum_{i \in l} x_{i}}
$$

Investment of optimal effort $B^{*}$ would result in a ROI for this investment of $64.44 \%$. Although our strategy here was to obtain the highest level of profitability, it is also possible to use the model to decide on the investment effort and profitability associated with a predetermined rate of return.

\subsubsection{Allocation of effort Besides deciding on what investment effort} leads to a maximum level of profitability, the allocation of investment effort over the various input variables is equally important to achieve this maximum level of profits (cf. Mantrala et al. 1992). The answer to this question lies in the magnitude of the derivatives. The derivative of the influence of $y_{i}$ on revenues reflects the change in profits obtained by investing an additional unit in variable $y_{i}$ (see also equation 14). We start investing in the variable $y_{i}$ with the highest incremental profit (i.e. highest derivate). Since the return on investment of each input variable $y_{i}$ is subject to diminishing returns, the derivative of the variable $y_{i}$ with the highest incremental profit will equal the derivative of the variable $y_{i}$ second-highest incremental profit at a certain stage. Upon reaching this point we continue investing in both variables in a ratio determined by the coefficients $\delta$, (see equation 1 ). This process continues until all input variable $y_{i}$ have zero derivatives. Of course, any chosen value for the derivative (incremental profit) can serve as a benchmark. Application of the principles outlined above leads to the situation presented in figure 3-3. 
Figure 3-3 Optimal allocation of investment effort

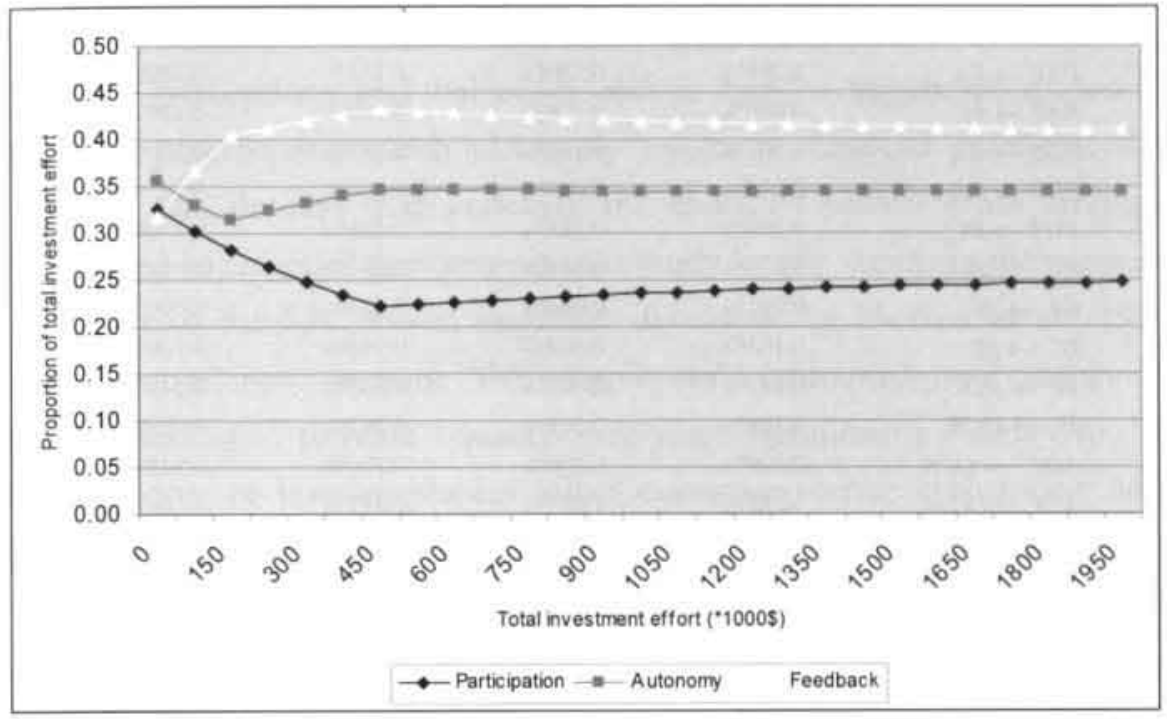

In order to achieve the maximum level of profits, the optimal total investment effort denoted by $B^{*}$ needs to be allocated as follows: $25 \%$ of $B^{*}$ should be directed at improving participation, $42 \%$ of $B^{*}$ should be directed at improving feedback, and finally $33 \%$ should be directed at improving autonomy.

3.4.2.3 Robustness of the optimal solution As with most decisions, service investment decisions are characterized by a degree of uncertainty. In order to assess the consequences of this uncertainty, the robustness of the optimal solution is investigated using sensitivity analysis.

In order to assess robustness of the optimal solution, we will investigate how the maximal profitability level alters as a function of changes in each of the coefficients in our SPC framework. A series of numerical experiments is performed to assess the impact of various changes on profitability. The results of these experiments are summarized below in table 3-3. 
Table 3-3 Robustness of the optimal solution

\begin{tabular}{|c|c|c|c|c|}
\hline & $-2 \sigma$ & $-1 \sigma$ & $+1 \sigma$ & $+2 a$ \\
\hline$P A R \rightarrow R A$, & $0.299 \%$ & $0.150 \%$ & $0.151 \%$ & $0.302^{\circ} \%$ \\
\hline$P A R \rightarrow R C$, & $0.445 \%$ & $0.176^{\circ} \%$ & $0.180^{\circ} \%$ & $0.451 \%$ \\
\hline$F D B \rightarrow R A$, & $0.391 \%$ & $0.157^{\circ} \%$ & $0.157 \%$ & $0.392^{\circ} \%$ \\
\hline$F D B \rightarrow R C$ & $0.280 \%$ & $0.093 \%$ & $0.094^{\circ} \%$ & $0.277^{\circ} \mathrm{s}$ \\
\hline$A U T \rightarrow R C$ & $0.368^{\circ} \%$ & $0.184^{\circ} \%$ & $0.185^{\circ} \%$ & $0.370^{\circ} \mathrm{s}$ \\
\hline$R C_{1} \rightarrow R A$, & $0.075^{\circ}$ & $0.043 \%$ & $0.033 \%$ & $0.078^{\circ} \%$ \\
\hline$R A_{t} \rightarrow J S_{t}$ & $0.091 \%$ & $0.046 \%$ & $0.047^{\circ} \%$ & $0.095 \%$ \\
\hline$R C_{,} \rightarrow J S_{1}$ & $0.103 \%$ & $0.052^{\circ} \%$ & $0.054 \%$ & $0.109^{\circ} \%$ \\
\hline$J S_{,} \rightarrow A O C$ & $0.147 \%$ & $0.063 \%$ & $0.063 \%$ & $0.147^{\circ} \%$ \\
\hline$J S_{f} \rightarrow O C B_{r}$ & $0.788^{\circ} \%$ & $0.263 \%$ & $0.263^{\circ} \%$ & $0.785^{\circ}$ 。 \\
\hline$A O C_{1} \rightarrow O C B_{1}$ & $0.400^{\circ}$ o & $0.200^{\circ} \%$ & $0.200 \%$ & $0.398 \%$ \\
\hline$O C B_{3} \rightarrow Q U A L_{1}$ & $3.235 \%$ & $1.622 \%$ & $2.442 \%$ & $3.160^{\circ} \%$ \\
\hline$Q U A L_{r} \rightarrow S A T_{r}$ & $1.743^{\circ} \circ$ & $0.871^{\circ} \%$ & $0.864^{\circ}$ 。 & $1.714^{\circ} \%$ \\
\hline$S A T \rightarrow L O Y_{i}$ & $6.522 \%$ & $3.209 \%$ & $3.308 \%$ & $6.312^{\circ} \circ$ \\
\hline$O U A L \rightarrow L O Y$ & $5.716 \%$ & $2.807 \%$ & $2.931^{\circ} \%$ & $5.064^{\circ} \%$ \\
\hline
\end{tabular}

Based on the results in table 3-3 we can conclude that the maximum level of profitability is pretty robust against changes in our model (maximum change is $6.522 \%$ when the relationship between customer satisfaction and loyalty decreases by 2 standard deviations). Consequently, it is rather likely that our projections of maximal service profitability hold even under conditions of uncertainty.

\subsection{Discussion and conclusion}

By merging the principles outlined in the SPC and the ROQ approach we developed a conceptual model that supports decision-makers in conducting both an economically justified and customer-oriented analysis of the financial consequences associated with service improvement initiatives. From a theoretical perspective this study aims to make the following contributions. First, we conceptually and empirically explore the complete chain of effects connecting employee perceptions of job design, employee attitudes and behaviors, customer service evaluations, and financial performance. Second, we develop a framework that allows for maximization of the profitability stemming from initiatives aimed at improving job design, from a customeroriented services marketing perspective. 
Concerning our first theoretical contribution, the integral assessment of the SPC provides empirical support for the basic notion of the SPC, namely that employee perceptions and behaviors indeed have a significant impact on customer perceptions, which ultimately results in financial revenues. With regard to the process that underlies the chain of effects from employee perceptions to financial performance our study largely supports the proposed extensions to the SPC model originally developed by Heskett et al. (1994). First, taking into account the employees' attitudinal and behavioral commitment to provide quality services significantly adds to the understanding of how employees affect customer service evaluations. More specifically, our analysis reveals that the explicit behavioral commitment to provide service quality which is assessed by extra-role service behaviors has a direct significant influence on customer perceived service quality. Although the influence of employee job satisfaction and affective commitment on customer perceived service quality is fully mediated by extra-role service behaviors, the Sobel test indicates that these indirect effects are still significant. Second, in line with Bettencourt and Brown (1993) our results indicate that role ambiguity and role conflict lead to reduced job satisfaction and affective commitment, which in turn lead to a decline in extra-role service behaviors. Given the significant direct and indirect effects of employee attitudes and behaviors on customer service evaluations, which in turn lead to improved financial performance, employee role stress indirectly reduces customer perceived service quality and financial performance. These findings underscore the need for actions that need to be undertaken to reduce role stress in boundary-spanning positions. Based on our empirical findings, efforts directed at improving job design, particularly feedback, provide ample opportunity to reduce the detrimental effect of role stress which in turn positively affect employee service attitudes and behaviors, customer service evaluations, and financial performance.

With regard to our second contribution, we developed a mathematical optimization framework that takes into account the complete set of relationships outlined in our core model. An important theoretical contribution is that this mathematical framework unites a financially sound 
and customer-oriented approach in a single model aimed at the evaluation and optimization of service investments. Besides this theoretical contribution, our optimization framework also provides several practical insights. First, it enables managers to assess the total amount of investment effort needed to achieve a maximum level of profitability. In a similar fashion the model can be used to determine the investment effort needed for any pre-stated profit objective. Second, the model provides all the output to determine the ROI of any investment effort, thereby placing investments on an even footing with other investment opportunities. Third, the derivative of the profit-function in our framework provides managers with a useful resource-allocation mechanism for marketing efforts. Fourth, we provide an analysis of the robustness of the model which can assist decision makers to judge the impact of uncertainty on the optimal solution. Finally, the results of the optimization model provide valuable input for decision support systems.

Although our model is general enough to be applied in many service industries, we believe that the main contribution of our work is not the development methodology or the generality of the specific findings. Rather, the contribution lies presenting a comprehensive approach that service firms can use as a proposal for action.

\subsection{Limitations and suggestions for further research}

This study presents one of the few empirical inquiries into the quantification and optimization of service evaluations in terms of financial consequences, a phenomenon of great managerial and academic interest. However, several limitations are warranted to qualify our findings and encourage future research efforts. First of all, we are well aware that the application of the SPC framework is likely to vary from firm-to-firm, depending on the idiosyncrasies of the service under investigation and the metrics and measures available. Or as Kamakura et al. (2002, p.312) put it: "we do not claim that ours is the best operationalization, nor do we claim to have provided the definitive test of the SPC. Rather, we view our work to be illustrative in nature, one that demonstrates how the SPC can be comprehensively implemented at a firm". Nevertheless, we would like to encourage fellow researchers to assess the 
generalizability of the following two phenomena. As the service encounter lies at the heart of service delivery, it is of the utmost importance that the interplay among employee service attitudes, employee service behaviors, and customer service evaluations is examined in greater detail. Although in our study customer loyalty was the only determinant of service revenues, research in other settings is needed to assess whether this finding holds true or whether there are other relevant predictors of service revenues.

Second, recognizing that the SPC links entail lag effects and persistence, it would be desirable to test the relationships in the SPC by means of a longitudinal design. Such a multi-period approach is also desirable in order to make strong causal inferences regarding the relationships in the SPC framework. Moreover, the use of a longitudinal design would also enrich the possibilities of the optimization model and useful insight can be gained about the long-term effects of service quality investments. Finally, the use of longitudinal of data would allow us to determine and incorporate the influence of possible seasonal effects and economic circumstances.

Third, inclusion of customer characteristics may permit managers and researchers to obtain a more accurate picture of how customer service evaluations render into revenues. Several studies have underscored this importance of segmentation of the customer base in assessing antecedents and consequences of customer satisfaction (e.g. Garbarino and Johnson 1999; Danaher 1998; Blattberg and Deighton 1991). In line with these studies, Zeithaml (2000) states that one of the key questions in research addressing the economic worth of customers is the investigation of what variables (demographic and psychographic) are most effective in characterizing profitable segments.

Finally, in evaluating the economic attractiveness of alternative service initiatives we only took defensive effects into consideration. According to Rust et al. (1995) the benefits of service improvements come in two forms: defensive and offensive effects. As the attraction of new clients is of vital importance to maintain a financially healthy customer base, effort also needs to be addressed at the offensive effects of investment strategies aimed at optimizing profitability. 


\section{Footnotes}

'The abbreviation AIMMS stands for Advanced Interactive Mathematical Modeling Software and is the name of an algebraic modeling language coupled with a data-driven user-interface builder.

${ }^{2}$ In order to assess the added value of the role stress variables in explaining job satisfaction a set of nested models is required. A Wald test was conducted on the following set of equations:

$J S_{q}=f\left(V A R_{q}, A U T_{q}, P A R_{q}, F D B_{q}\right)$

$J S_{q}=g\left(V A R_{q}, A U T_{q}, P A R_{q}, F D B_{q}, R A_{q}, R C_{q}\right)$

Similar procedures were followed when assessing the added value of role stress in explaining affective commitment and the added value of extra-role service behaviors in explaining customer perceived service quality.

${ }^{3}$ In line with the suggestions made by leading marketing scholars we only included variable investment costs. Failing to include fixed costs may result in an underestimating of the costs and an overestimation of profitability. However, as our model is flexible with regard to the cost module to be incorporated, fixed costs can be incorporated without any problem into our SPC conceptualization or optimization model for future applications of these models. 


\title{
Chapter 4
}

\section{Reconsidering Nonlinearity and Asymmetry in Customer Satisfaction and Loyalty Models ${ }^{1}$}

\begin{abstract}
The use of symmetric linear functional forms to describe the relationships among customer evaluative judgments is omnipresent in services research. However, according to several researchers, the use of symmetric linear functions to model the relationships among customer evaluative judgments leads to serious model misspecification. Although several asymmetric nonlinear functional forms have been proposed, only modest empirical evidence is available on the superiority of these more complex model specifications. Based on a formal empirical comparison in multiple service settings, we find that asymmetric nonlinear functions do not possess superior explanatory power compared to symmetric linear functional forms.
\end{abstract}

'This chapter is largely based on Streukens, S. and K. de Ruyter (2004). Reconsidering nonlinearity and asymmetry in customer satisfaction and loyalty models: An empirical study in three retail service settings. Marketing Letters, 15(2/3), 99-111. 


\subsection{Introduction}

Researchers continuously seek a deeper understanding of the exact nature of the relationships among customer evaluative judgments regarding services. In discussions concerning customer loyalty formation, constructs like perceived service quality, perceived customer value, and overall satisfaction have taken center stage (Cronin et al. 2000). Although there appears to be a general consensus regarding the positive associations between service quality, customer satisfaction, perceived value and customer loyalty (Kamakura et al. 2002; Cronin et al. 2000), considerable lack of clarity exists on how to best specify the relationships among the different customer evaluative judgments. Although the use of symmetric linear functional forms is ubiquitous in services research, recent research suggests that the relationships in customer satisfaction and loyalty models are in fact characterized by nonlinearity and asymmetry (Mittal, Ross, and Baldasare 1998; Anderson and Mittal 2000), implying that the frequently-used symmetric linear functional forms would result in model misspecification. Whereas several researchers (Mittal et al. 1998; Anderson and Mittal 2000; Ngobo 1999) propose that asymmetric nonlinear satisfaction and loyalty models have superior predictive power, formal comparisons of the performance of asymmetric nonlinear vis-à-vis symmetric linear model are still very limited.

The importance of understanding the true nature of the functional forms among customer functional forms is underscored by the fact that customer evaluative judgments are often used as leading indicators of firm performance. Here, model misspecification would lead to incorrectly prioritizing of programs aimed at improving customers' service evaluation and business performance (Anderson and Mittal 2000). Consequently, it seems worthwhile to extend the existing work on model specification among customer evaluative judgments into different service settings. In this study, we empirically assess the exact nature of the relationships among customer evaluative judgments with regard to the presence of nonlinearity and asymmetry using data from three different retail service settings. 


\subsection{Structural relationships among customer evaluative judgments}

Based on an extensive empirical study across different retail service settings, Cronin et al. (2000) indicate that customer behavioral intentions, which are indicative of loyalty, are directly and significantly influenced by overall satisfaction, perceived value and perceived service quality. Furthermore, these authors indicate that overall satisfaction in turn is influenced by perceived value and perceived quality and that perceived value is highly impacted by customers' quality perceptions. The value of the Cronin et al. (2000) framework lies in the fact that it provides a general, comprehensive and flexible nomological network of the structural relationships among the key customer evaluative judgments in services marketing. Consequently, we use the set of relationships put forward in the Cronin et al. (2000) framework as a starting point in our study. The framework of Cronin et al. (2000) is presented graphically in figure 4-1.

Figure 4-1 The Cronin, Brady, and Hult (2000) framework

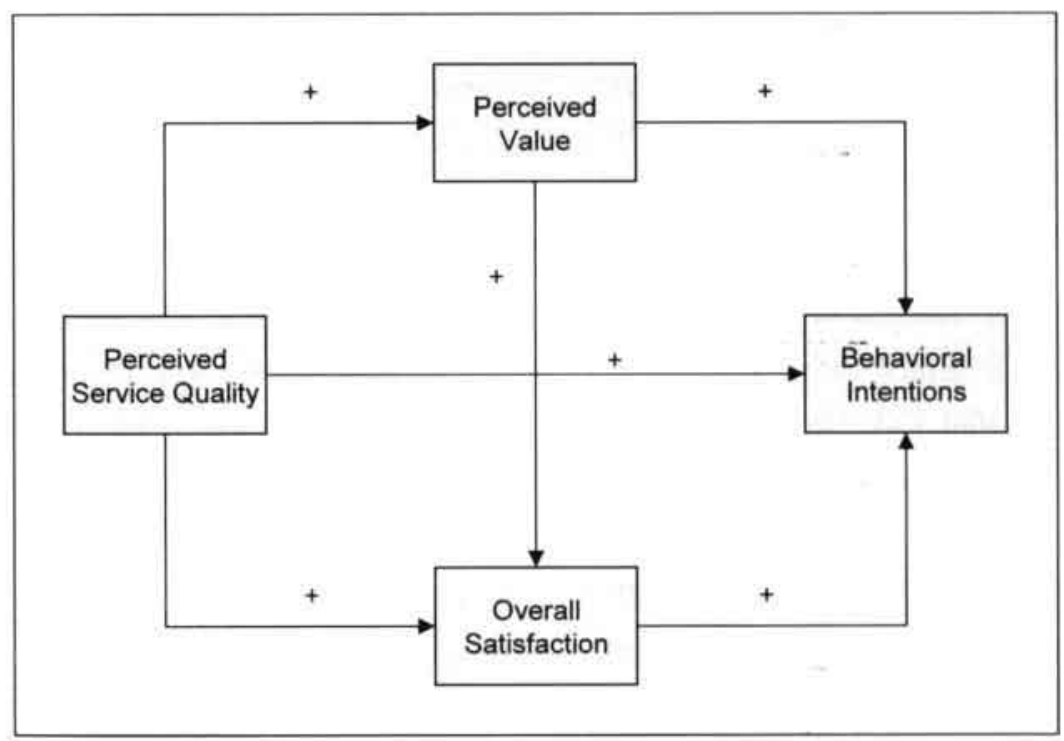




\subsection{Asymmetry}

In using symmetric functions, it is implicitly assumed that both positive and negative performance have an equal impact on the dependent variable. Recently however, Mittal et al. (1998), demonstrated that positively and negatively perceived service quality do not have an equal effect on the formation of higher order constructs. According to Anderson and Mittal (2000), asymmetry in customer satisfaction and loyalty models can be either of a negative or a positive nature. The occurrence of negative asymmetry can be explained from a variety of perspectives. First, according to prospect theory (Kahneman and Tversky 1979), people's judgments display loss aversion, suggesting that losses loom larger than gains. Furthermore, there is evidence showing that negative information (1) is more perceptually salient than positively valenced information, (2) is given more weight than positive information, and (3) elicits a stronger psychological response than positive information (Peeters and Czapinski 1990). Alternatively, positive asymmetry is suggested to occur in situations when the perceived service quality is unanticipated or unusual, relative to what customers normally envision a product or service experience to entail (Anderson and Mittal 2000).

The occurrence of negative asymmetry has been demonstrated empirically in a health care setting (Mittal et al. 1998), an automotive setting (Mittal et al. 1998), and other service industries (Anderson and Sullivan 1993). On the other hand, DeSarbo et al. (1994) provide empirical support for positive asymmetry. Despite this empirical evidence, it is indistinct whether the asymmetric effect of perceived service quality on higher order constructs holds in retail service settings. In a similar fashion, the exact nature of the possible asymmetry in retail service settings too remains unclear. Consequently, we hypothesize:

\section{Hypothesis 1}

Positive and negative perceived service quality do not have an equal effect on the formation of a) overall satisfaction, b) perceived customer value, and c) behavioral intentions. 


\subsection{Nonlinearity}

A second trend in recent research that has focused on loyalty formation in services is to specify nonlinear relationships between customer evaluative judgments (Mittal et al. 1998; Ngobo 1999). However, it again remains unclear whether nonlinear functional forms are truly superior in terms of explanatory power to simple linear functional forms. Nonlinearity may occur in two forms: increasing and decreasing returns (Anderson and Mittal 2000). Two possible explanations for the diminishing returns in the relationship between quality and higher order constructs have been advanced. First, according to prospect theory, attitudes like satisfaction should display diminishing sensitivity toward changes in perceived service quality at the lower and upper extremes of the scale (Mittal et al. 1998). Second, customers evaluate performance on the basis of relative performance rather than absolute changes (Anderson and Mittal 2000). In contrast, the relationship between perceived service quality and higher order constructs may also exhibit increasing returns, implying that quality changes toward the extremes of the scale are more consequential than changes in the middle range. According to Anderson and Mittal (2000), this is especially the case when service performance exceeds customer expectations.

Several scholars (Mittal et al. 1998; Anderson and Sullivan 1993) have modeled the link between service quality and higher order constructs as nonlinear (using a linear-log model) and found a good fit to the data for these nonlinear models. However, these authors pay only limited attention to comparing the proposed nonlinear models to linear models in terms of performance. Consequently, it remains unclear whether the nonlinear functional form indeed explains substantially more variance than the frequently used linear models. Therefore, in order to examine whether and which of the proposed nonlinear functional forms are better capable of explaining the relationship between perceived quality and higher order attitudinal constructs, we derive the following hypotheses: 


\section{Hypothesis 2}

Regarding the positive domain of perceived service quality, nonlinear functional forms (either with increasing or decreasing returns) have superior explanatory power compared to linear functional forms in explaining the relationship between perceived service quality and a) overall satisfaction, b) perceived value, and c) behavioral intentions.

\section{Hypothesis 3}

Regarding the negative domain of perceived service quality, nonlinear functional forms (either with increasing or decreasing returns) have superior explanatory power compared to linear functional forms in explaining the relationship between perceived service quality and a) overall satisfaction, b) perceived value, and c) behavioral intentions.

Similarly, the relationship among customer satisfaction, perceived customer value and customer retention has also been widely modeled as linear (Kamakura et al. 2002; Cronin et al. 2000). Although various nonlinear and piece-wise linear have been proposed, virtually no attention has been devoted to a formal comparison of these alternative specifications to linear functional forms in terms of explanatory power. According to Ngobo (1999), the links between satisfaction, value, and loyalty are characterized by diminishing returns, based on the presence of a saturation effect on customer information search. Two competing models have been proposed to account for aforementioned types of diminishing returns: (1) a quadratic model and (2) a two-threshold model with decreasing returns. Ngobo (1999) provides empirical support for the superiority of the two-threshold model with decreasing returns, as compared to the quadratic and linear model using data on customer who bought a new camera. Furthermore, in relation to insurance and bank services Ngobo (1999) indicates that the quadratic model explained the more variance in loyalty when compared to a linear model. Furthermore, Mittal and Kamakura (2001) and Rust et al. (1995) found that the relationship between customer satisfaction and behavioral intentions is characterized by diminishing returns. In contrast, however, other studies demonstrate that relationships between customer evaluations are characterized by increasing returns (Coyne 1989; Oliva et al. 1992). For instance, Coyne (1989) proposes a 
two-threshold model with increasing returns, which posits that the loyalty curve is relatively flat after a first threshold of satisfaction is passed and climbs rapidly after satisfaction has passed a second threshold. Empirically, Mittal and Kamakura (2001) indicate that the relationship between customer satisfaction and behavioral loyalty displays increasing returns. Exhibit 4-1 provides overview of the five models that describe the relationships among satisfaction, value, and loyalty outlined above.

Exhibit 4-1 Models that describe the association among satisfaction, value and loyalty intentions

\begin{tabular}{|c|c|c|}
\hline Name & Model & Remarks \\
\hline Linvir model & $Y_{i}=\alpha+\beta \cdot X_{i}$ & \\
\hline $\begin{array}{l}\text { Decreasung returns } \\
\text { (inlog-model) }\end{array}$ & $Y_{i}=\alpha+\beta \cdot L N\left(X_{i}\right)$ & $\begin{array}{l}\text { Captures censintently decreasing } \\
\text { returns }\end{array}$ \\
\hline $\begin{array}{l}\text { Decreasing renirns } \\
\text { (tweo threshotits model) }\end{array}$ & 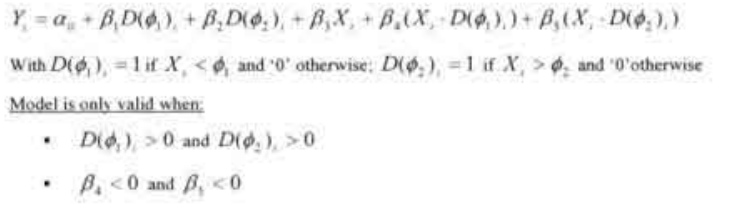 & \\
\hline $\begin{array}{l}\text { Instraring nturns } \\
\text { (loglen model) }\end{array}$ & $Y=e^{u_{j}+A_{1} !}$ & $\begin{array}{l}\text { Captures cunsiatentb increasing } \\
\text { returns }\end{array}$ \\
\hline $\begin{array}{l}\text { Itervazing returnx } \\
\text { (fene thresholds madel) }\end{array}$ & 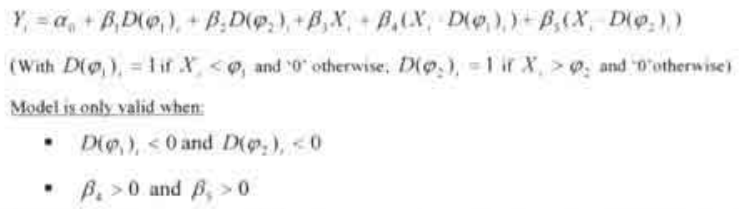 & \\
\hline
\end{tabular}

As can be concluded from the literature review, ample attention has been dedicated to explaining and modeling nonlinear and piece-wise linear representations of the associations among attitudinal constructs like satisfaction and loyalty. Yet, the crucial issue whether these nonlinear models 
have indeed superior predictive power over the often-used linear models has remained largely unaddressed. Consequently, we hypothesize:

\section{Hypothesis 4}

A nonlinear or piece-wise linear functional form is better capable of explaining the relationship between a) customer satisfaction and perceived customer value, b) perceived customer value and customer loyalty, and c) customer satisfaction and customer loyalty than a simple linear functional form.

\subsection{Methodology and analytical results}

\subsubsection{Sample}

Customers from three different retail service industries (dry cleaning, fast food restaurant, and supermarket) were interviewed by means of structured questionnaires. In order to be eligible for our study the respondents had to have purchased the service at least once during the last three months. We obtained an effective sample size of 511 respondents that was divided as follows over the three different service settings: dry cleaning $n=203$, fast food restaurant $n=200$; and supermarkets $n=108$.

\subsubsection{Questionnaire design and measurement properties}

Perceived service quality was measured by means of the SERVPERF items (cf. Cronin and Taylor 1992). Perceived service quality was evaluated on a nine-point scales ranging from -4 (least favorable anchor) to +4 (most favorable anchor). In line with the analysis of Brown et al (2003) we define the SERVPERF scale as a total disaggregated model. The set of scores $[-4,-3,-2,-1$, 0] will be referred to as the negative domain, whereas scores in the set $[0,+1,+2,+3,+4]$ will be referred to as the positive domain. Overall customer satisfaction was measured by means of a single item measure. Perceived customer value was measured by means of the two-item scale proposed by Cronin et al. (2000). Loyalty intentions were measured by means of three items of the Zeithaml et al (1996) behavioral intentions battery. Overall customer satisfaction, perceived customer value, and behavioral intentions 
have indeed superior predictive power over the often-used linear models has remained largely unaddressed. Consequently, we hypothesize:

\section{Hypothesis 4}

A nonlinear or piece-wise linear functional form is better capable of explaining the relationship between a) customer satisfaction and perceived customer value, b) perceived customer value and customer loyalty, and c) customer satisfaction and customer loyalty than a simple linear functional form.

\subsection{Methodology and analytical results}

\subsubsection{Sample}

Customers from three different retail service industries (dry cleaning, fast food restaurant, and supermarket) were interviewed by means of structured questionnaires. In order to be eligible for our study the respondents had to have purchased the service at least once during the last three months. We obtained an effective sample size of 511 respondents that was divided as follows over the three different service settings: dry cleaning $n=203$, fast food restaurant $\mathrm{n}=200$; and supermarkets $\mathrm{n}=108$.

\subsubsection{Questionnaire design and measurement properties}

Perceived service quality was measured by means of the SERVPERF items (cf. Cronin and Taylor 1992). Perceived service quality was evaluated on a nine-point scales ranging from -4 (least favorable anchor) to +4 (most favorable anchor). In line with the analysis of Brown et al (2003) we define the SERVPERF scale as a total disaggregated model. The set of scores $[-4,-3,-2,-1$, 0| will be referred to as the negative domain, whereas scores in the set $[0,+1,+2,+3,+4]$ will be referred to as the positive domain. Overall customer satisfaction was measured by means of a single item measure. Perceived customer value was measured by means of the two-item scale proposed by Cronin et al. (2000). Loyalty intentions were measured by means of three items of the Zeithaml et al (1996) behavioral intentions battery. Overall customer satisfaction, perceived customer value, and behavioral intentions 
with a formal statistical approach to assess whether the three competing functional forms significantly differ in their ability to explain the respective outcome variables. Originally, Steiger's test was developed to assess significant differences in dependent correlation coefficients. The multiple correlation coefficient used to evaluate model performance in regression analysis can be considered as the correlation coefficient between the actual value and the predicted value of the dependent variable, that is $r_{\dot{y} \dot{y}}$. As we impose several functional forms on each sample in order to evaluate the relative performance of the various proposed functional forms in explaining a certain dependent variable $Y_{i}$, we thus deal with dependent correlation coefficients. Consequently, Steiger's methodology can be used to assess the relative performance of the different non-nested sets of alternative predictor variables in explaining a dependent variable. computational details involved in performing Steiger's approach are summarized in the Appendix to this chapter. Furthermore, previous research has shown that this approach has very favorable small sample properties in terms of type I error rate and statistical power (Hittner et al. 2003; Steiger 1980). Table 4-1 presents the results concerning the relationships proposed in $\mathrm{H}_{2}$ and $\mathrm{H}_{3}$. Based on the results presented in table 4-1, we conclude that in almost all cases there is no significant difference in performance for the three proposed functional forms. This implies that nonlinear functional forms do not appear to have superior explanatory power over the more simple linear models. Or alternatively, that the use of linear functional forms does not lead to specification errors. Furthermore, the few significant $\mathrm{z}$-values in table 4-1 indicate the superiority in explanatory power of the linear model over the log-linear model. However, given the marginal significance and their limited incidence, caution is warranted in interpreting these significant results. Overall, we can reject $\mathrm{H}_{2}$ and $\mathrm{H}_{3}$ meaning that nonlinear functional forms do not have superior explanatory power over linear models in explaining the relationships among perceived service quality and higher order constructs in both the positive and negative domain of perceived service quality. 
In order to test $\mathrm{H}_{4}$, the five models proposed in exhibit 4-1 are estimated. Regarding the estimation of the linear-log and log-linear models, the same procedure applies as described for the association between quality and the three higher order customer evaluative judgments. Concerning the twothreshold models the coding schemes and specification criteria are summarized in exhibit 4-1. In order to determine the minimum and maximum thresholds we follow Ngobo's (1999) estimation procedure. Again Steiger's methodology (Steiger 1980; Steiger and Browne 1984) is used to formally compare the performance of the different models. The empirical results regarding $\mathrm{H}_{4}$ are summarized in table 4-2. 
Table 4-1 Analytical results concerning $\mathrm{H}_{1}, \mathrm{H}_{2}$ and $\mathrm{H}_{3}$

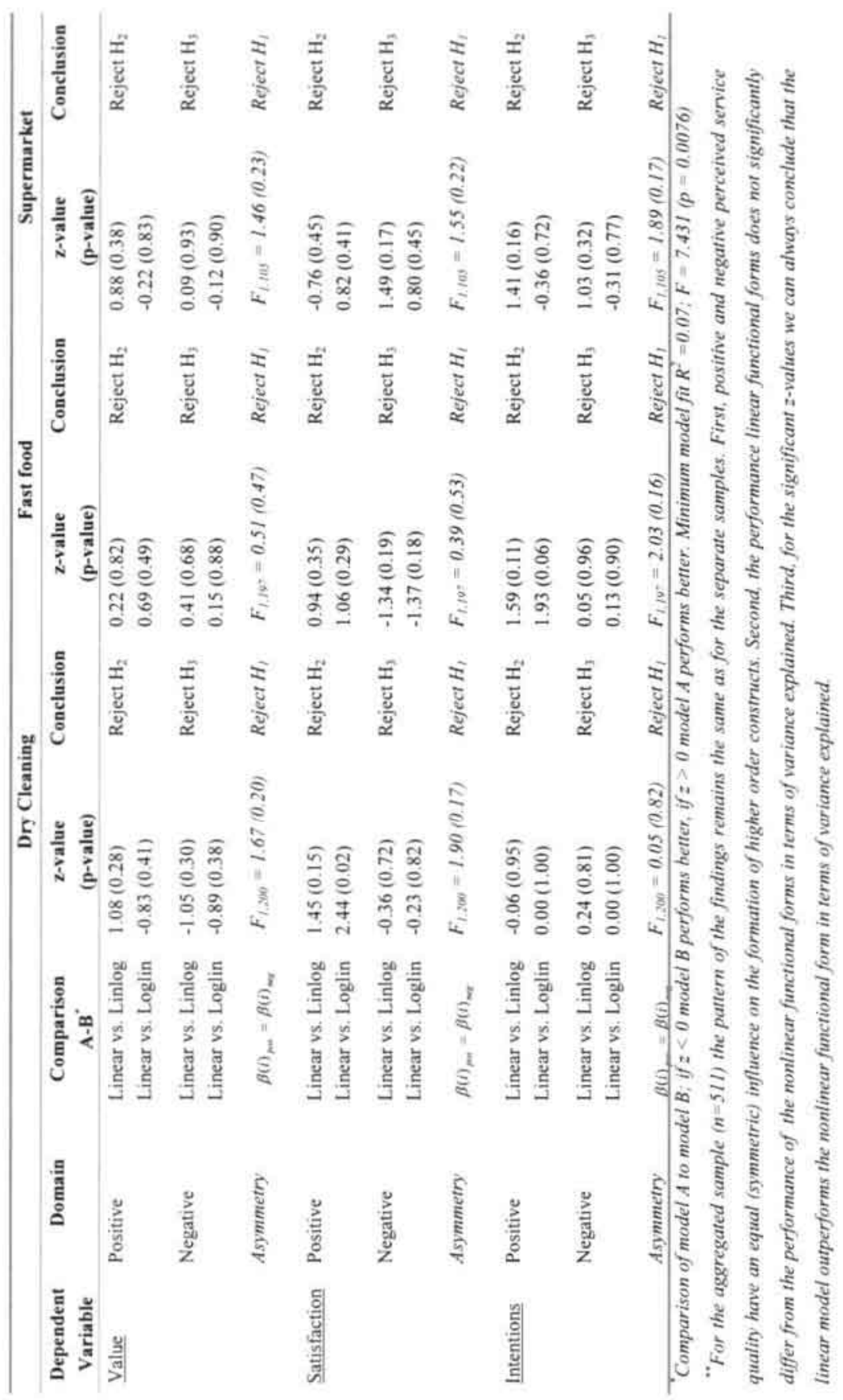


Table 4-2 Analytical Results concerning $\mathrm{H}_{4}$

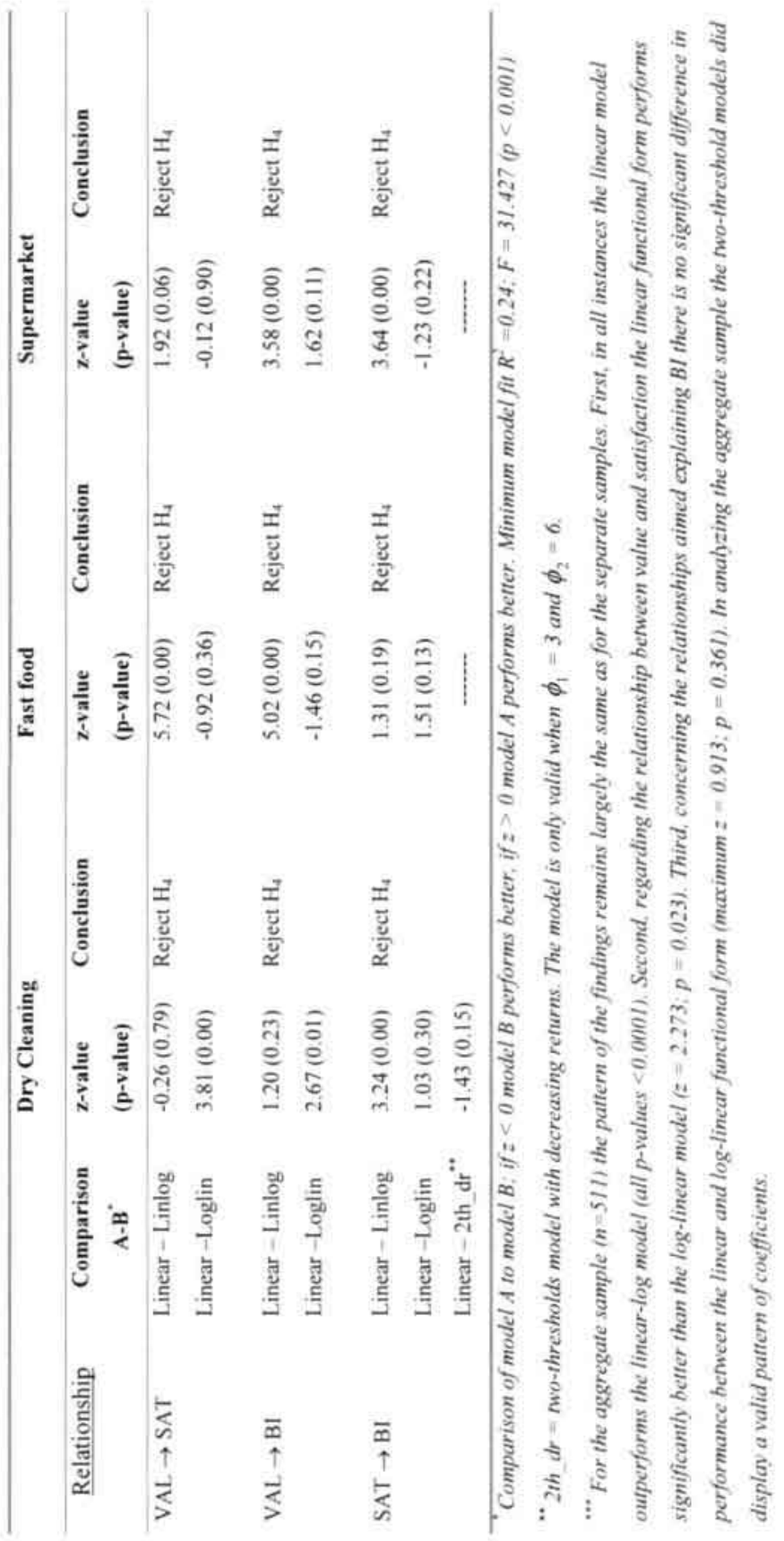


Concerning the dry cleaning sample we find that the relationship between value and satisfaction is significantly better explained by a linear functional form than by a $\log$-linear functional form $(z=3.81$; $p<0.001)$, whereas this relationship is equally well accounted for by a linear as by a linear-log model ( $\mathrm{z}$ $=-0.26 ; \mathrm{p}=0.79)$. For the relationship between value and behavioral intentions the same pattern of findings applies; the linear model performs significantly better than the $\log$-linear model $(z=2.67 ; p=0.01)$ and the linear and linear-log model perform equally well $(z=1.20 ; p=0.23)$. Finally, the association between satisfaction and behavioral intentions reveals a different pattern. For this link the linear model performs significantly better than the linear-log model $(\mathrm{z}=3.24 ; \mathrm{p}<0.001)$, whereas the linear model performs equally well compared to the log-linear model and the two-threshold model with decreasing returns $(z=1.03 ; p=0.30$ and $z=-1.43 ; p=0.15)$. In relation to the fast food sample we find that for the relationships in which value acts as a predictor variable the linear model performs significantly better than the linear- $\log$ model $(z=5.72 ; p<0.001$, and $z=5.02 ; p<0.001)$, whereas the linear and $\log$-linear model perform equally well $(z=-0.92 ; p=$ 0.36 , and $z=-1.46 ; p=0.15)$. Concerning the relationship between satisfaction and behavioral intentions for the fast food sample all proposed models perform equally well. This implies that using a linear model to explain this relationship will not result in significant misspecification error. For the supermarket sample, we find that the linear model performs significantly better than the linear-log model for all relationships under study (minimum $z$ $=1.92 ; \mathrm{p}=0.06)$. Moreover, all relationships are explained equally well by the linear model as by the $\log$-linear model (minimum $z=1.62 ; p=0.11$ ). Concerning our supermarket sample, we would like to note that the two marginally significant results $(z=1.92 ; p=0.06$, and $z=1.62 ; p=0.11)$ seem to indicate superior explanatory power of linear model compared to the nonlinear models. In general, it appears that nonlinear models do not possess superior explanatory power compared to linear models in explaining the pattern of relationships among higher order attitudinal constructs. Moreover, 
in 9 out of 19 comparisons the linear model significantly outperforms the nonlinear functional form. The remaining 10 comparisons reveal that linear and nonlinear functional forms perform equally well, meaning that the use of linear models will not result in significant specification error. This equal performance of linear versus nonlinear functional forms may imply that observed nonlinearities are very likely to occur by chance alone. Finally, it needs to be noted that the two-threshold models (Ngobo 1999; Coyne 1989) have not proven very useful, as the model only appeared valid in one of the three settings for only one pair of threshold coefficients. Overall, we reject $\mathrm{H}_{4}$, which implies that nonlinear functional forms do not appear to have superior explanatory power compared to linear models.

\subsection{Discussion and conclusion}

The key objective of this study was to provide empirical evidence regarding the performance of various alternative functional forms in explaining the relationships among key constructs in services research. More specifically, our empirical study across three retail service settings was aimed at assessing whether asymmetric nonlinear models have indeed superior explanatory power over the frequently used symmetric linear functional forms. The findings of our empirical study can be summarized as follows. First, we find that positive and negative perceived service quality have an equal impact on higher order constructs like customer satisfaction. Second, our results indicate that nonlinear models do not appear to have superior explanatory power compared to the more simple linear models in capturing the relationships among perceived service quality and higher order customer evaluative judgments. Third, concerning the interrelationships among satisfaction, value, and intentions, our results again show that nonlinear models do not have superior explanatory power over the more simple linear models. Here, the linear models often seem to perform even better in terms of explanatory power than some of the nonlinear models.

Our first finding, the symmetric influence of positive and negative perceived service quality is in contrast with findings from previous research, which followed a similar model approach as in our study (e.g. Mittal et al. 1998). A 
possible explanation for these diverging findings may be the nature of the research setting. The three samples we used in our study can be considered as low-involvement services. This complements the research by Mittal et al. (1998), who test the asymmetry hypothesis in the high- involvement contexts of health care and car dealerships. Our service settings represent relatively risk-less purchase situations for consumers, implying that there are no obvious gains and losses (cf. Kahn and Meyer 1991). Consequently, the conjecture that losses loom larger than gains does not seem to operate very prominently in the settings in our study. The reason why we fail to find positive asymmetric effects also seems attributable to the service settings under investigation. As the services we studied are familiar to most people, consumers are apt to have realistic expectations regarding these services, thereby failing to meet the condition that, according to Anderson and Mittal (2000), is assumed to lead to positive asymmetry.

Our finding that nonlinear functional forms do not have superior explanatory power over linear functional forms is in line with Mittal et al's (1998) notion that there is only a negligible difference in performance between a model with diminishing returns and a linear model. Furthermore, Otani et al. (2003) find only rather limited support for the superiority of nonlinear models over linear models in explaining the relationship between perceived service quality and higher order constructs, although it should be noted that Otani et al. (2003) use a different modeling approach.

Finally, our finding that nonlinear functional forms do not have superior explanatory power over linear models in explaining the links between customer satisfaction, value, and behavioral intentions is in line with Ngobo's (1999) results for a retail sample. Several reasons may account for the lack of superior performance of nonlinear models.

First, as customers of the retail services used in our study are likely to have a relatively small evoked set (c.f. Divine 1995), changes in satisfaction will not have a remarkable impact on the size of the evoked set, and therefore no obvious increasing returns characterize the association between satisfaction and loyalty (Anderson and Mittal 2000; Ngobo 1999). Second, in line with Oliva et al. (1992) who state that for situations in which there are low 
transaction costs a linear functional form is well capable of describing the relationship between satisfaction and loyalty, it may be reasonable to find that a linear functional form performs very well in the service settings under study.

\subsection{Limitations}

Although our results indicate that asymmetric nonlinear functional forms do not have superior explanatory power over symmetric linear models in explaining the dynamics among customer evaluative judgments, our study only covers a limited range of services. Another limitation of our study involves the use of only self-report measures. Data on actual customer behavior, and financial behavior would lead to an interesting extension and would increase the validity of our model. However, these objective performance data are very difficult and costly to obtain in the retail service settings we studied. Moreover, another limitation of our study relates to the use of cross-sectional data. As we did not use an experimental design, strong effects of causal effects cannot be inferred. Furthermore, dynamics like carryover effects cannot be incorporated when using single-period cross-sectional data.

\subsection{Suggestions for further research}

Comparing our results to those of previous studies, we see considerable divergence in empirical findings. Therefore, we encourage fellow researchers to conduct similar studies in different settings (e.g. electronic services), in order to establish a set of conditions for the various functional forms. In a similar fashion, the investigation of moderator variables provides a fruitful avenue for future research. Examples of potentially relevant moderator variables include the nature of decision-making (e.g. limited versus extensive decision making), the type of offering (pure services versus product-related services), the level of measurement of the variables involved (attribute based measures versus overall evaluations), the length and depth of the customerfirm relationship. Finally, it would be interesting to extend and integrate our research findings into a comprehensive framework like the service profit chain 
Chapter 4

(Heskett et al. 1994), which implies that we also need to collect employee data and data on financial performance. 


\subsection{Appendix}

When comparing the performance of three alternative models in predicting dependent variable $y$, the following values are important: $y$ (actual values of dependent variables) and $\hat{y}$, with $j=1,2,3$ (predicted values of dependent variable resulting from model $j$ ). The correlation matrix $R$ among these four variables can be expressed as:

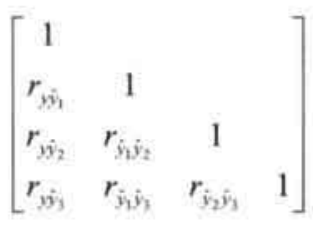

To test for significance between $r_{\dot{\dot{y}_{1}}}$ and $r_{\dot{w}_{2}}$, we use the following z-test:

$$
z=\sqrt{N-3}\left(z_{\dot{y}_{1}}-z_{\dot{y}_{2}}\right)\left(2-2 \operatorname{co} \mathrm{v}_{\dot{\dot{y}_{1}} \dot{y}_{2}}\right)^{-\frac{1}{2}}
$$

Where:

$$
\operatorname{cov}_{\dot{y}_{1} \dot{y}_{2}}=\frac{r_{\dot{y}_{y_{2}}}\left(1-\bar{r}^{2}\right)-1 / 2\left(\bar{r}^{2}\right)\left(1-2 \bar{r}^{2}-r_{j_{1} \dot{j}_{2}}^{2}\right)}{\left(1-\bar{r}^{2}\right)^{2}}
$$

Furthermore, $z_{\dot{y} \dot{y}_{1}}$ and $z_{\dot{y}_{2}}$ are the Fisher r-to-z transformations of respectively $r_{\dot{j_{1}}}$ and $r_{\dot{y} \dot{y}_{2}} ; \bar{r}$ reflects the average of $r_{\dot{y}_{1}}$ and $r_{\dot{y} \dot{y}_{2}}$; and $N$ denotes the sample size. 



\section{Chapter 5}

\section{Managing Customer Relationships by the Customer Equity Criterion: An Expected Value Approach}

This study develops and estimates a model that assists in managing
customer relationships by the customer equity criterion. Following
the principles of an expected value approach, customer equity is
defined as the product of a customers' retention probability and a
customer's monetary value. Our model contributes to effective
customer equity management by incorporating the following aspects
into the customer equity calculation (1) customer perceptions, (2)
customer segment heterogeneity, and (3) uncertainty inherent to
customer behavioral dynamics. Finally, we place our expected value
approach to customer equity at the center of a mathematical
optimization framework and implement this optimization model.




\subsection{Introduction}

Customer relationship management is the establishment, development, maintenance, and optimization of long-term mutually valuable customer-firm relationships (Panda 2003). In the service industry, strong customer relationships are particularly important because of the intrinsically interpersonal focus characterizing most services (Czepiel 1990). According to Blattberg and Deighton (1996), the most appropriate criterion for firm's to manage their customer relationships is by means of the customer equity criterion. This criterion implies that all marketing efforts aimed at improving customer relationships should be evaluated as to whether or not they increase customer equity. However, in order to effectively manage customer relationships by means of the customer equity criterion there is a pressing need for models that meet the following requirements. First, customer perceptions need to be incorporated into the customer equity calculation (Libai et al. 2002). Second, customer heterogeneity needs to be taken into account when determining customer equity (Berger et al. 2002). Third, the uncertainty which is inherent to customer behavior dynamics needs to be taken into account (Hogan et al. 2002). Finally, the models must assist managers in strategic decision-making with the objective of customer equity maximization (Bell et al. 2002).

This study intends to develop a model aimed at improving the effectiveness of customer equity management by taking these requirements into account. Our customer equity approach follows the principles of an expected value approach, which has been widely applied in finance and accounting. In line with the expected value approach we propose that customer equity is determined by two distinct elements; (1) the probability that a customer will be retained by the firm (2) the projected customer monetary value (CMV). The first component of our proposed model, the probability of a customer's retention over a given time period, draws lineage from recent advances in relationship marketing theory (cf. Garbarino and Johnson 1999, Verhoef 2003) and incorporates customer perceptions, customer heterogeneity, and uncertainty into the customer equity calculation. The second component of 
our expected value approach to customer equity, the customer monetary value, will be assessed by time series modeling. In addition, as the assessment of customer equity is only useful to the extent that it changes a firm's actions in a way that increases financial performance (cf. Rust et al. 2000), we place our expected value approach at the center of a mathematical framework in which the decisions with regard to management and maximization of customer equity in terms of financial consequences are formalized.

The main objective of this study is to develop a general customer-oriented approach that can be used to assist in effective decision-making with regard to customer equity management. In developing this approach we attempt to make the following theoretical and practical contributions. First, we conceptually and empirically explore key antecedents of customer retention. Second, we empirically explore the effect of customer heterogeneity in the formation of customer retention. Third, we develop an optimization model that has practical value for decision makers.

In order to make these contributions, our paper is structured as follows. We start by developing a conceptual model of customer equity based on the expected value approach. We then proceed by empirically testing our model using cross-sectional and time series data describing customer of a large office equipment company over a 12 -month period. Next, our study focuses on developing a mathematical framework aimed at designing investment strategies that maximize the amount of customer equity and provides a detailed illustration on the practical implementation of the optimization model. Finally, we discuss the implications and limitations of our study.

\subsection{An expected value approach to customer equity}

Consistent with Blattberg and Deighton (1996), we define customer equity as the total of discounted lifetime values of all of its customers. In this paper we propose an expected value approach to measuring and maximizing customer equity. According to this approach, the expected value of an investment is a weighted average using the probability of each event to weight the outcomes for each action (Horngren and Sundem 1993). Analog to this definition of 
expected value, we propose that a firm's customer equity equals the projected monetary value of a customer multiplied by the probability that a customer remains loyal over a given time period, summed over all its customers. Pursuing an expected value approach to customer equity offers the following opportunities. First, the use of predictive response modeling to assess the probability that customers remain loyal over a given period offers a rich opportunity to incorporate customer perceptions and customer heterogeneity into the calculation of customer equity. Second and synergistically, treating customer perceptions as an integral part of the customer equity assessment provides ample chance to project the financial impact of actions aimed at improving customer evaluations. Third, adjusting the expected cash flows by the probability that a customer remains loyal explicitly takes into account the customers' differential risk in terms of loyalty. The expected value approach to customer equity is expressed algebraically in exhibit 5-1.

Exhibit 5-1 Expected value approach to customer equity

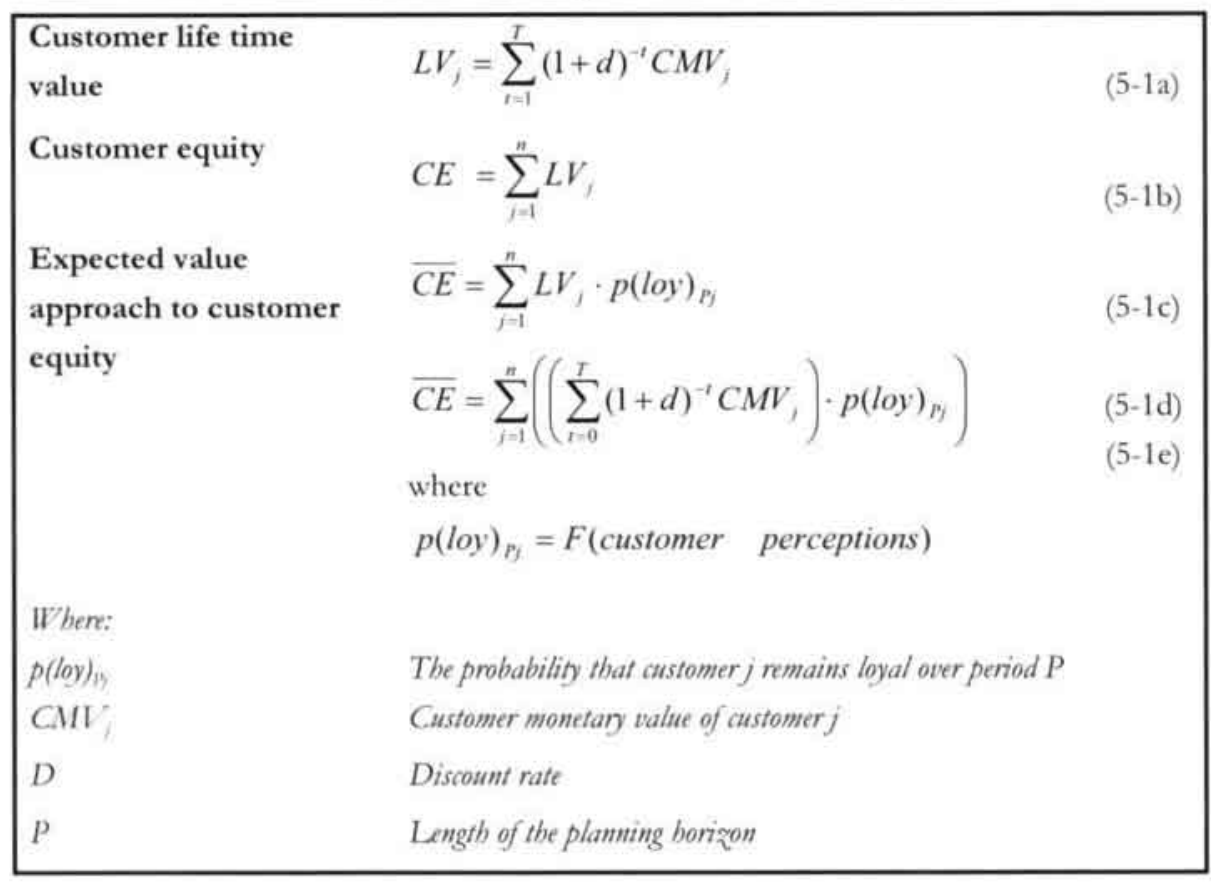


We proceed by developing the two models to estimate the two main determinants of our expected value approach to customer equity. First, drawing upon relationship marketing theory and services research (e.g. Garbarino and Johnson 1999; Cronin et al. 2000), we develop a model that explains the probability of customer retention. Second, customer monetary value over period $\mathrm{P}$ is forecasted by applying time series techniques. According to DeKimpe and Hanssens (2000) time series techniques are particularly useful in determining future customer monetary value. Yet, the forecasting of future customer monetary value has received relatively little attention so far (Mulhern 1999).

\subsection{The probability of customer retention}

Customer retention is considered one of the key metrics in customer relation management (CRM) (Verhoef 2003, Hennig-Thurau et al. 2002). The focal constructs in our probabilistic customer retention model include perceived quality, customer satisfaction, perceived value, and trust. Because these constructs and their interrelations have received significant attention in the literature (e.g. Garbarino and Johnson 1999; Cronin et al. 2000) and mostly have been empirically established, we provide a brief discussion here. We first focus on the definitions of our focal model constructs and then proceed with a discussion of their interrelations. In developing the hypotheses underlying our customer retention model, we start our discussion with our key outcome variable, the probability that a customer will remain loyal over a certain period, and work back to the input variables of our model.

\subsubsection{Focal constructs}

Quality As customers' evaluations of a supplier's offering influence future customer's behavior (Verhoef 2003), perceived quality evaluations play an important role in assessing customer retention probabilities.

Satisfaction In this study we define customer satisfaction as the cumulative evaluation that is based on all experiences with the supplier's offering over time (cf. Anderson et al. 1994). It is cumulative satisfaction that eventually leads to customer loyalty and enhanced financial performance, and 
consequently provides a rationale for initiatives aimed at improving customer satisfaction (Oliver 1999; Anderson et al. 1994).

$V$ alue Whereas satisfaction solely addresses the benefits associated with service use, perceived value explicitly addresses the trade-off between sacrifices and returns involved in using a particular service. According to Rust and Oliver (1994) it is perceived value that attracts a customer or lures a customer away from a competitor. Hence, including perceived value in our model will result in a richer portrayal of the dynamics surrounding satisfaction and behavioral intentions (cf. Bolton and Drew 1991; Cronin et al. 2000).

Trust Trust is viewed as a key element for developing and sustaining long-term relationships (Moorman et al. 1993; Ganesan 1994). Based on a review of the rich literature on trust Rousseau et al. (1998, p.395) propose the following definition of trust: "trust is a psychological state comprising the intention to accept vulnerability based on positive expectations of the intentions or behaviors of another".

\subsubsection{Hypotheses}

According to Garbarino and Johnson (1999), constructs like perceived service quality, customer satisfaction, perceived value and trust summarize consumers' knowledge and experience with a particular organization and therefore guide subsequent action of the consumer. Empirically, it has been shown that customers' intentions to remain with a service provider are indeed positively related to perceived service quality, perceived value, customer satisfaction, and trust (e.g. Cronin et al. 2000; Dodds et al. 1991; Morgan and Hunt 1994; Doney and Cannon 1997).

Selnes (1998) proposes that trust is an aggregate evaluation at some higher level than satisfaction, and that satisfaction has a significant positive influence on trust. Ganesan (1994) explains this positive relationship by equity and social exchange theory. The relationship between trust and perceived value has not been extensively tested and is subject to considerable debate. According to Sirdeshmukh et al. (2002) perceived value mediates the relation between trust and loyalty; implying that trust leads to value. Sirdeshmukh et al. (2002) assume that value is a more superordinate consumer goal than trust, 
and based on goal and action identification theory Sirdeshmukh et al. (2002) reason that trust therefore influences value. However, research by Gwinner et al. (1998) indicates that across different types of services, confidence benefits (including trust) are considered more important than special treatment benefits (including an economical value component) by customers. Consequently, drawing upon Sirdeshmukh et al. (2002) line of reasoning, we propose that perceived value determines trust. This proposed relationship between value and trust is in line which Singh and Sirdeshmukh's (2000) notion that perceived value is likely to confirm and possibly enhance postpurchase trust expectations.

Empirically, it is been shown that customer satisfaction and perceived value are in turn consequences of customers' perceived service quality (Cronin et al. 2000; Sweeney et al. 1999; Streukens and De Ruyter 2004). In addition, based on a comparison of different competing models Cronin et al. (2000) provide empirical evidence that perceived value is an important determinant of customer satisfaction. The hypotheses we state based on the discussion above are summarized in figure 5-1.

Figure 5-1 Hypotheses probabilistic customer retention model

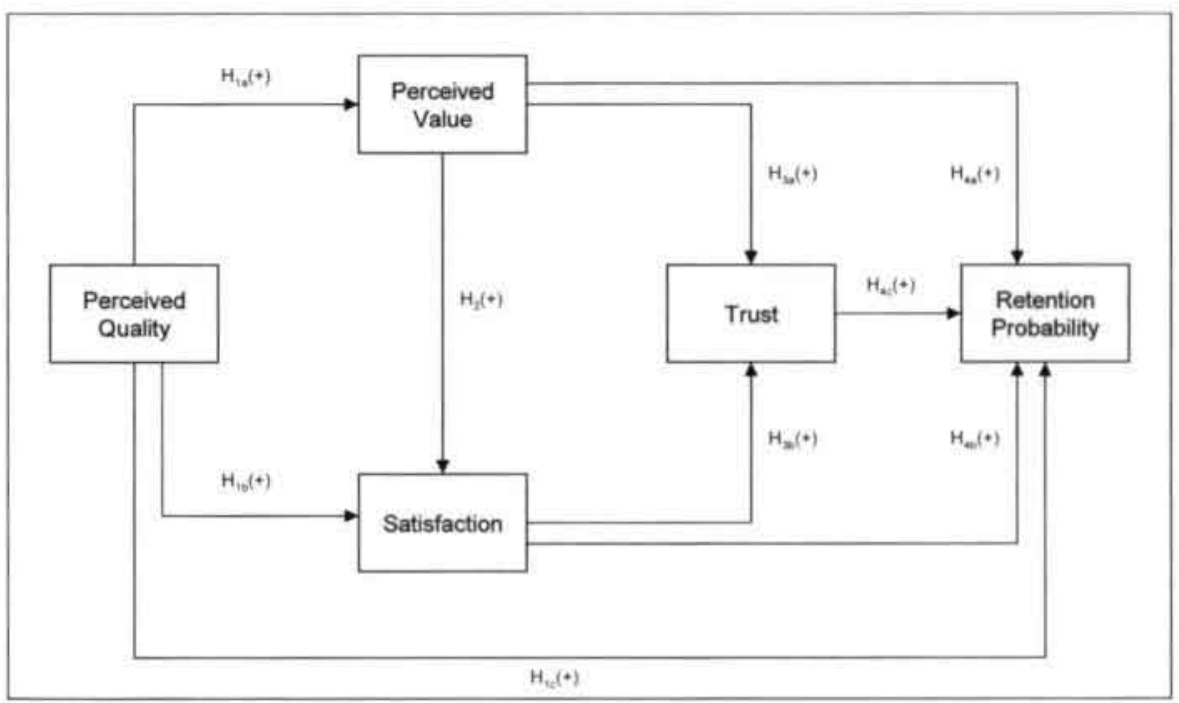




\subsubsection{Customer heterogeneity}

Several researchers (Kamakura and Mittal 2001; Garbarino and Johnson 1998; Kekre et al. 1995) illustrated that customers differ with regard to the magnitude and strength of the relationships among customer evaluative judgments. Consequently, ignoring customer heterogeneity may lead either to over or underestimation of relationships among constructs that aim to explain customer loyalty (cf. Anderson and Mittal 2000). Similarly, Berger et al. (2002) stress the importance of customer segmentation in managing and maximizing customer equity.

Bock and Uncles (2002) propose a taxonomy of generic differences between customers as a basis for developing segmentation strategies. Two segmentation variables in the Bock and Uncles' (2002) taxonomy are especially promising, and will be used in this study. The first segmentation variable is preferences for product/service benefits, which relates segmentation to the customers' preferences. According to Aaker (1995) this is the most useful segmentation variable, because the selection of benefits can determine a total business strategy. The second useful segmentation variable is profitability. With regard to this second segmentation variable it should be noted that profit heterogeneity may itself be a function of other differences between consumers (Bock and Uncles 2002).

Customer heterogeneity is taken into account in both components of our expected value approach to customer equity. Customer heterogeneity with regard to customer monetary value is taken into account through assuming different usage and contribution margins across the segments (for more details see paragraphs 5.6.2 and 5.7.2 below). Segment-wise differences with regard to customers' retention probability are assessed as follows. We formally assess the presence of segment-wise differences in the relationship between customer perceptions and retention probability means testing the following hypothesis $\left(\mathrm{H}_{5}\right)$. If we fail to reject $\mathrm{H}_{5}$ we estimate the relationship between customer perceptions and retention probability separately for each segment. 


\section{Hypothesis 5}

The relationships put forward in our model as hypothesized in $H_{4}$ to $H_{4}$ differ significantly across different customer segments.

In testing this hypothesis, we assume that all customers will have similar component attitude on their overall customer satisfaction, but differ in the weights they assign to the different components (cf. Garbarino and Johnson 1999).

\subsection{Customer monetary value}

The second element of our customer equity conceptualization consists of CMV. The importance of this second element follows from the definition of customer equity, which states that customer equity is the total of the discounted life-time values of all customers (Rust et al. 2004). As our expected value approach brings customer characteristics into the determination of customer equity by adjusting the customer life time value by the probability that a customer remains loyal, our starting point in determining a model that assesses the monetary value of customers is the customer lifetime value of a customer that would be obtained if a customer would be perfectly loyal $\left(p(L O Y)_{p^{\prime}}=1\right)$. The monetary value of a customer that would be realized if the customer would be perfectly loyal will be referred to as usage capacity. The reason that we use capacity rather than actual sales is threefold. First, usage capacity is independent of the customers' actual loyalty. Second, the capacity of customer gives us a more accurate picture about their actual behavior as capacity cannot be bought on before hand and stocked for some time. Third, using actual sales data and adjusting this figure for the probability that a customer would remain loyal, would lead to an underestimation of the actual customer monetary value. It should be noted that if a customer is perfectly loyal $\left(p(L O Y)_{p j}=1\right)$ usage capacity and actual sales volume are equal.

To arrive at a model that explicitly assesses CMV in terms of profitability, we combine a general revenue model and a general cost model (cf. Niraj et al. 2001), for which we assume that both revenues and costs are linearly related 
to usage capacity. Consequently, CMV equals the contribution margin times the usage capacity.

Algebraically, the model can be expressed as:

$$
C M V_{,}=C A P_{,} \times\left(R_{\text {lnit }_{i}}-C_{\text {Unit }_{i}}\right)
$$

Where:

$C M V,=\quad$ Customer monetary value of customer $j$ when $p(L O Y)_{P j}=1$

$C A P_{,}=$Usage capacity of customer $j$ in units

$R_{\text {Unit, }}=$ Revenues associated with each unit of usage capacity of customer $j$

$C_{\text {Unit },}=\quad$ Costs associated with eacb unit of capacity of customer $j$

With regard to revenues $\left(R_{\text {Lnir }}\right)$, we assume constant prices throughout time period $\mathrm{P}$ for reasons of clarity. Data concerning the costs $\left(C_{\text {Lnit }_{j}}\right)$ was obtained directly from internal company databases. Both variable and fixed costs are included in $C_{\text {lnit }}$, which were assigned through an activity-based costing approach to the various customer segments by the company. In order to assess the customer monetary value of a given time period in the future, we therefore apply econometric forecasting models on company records that describe the history of customer usage capacity $\left(C A P_{j}\right)$. In assessing $R_{\text {tinit }}, C_{\text {timt }}$, and $C A P$, separate estimates are made for each customer segment in order to take into account customer heterogeneity (cf. Niraj et al. 2001; Foster et al. 1996).

\subsection{Data and Methodology}

\subsubsection{Sampling}

Survey data were obtained from business customers of the supplies business unit of a large international operating manufacturer of office equipment. This business unit sells the supplies (paper and toner) needed to operate their 
office equipment (copiers and printers). Furthermore, the company aims to build long-term relationship with its customers based on service excellence.

Driven by the two proposed segmentation variables to account for customer heterogeneity, we employed a stratified sampling procedure. The strata were formed based on preferences for product/service benefits ( 2 categories) and profitability (4 categories; based on quartiles), which resulted in eight strata. Instead on drawing random samples from all eight strata, we only sampled respondents from the second-lowest profitability quartile for each product/service benefit category. Although this choice appears to contrast the vision expressed by Zeithaml et al. (2001), our sampling decision to use the second-lowest profitability quartile was guided by the following rationale. First, the second-lowest profitability quartile for each product/service benefit category is of substantial size $(20.2 \%$ and $16.5 \%$ of all customers respectively). Second, in contrast with the two upper profitability quartiles is it economically infeasible to have salespeople directly monitor the customers in the second-lowest profitability quartile.

The total sample size consisted of 462 respondents, of which 222 respondents were classified as OU (Office Usage) and 240 respondents were classified as PU (Professional Usage). The distinction between OU and PU is based on preferences for product/service benefits. For customers in the OU segment the office equipment only plays a supporting role in their business (e.g. marketing research agencies). The PU segment contains customer for whom the office equipment forms the core technology of their business (e.g. copy shops). Examination of the samples' profiles by managers led to the conclusion that both samples are representative of the population in the segments.

\subsubsection{Questionnaire design and measurement properties}

Perceived quality was measured by means of 16 attributes that covered the most important aspects of the customer-firm encounter (cf. Rust et al. 1995), including both product and service dimensions. A problem that often arises when relating perceived quality to higher order constructs is multicollinearity (Peterson and Wilson 1992). In order to overcome this problem the 16 
attributes were subjected to a principal component analysis. The resulting principal components are then used in subsequent analyses (cf. Rust et al. 2002). For both segments a solution with four principal components yielded the most interpretable solution. Furthermore, for both segments the same attributes loaded on the same components. The resulting principal components were labeled as follows: product $\left(\mathrm{PC}_{\text {prod }}\right)$, delivery $\left(\mathrm{PC}_{\text {deliv }}\right)$, aftersales $\left(\mathrm{PC}_{\text {aftet }}\right)$, and invoicing $\left(\mathrm{PC}_{\text {inv }}\right)$. The rotated solution of the principal component analysis for each segment is given in table 5-1.

Table 5-1 Results principal components analysis

\begin{tabular}{|l|c|c|c|c|c|c|c|c|}
\hline \multicolumn{3}{c}{ PU Segment } & \multicolumn{3}{c}{ OU Segment } \\
\hline Items & PC01 & PC02 & PC03 & PC04 & PC01 & PC02 & PC03 & PC04 \\
\hline Product: assortment & 0.55 & & & & 0.69 & & & \\
Product: quality & 0.78 & & & & 0.76 & & \\
Product: fulfillment of needs & 0.78 & & & & 0.64 & & & \\
Product: price-quality ratio & 0.82 & & & & 0.76 & & & \\
Delivery: taking customer's wishes into account & & 0.92 & & & & 0.75 & & \\
Delivery: presentation of employees & & 0.83 & & & & 0.88 & \\
Complaints: accessibility of Company Z & & & 0.28 & & & & 0.82 & \\
Complaints: attention of employees & & & 0.81 & & & & 0.79 & \\
Complaints: knowledge of employees & & & 0.61 & & & & 0.66 & \\
Complaints: solving complaint first time right & & & 0.83 & & & & 0.84 & \\
Complaints: speed of dealing with complaint & & & 0.91 & & & & 0.89 & \\
Complaint: information on time solving compl. & & & 0.72 & & & & 0.90 & \\
Invoice: Clarity & & & & 0.62 & & & & 0.82 \\
Invoice: Correct & & & & 0.67 & & & & 0.72 \\
Invoice: Lay out & & & & 0.78 & & & & 0.82 \\
Invoice: Timing & & & & 0.69 & & & & 0.77 \\
& & & & & & & & \\
Initial Eigenvalues & 7.89 & 1.78 & 1.48 & 1.28 & 9.35 & 1.64 & 1.14 & 0.83 \\
Variance explained after rotation (\%) & 26.0 & 20.1 & 18.5 & 12.6 & 29.0 & 20.4 & 18.3 & 13.2 \\
Variance explained cumulative after rotation (\%) & 26.0 & 46.1 & 64.7 & 77.3 & 29.0 & 49.4 & 67.8 & 81.0 \\
\hline
\end{tabular}

Overall cumulative satisfaction was measured by means of a single item (cf. Anderson et al. 1994). Perceived value (6 items) was assessed using an adapted version of Dodds et al.'s (1991) scale. Trust (10 items) was measured by means of Kumar et al.'s (1995) scale. All above-mentioned constructs were measured on 8-point Likert scales. Furthermore, all questionnaires were labeled with the customers' unique IDcode enabling us to decide to with user segment a customer belongs.

In order to estimate the probability of customer retention, we need a binary dependent variable as input for our analysis. In order to achieve this, a group 
of five company sales representatives were asked to rate the customers in our sample as loyal (1) or not loyal (0). Customers on whom there was considerable disagreement whether they were loyal or not, were left out of the analysis (a total of 11 customers).

In order to estimate the customer monetary value, objective data is needed with regard to the usage of a perfectly loyal customer. As each copier and printer is equipped with a counter this data was easily obtained. In the company's database 129 monthly observations concerning average usage capacity for the PU segment were available and 52 monthly observations concerning average usage capacity were available for the OU segment ${ }^{2}$.

\subsubsection{System of equations and estimation procedure}

To test the hypotheses underlying the model to assess the probability of customer retention over period $\mathrm{P}$, we use the system of equations depicted in exhibit 5-2.

Exhibit 5-2 system of equations

\begin{tabular}{|c|c|}
\hline$P C_{,}=\underset{(p \times 1)}{W} \underset{(p \times q)}{W} X_{(q-1)}$ & $(5-3)$ \\
\hline$V A L U E_{j}=\alpha_{1}+\underset{(1+p)}{P} P C_{(p+1)}+\varepsilon_{1}$ & $(5-4)$ \\
\hline$S A T_{1}=\alpha_{2}+\beta_{1} V A L U E_{1}+\underset{(1 \times p)(p \times+1)}{Z} P C+\varepsilon_{2}$ & $(5-5)$ \\
\hline TRUST,$=\alpha_{3}+\beta_{2} V A L U E_{i}+\beta_{3} S A T_{j}+\varepsilon_{3}$ & $(5-6)$ \\
\hline 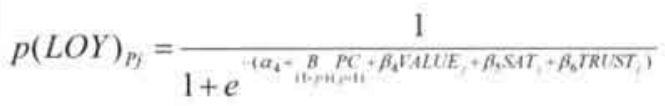 & $(5-7)$ \\
\hline
\end{tabular}

The relationship expressed in equation (5-3) was estimated by means of a principal component analysis. Equations (5-4) - (5-6) were estimated using Seemingly Unrelated Regression (SUR). The reason why we opted for SUR is twofold. First of all, we aim for optimal prediction accuracy when prediction the probability that a customer remains loyal over time period P. Second, as indicated by the Breusch-Pagan test for contemporaneous error correlation, 
the error terms of equations (5-4)-(5-6) are correlated. As SUR provides optimal prediction accuracy while simultaneously taking into account the intercorrelations among the error terms, we believe SUR is the best option.

To our best knowledge there is no statistical package that allows performing SUR with a binary dependent variable. As a result the relationship put forward in equation (5-7) was estimated separately using logistic regression (cf. Long 1997). As independent variables in equation (5-7) we used the predicted values of VALUE, SAT and TRUST that resulted from the SUR estimation as well as the estimated principal components.

To estimate the future profitability of each customer unit we employ the BoxJenkins methodology. The Box-Jenkins methodology, also known as ARIMA modeling, provides us with a useful class of models for describing the dynamics of an individual time series and has been proven to be adequate for a wide variety of series (Hamilton 1994).

\subsection{Empirical findings}

5.6.1 Customer retention probability In order to assess whether customer heterogeneity should be taken into account, we test whether significant differences exist between the two segments in terms of the hypothesized relationships $\mathrm{H}_{\mathrm{aa}}-\mathrm{H}_{4 \mathrm{c}}$ by means of a Chow test. The results of the Chow test indicate that all relationships differ significantly across the segments, except the relationship expressed in equation (5-5). Hence, we will estimate the probability of customer retention over period $\mathrm{T}$ for each segment separately. As can be concluded from table 5-2a, the majority of the hypothesized relationships are supported by the data. Furthermore, for both segments our model fits the data well as demonstrated by the $\mathrm{R}$-square values presented in table 5-2b. 


\begin{tabular}{|c|c|c|c|c|c|c|c|c|c|}
\hline \multirow[b]{2}{*}{ Equation } & \multirow[b]{2}{*}{ Relationslsip } & \multicolumn{4}{|c|}{ Segment PU } & \multicolumn{4}{|c|}{ Seqment OU } \\
\hline & & $\bar{b}$ & e-value & p-value & Concluxion & b & I-velue & p-value & Conclusian \\
\hline \multirow[t]{4}{*}{ (4) } & $\mathrm{PC}_{\mathrm{COMP}} \rightarrow$ VALUE & 0.24 & 5.63 & $<0.0001$ & Fail to reject $\mathrm{H}_{\mathrm{ls}}$ & 0.17 & 3.46 & 0.0007 & Fail to reject $\mathrm{H}_{12}$ \\
\hline & $\mathrm{PC}_{\mathrm{PROD}} \rightarrow$ VALUE & 0.24 & 5.11 & $<0.0001$ & Fail to reject $\mathrm{H}_{12}$ & 0.19 & 3.82 & 0.0002 & Fail to reject $\mathrm{H}_{1}$, \\
\hline & $\mathrm{PC}_{\mathrm{BV}} \rightarrow$ VALUE & 0.12 & 2.11 & 0.0097 & Fail to reject $\mathrm{H}_{\mathrm{t}}$ & 0.38 & 7.73 & $<0.0001$ & Fail to reject $\mathrm{H}_{\mathrm{is}}$ \\
\hline & $\mathrm{PC}_{\mathrm{DE} I \mathrm{~V}} \rightarrow$ VALUE & 0.17 & 3.70 & 0.0003 & Fail to reject $\mathbf{H}_{1}$, & 0.26 & 5.40 & $<0.0001$ & Fail to reject $\mathrm{H}_{\mathrm{l}_{\mathrm{s}}}$ \\
\hline \multirow[t]{5}{*}{ (s) } & VALUE $\rightarrow$ SAT & $0.3 \mathrm{~s}$ & 5.73 & $\times 0.0001$ & Fail to rejecl Hz & 0.19 & 2.86 & 0.0049 & Fail to reject $H_{2}$ \\
\hline & $\mathrm{PC}_{\text {COMPL }} \rightarrow \mathrm{SAT}$ & 0.18 & 4.76 & $<0.0001$ & Fail to reject $H_{1 b}$ & 0.31 & 7.37 & $<0.0001$ & Fail to reject $\mathrm{H}_{1 \mathrm{~s}}$ \\
\hline & $\mathrm{PC}_{\text {PROD }} \rightarrow \mathrm{SAT}$ & 0.18 & 4.61 & $\lessdot 0.0001$ & Fail to reject $\mathrm{H}_{1 \mathrm{~b}}$ & 0.17 & 4.16 & $<0.0001$ & Fail to reject $\mathrm{H}_{1 \mathrm{~s}}$ \\
\hline & $\mathrm{PC}_{\mathrm{ANV}} \rightarrow \mathrm{SAT}$ & 0.17 & 4.68 & $<0.0001$ & Fail to reject $\mathrm{H}_{1 \mathrm{t}}$ & 0.15 & 3.44 & 0.0008 & Fail to reject $\mathrm{H}_{18}$ \\
\hline & $\mathrm{PC}_{\text {DEHIV }} \rightarrow \mathrm{SAT}$ & 0.09 & 2.37 & 0.0188 & Fail to reject $\mathrm{H}_{16}$ & ns & ns & ns & Reject $H_{15}$ \\
\hline \multirow[t]{3}{*}{ (6) } & VALUE $\rightarrow$ TRUST & 0.41 & 7.25 & $<0,0001$ & Fail to reject $\mathbf{H}_{3,}$ & 0.45 & 6.80 & $<0.0001$ & Fail to reject $\mathrm{H}_{3,}$ \\
\hline & SAT $\rightarrow$ TRUST & 0.32 & 5.35 & $<0.0001$ & Fail to reject $\mathrm{H}_{s}$ & 0.40 & 5.28 & $<0.0001$ & Fail to reject $\mathrm{H}_{\mathrm{ss}}$ \\
\hline & & $e^{\circ}$ & Wald $x^{\prime}$ & p-value & Conclusion & $e^{0}$ & Wild $\tau^{2}$ & p-value & Conclusion \\
\hline \multirow[t]{7}{*}{ (7) } & $\mathrm{PC}_{\text {Coser }} \rightarrow \mathrm{p}(\mathrm{LOY})$ & ns & ns & ns & Reject $H_{i \mathbf{r}}$ & $\mathrm{nx}$ & ns & ns & Reject $H_{i s}$ \\
\hline & $P C_{P R O O} \rightarrow$ p(LOY $)$ & กร & $\mathrm{ns}$ & ns & Reject $H_{l e}$ & ns & ns & ns & Reject $\mathrm{H}_{46}$ \\
\hline & $P C_{\mathrm{INY}} \rightarrow \mathrm{p}(\mathrm{LOY})$ & ns: & ns & ns & Rejecı $\mathrm{H}_{1 \mathrm{c}}$ & ns & $\mathrm{ns}$ & ns & Reject $H_{16}$ \\
\hline & $\mathrm{PC}_{\mathrm{DE} I \mathrm{~N}} \rightarrow \mathrm{P}(\mathrm{LOY})$ & ns & ns & ns & Reject $\mathrm{H}_{1 \mathrm{~s}}$ & ns & $n s$ & ns & Reject $H_{16}$ \\
\hline & VALUE $\rightarrow$ p(LOY $)$ & 15.80 & 25.59 & $<0.0001$ & Fail to reject $\mathbf{H}_{\mathbf{u}_{1}}$ & 19.92 & 5.78 & 0.0162 & Fail to reject $\mathrm{H}_{4}$ \\
\hline & SAT $\rightarrow$ p(LOY $)$ & 5.81 & 18.77 & $<0,0001$ & Fail to reject $\mathrm{H}_{\mathrm{b}}$ & 2.41 & 6.56 & 0.0104 & Fail to reject $\mathrm{H}_{4 b}$ \\
\hline & TRUST $\rightarrow \mathrm{p}($ LOY $)$ & 17.29 & 27.52 & $<0.0001$ & Fail to reject $\mathrm{H}_{\mathrm{tc}}$ & 4.85 & 19.79 & $<0.0001$ & Fail to reject $\mathrm{H}_{6}$ \\
\hline
\end{tabular}


Table 5-2b Goodness of fit statistics customer retention model

\begin{tabular}{ccccccc}
\hline & \multicolumn{3}{c}{ PU Segment } & \multicolumn{3}{c}{ OU Segment } \\
\hline Equation & F-value & p-value & $\mathbf{R}^{2}-$ adj & F-value & p-value & $\mathbf{R}^{2}-$ adj \\
$(5-4)$ & 12.09 & $<0.0001$ & $19.3 \%$ & 22.27 & $<0.0001$ & $36.3 \%$ \\
$(5-5)$ & 30.95 & $<0.0001$ & $44.7 \%$ & 27.02 & $<0.0001$ & $47.0 \%$ \\
$(5-6)$ & 43.19 & $<0.0001$ & $34.2 \%$ & 38.00 & $<0.0001$ & $33.2 \%$ \\
& & & & & & \\
& Likelihood ratio $\chi^{2}$ & p-value & $\mathbf{R}^{2}-$ logit & Likelihood ratio $\chi^{2}$ & p-value & $\mathbf{R}^{2}-\operatorname{logit}^{2}$ \\
& 127.91 & $<0.0001$ & $29.2 \%$ & 74.95 & $<0.0001$ & $51.1 \%$
\end{tabular}

5.6.2 Customer monetary value Taking into account the between segment heterogeneity with regard to usage and therefore monetary value, we conduct a separate time series analysis for each of the two segments. Concerning usage capacity, within-segment homogeneity is assumed, as taking into account individual differences is not economically feasible for the segments under study (cf. Mulhern 1999). In addition, the reasonableness of this assumption rests in the fact that the use of profitability as a segmentation criterion to a large extent warrants usage capacity homogeneity.

For the PU segment we investigate an aggregated time series consisting of 129 monthly observations concerning capacity. To proceed with the Box-Jenkins methodology, both level and variance stationarity of the series are required. Variance stationarity is achieved by applying a natural $\log$ transformation of the original series. In order to obtain level stationarity, differencing seems necessary. The Dickey-Fuller unit root test provides evidence that the working series exhibits both level and variance stationarity.

To tentatively identify the model, we examine the behavior of the autocorrelation function (ACF) and the partial autocorrelation function (PACF) of the working series. Based on a series of estimating and inspecting of various models and the examination of the ACF and PACF of the accompanying residuals, we concluded that an $\operatorname{ARIMA}(1,1,1)$ model captures the systematic part of the series best. Moreover, inspection of the residuals shows no further room for improvement of the model. The results for the 
ARIMA $(1,1,1)$ model together with one-year ahead forecasts are presented in table 5-3.

For the OU segment we assess a time series consisting of 52 monthly observations regarding capacity. Inspection of the original series reveals a pattern characterized by a clear deterministic trend. To obtain variance and level stationary, a natural $\log$ transformation was applied and the first differences were taken. The Dickey-Fuller test indicates that our working series are indeed stationary. Examination of the ACF and PACF of working series leads us to tentatively identify an $\operatorname{ARIMA}(0,1,1)$ model. This ARIMA $(0,1,1)$ model shows a good fit to the data. In addition, investigation of the ACF and PACF of the residuals indicated that further improvement of the model is not necessary. The results for the ARIMA $(0,1,1)$ model together with one-year ahead forecasts are presented in table 5-3.

Table 5-3 Estimation results time series

\begin{tabular}{|c|c|c|c|c|c|c|c|c|}
\hline & & Coefficient & t-value & \multicolumn{2}{|c|}{ p-value } & \multicolumn{3}{|c|}{ Log-Likelihood } \\
\hline \multicolumn{9}{|c|}{ PU-Segment } \\
\hline $\operatorname{AR}(1)$ & & 0.29 & 2.52 & \multicolumn{2}{|c|}{0.012} & \multicolumn{3}{|c|}{$108.5(\mathrm{p}<0.0001)$} \\
\hline $\mathrm{MA}(1)$ & & 0.70 & 8.12 & \multicolumn{2}{|c|}{$<0.0001$} & & & \\
\hline Constant ter & $\mathrm{rm}$ & Not included & $n s$ & \multicolumn{2}{|c|}{$n s$} & & & \\
\hline \multicolumn{9}{|c|}{ OU-Segment } \\
\hline $\mathrm{MA}(1)$ & & 0.62 & 5.26 & \multicolumn{2}{|c|}{$<0.0001$} & \multirow{2}{*}{\multicolumn{3}{|c|}{$129.5(p<0.0001)$}} \\
\hline Constant ter & & 0.01 & 6.40 & \multicolumn{2}{|c|}{$<0.0001$} & & & \\
\hline \multirow{3}{*}{\multicolumn{2}{|c|}{ PU-Segment }} & \multirow{2}{*}{$\begin{array}{l}\text { Model } \\
\text { where }\end{array}$} & \multicolumn{6}{|c|}{$w_{t}=0.29 w_{t-1}+v_{1}+0.70 v_{t-1}$} \\
\hline & & & \multicolumn{6}{|c|}{$w_{t}=\ln \left(y_{t}\right)-\ln \left(y_{t-1}\right)$} \\
\hline & & & \multicolumn{6}{|c|}{$y_{1}=$ the original series for the $\mathrm{PU}$ segment } \\
\hline \multirow{3}{*}{\multicolumn{2}{|c|}{ OU-Segment }} & \multirow{3}{*}{$\begin{array}{l}\text { Model } \\
\text { where }\end{array}$} & \multirow{3}{*}{\multicolumn{6}{|c|}{$\begin{array}{l}z_{t}=0.01+v_{t}-0.62 v_{t-1} \\
z_{t}=\ln \left(x_{t}\right)-\ln \left(x_{t-1}\right) \\
x_{t}=\text { the original series for the OU segment }\end{array}$}} \\
\hline & & & & & & & & \\
\hline & & & & & & & & \\
\hline \multicolumn{9}{|c|}{ One-year ahead forecasts ( $t$ in months) for $\mathrm{PU}$ and $\mathrm{OU}$ segment } \\
\hline$t$ & PU & $\mathrm{OU}$ & $t$ & PU & $\mathrm{OU}$ & $t$ & $\mathrm{PU}$ & OU \\
\hline 1 & 164.58 & 31.44 & 5 & 171.58 & 32.17 & 9 & 204.85 & 32.91 \\
\hline 2 & 119.32 & 31.62 & 6 & 149.80 & 32.35 & 10 & 169.57 & 33,10 \\
\hline 3 & 155.17 & 31.80 & 7 & 150.59 & 32.54 & 11 & 156.82 & 33.29 \\
\hline 4 & 180.42 & $2 \quad 31.98$ & 8 & 183.76 & 32.72 & 12 & 169.92 & 33.48 \\
\hline \multicolumn{4}{|c|}{ Summary statistics $\mathrm{PU}$ segment forecasts } & \multicolumn{5}{|c|}{ Mean per period $=164.70 ;$ Sum of forecasts $=1976.37$} \\
\hline \multicolumn{4}{|c|}{ Summary statistics OU segment forecasts } & \multicolumn{5}{|c|}{ Mean per period $=32.45 ;$ Sum of forecasts $=389.39$} \\
\hline
\end{tabular}


Now that we modeled both parts of our expected value approach to customer equity, we proceed by implementing an optimization analysis. The two parts modeled above will serve as input for the development of an optimal strategy.

\subsection{Maximizing Customer Equity}

\subsubsection{Model development}

Although our expected value approach provides direction on how to improve customer equity, effective customer equity management is only possible when customer improvement efforts are made financially accountable. In this section, we develop a mathematical model aimed at designing investment strategies that maximize customer equity. At the heart of this optimization models lies the expected value approach we developed and estimated previously in this paper. According to Hogan et al. (2002a) the two main opportunities to leverage a current customer to create value are by increasing customers' retention rates or by increasing customer monetary value. In the spirit of the relation-marketing approach we pursue in our customer equity model we aim at maximizing customer equity through increasing customer retention. Moreover, Gupta et al. (2004) recently reported that increasing customer retention is the most important driver of customer value. In order to maximize customer equity through improved customer retention, the perceived quality variables serve as input variables in our optimization analysis. The development of our optimization framework proceeds as follows. First, we explain how customer heterogeneity and the investments characterized by various degrees of persistence will be captured in our model. Second, we design the actual optimization framework.

As different segments of customers are exposed to the same service processes of one single organization, the effects of the investments are not restricted to only one customer group. To cope with this issue we introduce the set of customer groups $\mathrm{G}=\{\mathrm{PU}, \mathrm{OU}\}$ in the model. By introducing the set of customer groups in the model, we are able to capture the between-group differences in the effects of investments on the probability to remain loyal. 
Given the dynamic nature of our approach to customer equity as implied by our time-series approach to modeling customer monetary value, it is important to take into account the degree of persistence of investments and their effect on customers' service evaluations. We distinguish between two types of investments. On the one hand, investments in information technology for better information processing that, once the investment is made, its effect on customer retention persists during the succeeding periods. On the other hand, there are investments such as investments in temporary staff during peak-times for which the effects on customer retention are reduced once staffing levels are reduced. We capture these effects in a persistence factor $\gamma$, which is high for investments that have a long lasting effect, and low for investments that have a short-term effect only.

In order to maximize customer equity by directing investment effort at improving customers' retention probability, both the positive and negative consequences in terms of customer equity stemming from these investment initiatives need to be taken into account. The positive effects of the improvement efforts are directly captured by the set of relationships entailed by the expected value approach. Consequently, the positive financial consequences of improving perceived quality can be summarized as follows:

where

$$
\begin{aligned}
& \sum_{j=1}^{N}\left(p(\text { loy })_{P \mid, g . t} \cdot C M V_{P,-g, t}\right)
\end{aligned}
$$

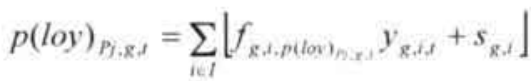

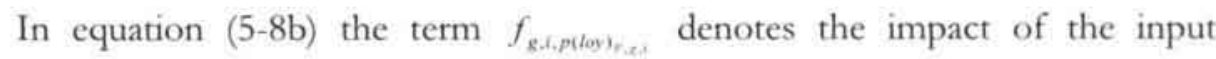
variables $y_{i}$ on the customer retention probability for each group of customers. Furthermore, $s_{g, i}$ is directly related to the status quo level of investments. Finally, $\mathrm{N}$ denotes the total number customers in segments $\mathrm{OU}$ and PU.

The costs associated with the customer equity improvement initiatives have both a direct negative and an indirect positive effect on the profitability of the investments. The indirect positive effect stems from the fact that investments drive customer perceptions of perceived quality which in turn translate into 
revenues. The quantification of this particular relation between investment effort $\left(x_{i}\right)$ and perceived quality (the input variables $y_{t}$ ) is crucial to develop our optimization model. We use the response curve proposed in Little's (1970) ADBUDG function to estimate this function. Calibration of the ADBUDG function combines statistical rigor and human input, thereby ensuring an ideal level of quality in decision making (cf. Blattberg and Hoch 1990). The ADBUDG function is defined as follows:

$$
y_{i}=a_{i}+\left(b_{i}-a_{1}\right) \frac{x_{i}^{c_{i}}}{d_{i}+x_{i}^{c_{i}}}
$$

Parameters $a_{i}$ and $b_{i}$ restrict the range of $y_{i}$ to $\left[a_{i}, b_{i}\right]$. Specifically, $a_{i}$ represents the level of $y_{i}$ when $x_{i}=0$ and corresponds to the lower bound (1) of the scale we use to assess customers' perceived quality regarding the supplier's offering. Furthermore, $b_{i}$ represents the level of $y_{i}$ when $x_{i} \rightarrow \infty$ and corresponds to the upper bound (8) of the scale we use to assess customers' quality perceptions of the supplier's offering. Parameters $c_{i}$ and $d_{i}$ determine the shape of the relationship between $y_{i}$ and $x_{i}$. Parameter $c_{i}$ was set to 1 in order to capture the diminishing returns characterizing the relationship between investment effort and customers' perceived quality. Parameter $d_{i}$ varies across the different input variables and was chosen in consultation with three managers of the company to capture the appropriate degree of diminishing returns characterizing the relationship between investment effort and quality perceptions. Taking into account the dynamic effects of investment effort in terms of persistence, the function linking investment effort to the input variables extends to:

$$
y_{s, U, j}=1+8 \frac{\left(x_{i}+\sum_{i=1}^{t} \gamma^{t-r} \Delta x_{i, t}\right)^{c_{i}}}{d_{i}+\left(x_{i}+\sum_{i=1}^{t} \gamma^{t-\tau} \Delta x_{i, t}\right)^{c_{i}}}
$$


Here, the term $\sum_{i=1}^{1} \gamma^{i-r} \Delta x_{i, t}$ describes the effects through time of the investments depending on their degree of persistence.

The total amount of investment effort, $\sum_{i \in l} x_{i}$, has a direct negative influence on the projected profitability consequences. In order to maximize the level of customer equity the negative and positive financial consequences need to be balanced. This leads to maximizing the following objective function.

$$
\sum p(\text { loy })_{P j, s, t} C M V_{P j, s}-\sum_{i=1} x_{i}
$$

The objective function is maximized subject to the following constraints. The first constraint models the compact of the changes in the input variables $y_{\text {, }}$ on the retention probability. The second constraint models the impact of investment effort $x_{i}$ on the level of the input variables $y_{i}$. Third, we impose a budget constraint, $\sum_{i \in I} x_{i} \leq B$, implying that the total investment effort cannot exceed a pre-set budget $B$. Fourth, we impose a non-negativity constraint for $x_{i}$. Finally, we impose the constraint that for the optimal solution the level of the input variables should be at least equal to their starting value. The relationships and constraints described above are summarized in exhibit 5-3. 
Exhibit 5-3 Optimization framework

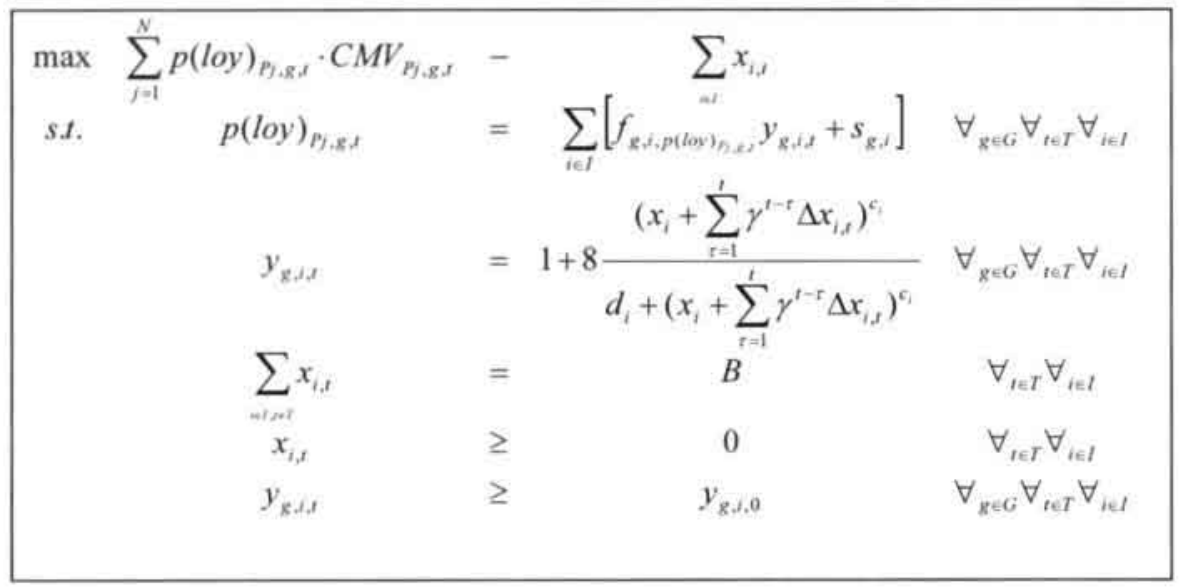

\subsubsection{Model Implementation}

In this section we demonstrate how the mathematical framework described above can be used to optimize customer equity in terms of profitability through increasing customer retention by investments directed at improving perceived quality. In this application of the model explicit attention will paid to the level of effort required to obtain an optimal level of customer equity, the return of investment of our decision, and the allocation of the total investment effort over the various input variables.

To address the issues outlined above, the framework presented in exhibit 5-3 will be solved in AIMMS using a subgradient optimization algorithm with a multi-start procedure. Based on a series of numerical experiments it becomes clear that the maximum level of customer equity decrease as the degree of persistence decreases; consequently our optimization analysis focuses on investments characterized by a high degree of persistence $(\gamma=1)$. As a result, investments characterized by $\gamma=1$ should be placed at the beginning of the investment horizon in order to obtain an optimal result. Finally, a discount rate of $10 \%$ was used. 
To calibrate the customer monetary value model outlined in equation (5-2), figures on revenues and costs are required. As the term $\left(R_{t_{\text {mit }}}-C_{t_{\text {mit }}}\right)$ in equation (5-2) equals the contribution margin, only an estimate of the contribution margin is required to estimate CMV. Based on an analysis of internal company information it was evidenced that the contribution margin ${ }^{1}$ for OU segment equals $22.5 \%$, whereas for the PU segment the contribution margin equals $39.4 \%$.

As implied by the nonlinear association between the input variables and the retention probability, changes in the input variables do not result in a constant change in each customer's retention probability. From an analytical perspective, this means that in order to estimate the effect of changes in the input variables on the retention probability for the whole segment of customers, we would have to estimate the effect of a certain change in the input variable on each individual customer's retention probability and subsequently aggregate the resulting changes in retention probability of the entire group of customers. However, in order to estimate the effect of changes in the input variables on each customer's retention probability both effectively and efficiently we pursued the following approach. We estimated the effect of various changes in the input variables on the aggregated retention probability through a series of numerical experiments. Plotting the changes in the input variables and the changes in the aggregated retention probability revealed a perfectly linear relationship. Subsequently, we estimated this linear relationship by means of an ordinary least squares procedure and incorporated it in the objective function of our optimization framework.

Based on the results of the optimization analysis, a total of $\$ 2.2 \mathrm{M}$ dollar is needed to optimize the firm's total amount of customer equity in terms of profitability. This amount of effort would increase the total level of equity by $\$ 3.6 \mathrm{M}$ dollar, implying a ROI of $66.1 \%{ }^{3}$. From an analytical perspective, the optimal level of customer equity is obtained when the derivative of the objective function equals zero. The changes in perceived quality that would result from this optimal investment strategy are presented in table 5-4. 
Table 5-4 also summarizes how much of the total amount of effort should be allocated to each of the input variables in order to achieve the customer equity optimum. Analytically, the key to the optimal allocation of effort follows directly from the magnitude of partial derivative of the objective function with respect to the input variables $y_{i}$.

Table 5-4 Results optimal investment strategy

\begin{tabular}{lccc}
\hline Input variables & Starting level & Optimal level & Allocation $(\% \text { of B* })^{*}$ \\
\hline Product: assortment & 3.80 & 6.04 & 5.9 \\
Product: quality & 3.87 & 6.26 & 6.6 \\
Product: fulfillment of needs & 4.02 & 6.08 & 6.0 \\
Product: price-quality ratio & 3.87 & 6.27 & 6.7 \\
Delivery: Taking customer's wishes into account & 3.70 & 5.84 & 5.3 \\
Delivery: Presentation of employec & 3.65 & 5.95 & 5.6 \\
Complaints: Accessibility of Company Z & 3.96 & 6.31 & 7.2 \\
Complaints: Attention of employces & 3.91 & 6.41 & 6.1 \\
Complaints: Knowledge of cmployees & 3.87 & 6.12 & 7.5 \\
Complaints: Solving complaint first time right & 3.63 & 6.47 & 7.8 \\
Complaints: Speed of dealing with complaint & 3.76 & 6.55 & 7.5 \\
Complaints: Information on time solving complaint & 3.73 & 6.48 & 4.8 \\
Invoice: Clarity & 3.87 & 5.67 & 5.2 \\
Invoice: Correct & 3.98 & 5.79 & 5.8 \\
Invoice: Lay out & 3.86 & 6.03 & 5.3 \\
Invoice: Timing & 3.83 & 5.84 & \\
\hline
\end{tabular}

+ B' denotes the investment effort needed to obtain the customer equity optimum.

\subsection{Discussion and conclusion}

To a large extent, customer relationships determine the value of a firm (Gupta et al. 2004; Rust et al. 2000). The customer equity criterion (cf. Blattberg and Deighton 1996) offers a useful instrument to manage and maximize this source of financial value. In this paper, we develop a customer-oriented approach that can be used to assist in decision-making concerning customer equity management. Our approach follows the principles of an expected value approach and contributes to effective customer equity management in the following ways. First, it incorporates customer relationship perceptions in the 
customer equity calculation. Second, our approach allows taking customer heterogeneity into account. Third, the use of a probabilistic retention model as a key component of the customer equity determination models the uncertainty associated with customer behavior. Finally, by integrating our expected value approach into a mathematical optimization framework we provide a strategic decision-making model that links customer equity improvement to financial performance.

From a theoretical perspective, this study aims to provide insight into the formation of customer retention and the impact of customer heterogeneity on the formation of customer loyalty. With respect to this, the empirical results stemming from the estimation of the two model components revealed several interesting findings. First, we find that the probability that a customer remains loyal in a future time period is influenced by both emotion-based constructs like satisfaction and trust and more cognition-based judgments like perceived value. Considering the key role of customer retention in both customer relationship management and customer equity management, our empirical results demonstrate that for effective management of customer equity, relational and service perceptions need to be taken into account. A second notable finding concerns the need for customer segmentation. First of all, our analysis indicates that the influence of customer relationship perceptions on retention is significantly different across customer segments. This finding reflects the notion of Anderson and Mittal (2000) who state that failing to account for customer heterogeneity leads to suboptimal allocation of resources. Second, the notion of Anderson and Mittal (2000) is even further emphasized if we take into account segment heterogeneity with regard to customer monetary value. Time series analysis indicates that the behavioral pattern differs both in magnitude and functional form across the two segments we examined. Furthermore, segment wise differences in cost structures were explicitly incorporated in our model by allowing usage rated and contribution margins to vary. Our third relevant finding relates to incorporating the uncertainty inherent to customer behavior dynamics into the customer equity calculation. Comparison of the estimated retention probability to the true retention behavior of customers reveals a high correct 
classification rate (both segments $>80 \%$ ). Strengthened by the results, we believe that using customer relationship perceptions to estimate customers' retention probability leads to a good approximation of the risk that reflects the uncertainty of customer behavior.

Driven by the need for tools that assist managers in strategic decision-making regarding customer equity, we placed our expected value approach to customer equity at the heart of an optimization framework. As our optimization framework takes into account both costs and revenues associated with initiatives aimed at improving customer equity, our model allows for an economically justified analysis concerning strategies aimed at increasing and maximizing customer equity. The strength of our optimization framework lies in its versatility. Specifically, our optimization model assists decision makers with regard to the following four aspects of customer equity management. First, it allows for the determination of the total amount of investment effort needed to achieve a certain level of customer equity. Second, it provides an answer to the allocation of efforts in order to yield a maximum amount of customer equity. Third, it places efforts aimed at improving customer equity on an even footing with all other investment alternatives. Fourth, it allows taking into account investment strategies with various degrees of persistence.

\subsection{Limitations and suggestions for further research}

Our model and analysis in this paper are based on several assumptions that need to be taken into consideration. Although these assumptions may be perceived as limiting the generalizability of our results, they also provide rich opportunities for further research in this area. First of all, our findings exclusively pertain to the client base of only one firm. Although constraining the study to a single industry eliminates the problems associated with industry differences (Hartline and Ferrell 1996), future research will have to point out whether the results are generalizable to other settings. Second, although we aimed at modeling dynamic effects, it would be interesting to measure more constructs at more periods in time. This type of longitudinal research design would allow us to examine the existence of possible lagged and carry-over 
effects in the determination of the probability that a customer remains loyal. Third, we made the assumption of an average behavioral pattern for all customers in a specific segment. It would be interesting to extent our model to take into account idiosyncrasies in individual customer behavior. Fourth, in assigning costs to customers we only took into account variable costs and assumed that they were perfectly related to volume. A possible interesting extension would be to pursue a truly activity-based costing approach in assigning all relevant costs to customers. Fifth, we assumed that the CMV component of our customer equity approach is independent of marketing effort. An interesting extension of the current study would be to permit the customer monetary value component to vary as a function of marketing tactics. Finally, our model did not take competition into account. Although Rust et al. (2004) meritoriously modeled the influence of competition in the calculation of customer equity we agree with them that much work is still left.

\subsection{Managerial Implications}

Our results also suggest a number of managerial implications. First, in designing strategies aimed at optimizing customer equity, segmentation of the customer base may be necessary. Significant differences between the segments arise both in building customer loyalty and the pattern of the customer monetary value. Failing to recognize segment-related differences may lead to a suboptimal allocation of resources when aiming to maximize customer equity. Second, we find that customer relationship perceptions indeed significantly influence customers' retention probability, and thus indirectly affect customer equity. Consequently, managing these perceptions offers ample opportunity for increasing the total amount of customer equity. Third, the important role of perceived value in building customer retention has important consequences for the firm's offering. Due to the additive nature of benefits and sacrifices, shortcomings in benefits can be compensated by perceived reductions in sacrifices and may still lead to satisfaction. Hence, the perceived value should not be neglected when aiming to optimize customer equity. Fourth, given the relationship between customer equity and firm value (see Gupta et al. 2004) effort should be directed to include customer equity on firms' balance sheets. 
Chapter 5

Finally, our approach provides new metrics for managers. An approach that is customer centered and that allows evaluating the financial impact of marketing expenditures. Furthermore, our model can be used as a strategic tool for targeting and focusing a company's marketing efforts in order to maximize customer equity. 


\section{Footnotes}

${ }^{1}$ For reasons of confidentially percentages rather than absolute values are given.

${ }^{2}$ The time series on usage capacity are converted to units that are sold to the customers by means of a linear transformation.

${ }^{3}$ In line with the suggestions made by leading marketing scholars we only included variable investment costs. Failing to include fixed investment costs may result in an underestimating of costs and an overestimation of profitability. However, as our model is flexible with regard to the cost module to be incorporated, fixed costs can be incorporated without any problem into our customer equity optimization model for future applications of these models. 

Chapter 6

Conclusion 


\subsection{Synopsis}

Based on the broad consensus that satisfied and loyal customers provide a tremendous source of financial value to a firm, the main focus of this dissertation was to assess and quantify the relationship between customer service evaluations and the financial returns, in order to contribute greater financially viable effectiveness in service management. This dissertation is driven by shortcomings in the empirical literature that impede effective management of customer service evaluations in terms of their financial consequences, the dominance of the service industry in many Western economies, and current changes in the service industry that mark an era in which there is a need for a much more results-oriented approach to service management. The overall objective guiding this dissertation was formulated as follows:

"To investigate how to effectively manage customer service evaluations in terms of financial consequences"

In order to effectively address this overall objective, we formulated the following five research objectives based on the gaps in the empirical literature that form the main theoretical motivation for writing this dissertation.

1. To conduct an integral test of the relationships put forward in the SPC

2. To understand what service employees' perceptions, attitudes, and behavior are relevant antecedents of customer service evaluations and how these employee constructs affect customer service evaluations

3. To understand what customer service evaluations contribute to the formation of customer loyalty and how these customer service evaluations are interrelated

4. To empirically test the true nature of the functional forms describing the relationships among customer evaluative judgments 


\section{To design a mathematical optimization framework that can be} used for a formal and economically justified evaluation and optimization of the financial consequences of efforts directed at improving service evaluations.

In order to address the research objectives outlined above we conducted four empirical studies. The SPC framework, the ROQ approach, and customer equity were the three critical building blocks of the separate studies of this dissertation. The four studies presented in this dissertation can be briefly summarized as follows. In chapter 2 we reviewed the available empirical literature on the relationships put forward in the SPC and conducted a metaanalysis to synthesize and integrate empirical evidence on the complete set of SPC relationships. In chapter 3, we integrally tested the entire set of relationships put forward in the SPC using multi-source data. In addition, we developed a mathematical model based on an integration of the SPC and ROQ framework in order to make the suggested service improvement initiatives financially accountable and to optimize these service improvement efforts in terms of financial consequences. In chapter 4 we examined the true nature of the relationships among customer evaluative judgments that play a prominent role in the SPC. Finally, in chapter 5, we proposed and empirically assessed a model aimed at understanding and optimizing customer-firm relationships from a customer equity perspective.

In this concluding chapter, we will summarize and integrate the findings that have been discussed in the separate chapters. We end this chapter and dissertation by offering a number of suggestions for further research.

\subsection{An integrated perspective}

Our four studies explore the leading objective of this dissertation from different angles and different theoretical backgrounds. Notwithstanding these differences, there are several issues that unify the four studies. In this section, we discuss these issues and address their service management implications. 


\subsubsection{Service employees}

With regard to the role of service employees in the formation of customer evaluative judgments this dissertation addressed the following topics. First, we explored which employee perceptions, attitudes, and behaviors are relevant antecedents of customer service evaluations. Second, we empirically assessed the processes how these relevant employee constructs impinge on customer service evaluations.

Based on our meta-analytic study we discerned following three types of employee attitudes and behaviors that are relevant to explaining the formation of customer evaluative judgments: job satisfaction, affective commitment, and organizational citizenship behavior. Our empirical results revealed several interesting results concerning the relationships between employee attitudes, employee behaviors and customer service evaluations. To begin with organizational citizenship behavior is found to be a key determinant of customer perceived service quality. In turn, citizenship behavior is significantly influenced by job satisfaction and affective commitment. Moreover, job satisfaction and affective commitment exert a significant indirect effect on customer perceived service quality. Overall, the results of the studies presented in chapters 2 and 3 confirm the significant influence of employee attitudes and behaviors on customer evaluative judgments.

Given this central role of employee attitudes and behaviors in the formation of customer service evaluations, a key challenge faced by service managers is to elicit the appropriate employee attitudes and behaviors. The findings of this dissertation stress the importance of employee perceptions concerning their work environment in bringing forth relevant employee service attitudes and behaviors. Our results show that employees' perceptions concerning the service organization that employs them are the most important drivers of job satisfaction and affective commitment. Among the employee perceptions concerning the organization they work for, perceived organizational support has the largest influence of the formation of job satisfaction and affective commitment.

Employee perceptions concerning their job are the second most important category of antecedents of job satisfaction and affective commitment. Within 
this group of job-related antecedents perceptions of role ambiguity have the largest influence on employee service attitudes. Furthermore, service employees' perceptions concerning their immediate colleagues and supervisors also contribute to the formation of service attitudes. With regard to job satisfaction the degree of leadership support employees experience is particularly important. On the other hand, feelings of affective commitment are primarily driven by leadership participation.

Chapter 3 examines the influence of job characteristics on the formation of employee service attitudes and behaviors into greater detail. The analytical results of the study described in chapter 3 also underscore the importance of role stress reduction in order to drive favorable employee service attitudes. The influence of role stress on organizational citizenship behavior is fully mediated by job satisfaction and affective commitment. Our results also reveal that efforts aimed improving job design represent an effective way to reduce employees' role stress.

Finally, chapter 2 reveals that the strength and magnitude of the relationships among relevant service employees significantly vary across service industries. First of all, the effect of role ambiguity on the formation of job satisfaction and affective commitment is much stronger in educational service settings. Second, the negative effect of role conflict on job satisfaction and affective commitment is significantly stronger on retail services. Third, the influence of both job satisfaction and affective commitment on citizenship behavior is strongest in educational service settings. Fourth, the relationship between job satisfaction and affective commitment is least strong in educational services.

\subsubsection{Customer service evaluations}

Concerning the relationships among customer evaluative judgments this dissertation addressed two issues. First of all, we empirically assessed the true nature of the relationships among key evaluative judgments. Second, we aimed to add to the understanding the nomological net tying together customer evaluative judgments.

In assessing the true nature of the relationship among service evaluations such as perceived quality, satisfaction, value, and loyalty attention was paid to the 
presence of asymmetry and nonlinearity. The two main conclusions regarding the shape of the relationships among customer evaluative judgments can be summarized as follows. First, our empirical results indicate that nonlinear functional forms do not possess superior explanatory power compared to linear functional forms. Second, positive and negative perceived service quality have an equal effect on the formation of higher order construct. Consequently, these findings underscore that specification errors due to the use of symmetric and linear functional forms are rather unlikely.

Departing from the chain of effects among customer evaluative judgments proposed in the SPC, our empirical results suggest several refinements to the original SPC that add to the understanding of customer loyalty. First of all, the inclusion of value seems to add significantly to our understanding of customer loyalty intentions. Due to the additive nature of benefits and sacrifices, shortcomings in benefits can be compensated by perceived reductions in sacrifices and may still lead to satisfaction (cf. Spreng et al. 1993). Hence, the perceived value should not be neglected when aiming to enhance customer loyalty. Second, our results point out that customer relationship perceptions are important determinants of customer retention. Thus, in line with the relationship marketing paradigm building and maintaining strong customer relationships appears to be an economically feasible approach to enhancing financial performance.

Besides introducing constructs that add to our understanding of the development of customer loyalty, the manner in which these constructs are linked and contribute to customer loyalty is fundamental to directing efforts aimed at improving customer retention. The findings reported in this dissertation suggest that consumer decision-making in a service setting is a complex system that includes both direct and indirect paths leading to loyalty. One relationship that has been subject to considerable debate is the relationship between perceived service quality and customer loyalty (e.g. Cronin et al. 2002; Dabholkar et al. 2000; Mittal et al. 1998). Our findings presented in this dissertation provide ample evidence for a complex twofold effect of perceived service quality on customer intentions, consisting of both an indirect and a direct effect. 
This dissertation also reveals several relevant factors that moderate the relationships among customer evaluative judgments. First of all, the effects among customer evaluative judgments are significantly higher for pure services compared to product-based services. Based on this result the consequences gained from service quality improvement efforts appear to be much larger in case of pure services. Second, the use of single item measures in assessing customer evaluative judgments seems to artificially inflate the magnitude of the relationships among the respective constructs due to a lack of discriminant validity (cf. Yi 1990). Consequently, this finding emphasizes the use of scales with a high degree of construct validity in order to obtain a sound and realistic estimate of the financial consequences of service improvement initiatives. Finally, the results of the empirical study described in chapter 5 point out that the magnitude and strength of the relationships among customer evaluative judgments differ significantly across customer segments. Hence, recognizing customer heterogeneity is a prerequisite in effectively managing customer service evaluations in terms of financial performance.

\subsubsection{Return on services}

The previous two sections summarized our findings concerning service employees, customer service evaluations, and the connection between service employees and customer service evaluations. However, in order to manage service delivery effectively in terms of financial performance the following two issues still merit special attention. First, the relationship between customer service evaluations and financial performance needs to be quantified. Second, efforts to improve customer service evaluations need to be made financially accountable.

Based on our meta-analytic review we conclude that customer service evaluations are indeed related to financial performance. In addition, chapter 3 reveals that increments in customer loyalty enhance financial performance. These findings are crucial as they reflect the basic premise of the SPC and the ROQ approach. Moreover, these findings reflect the thought of using customer oriented measures like customer service evaluations as leading 
indicators of financial performance, rather than relying on hard but historic figures such as market share (Pitt et al. 2000).

In order to make service improvement initiatives financially accountable we developed a mathematical framework around the principles underlying Rust et al.'s (1995) ROQ approach, pursuing a nonlinear programming approach. A fundamental benefit of this approach is that the link between service improvement efforts, customer service evaluations, and financial consequences is made unequivocal (cf. Lewis 2003).

This mathematical framework formalizes the relationships between service improvement effort, service revenues, and service profitability. Within our mathematical model, the relationships entailed in the SPC play a central role in describing the revenues that stem from service improvement initiatives.

From a service management perspective the value of our mathematical approach to making service improvements financially accountable lies in the versatility of decision-making issues our framework can address. First, our framework allows for the determination of the total amount of investment effort needed to achieve a certain level of financial performance. One possible application here would for instance be the determination of the budget needed to achieve a maximum level of profitability. Second, a direct estimate of the rate of return can be obtained, thereby placing service improvement efforts on an even footing which other investments. Third, our model provides an explicit answer to questions related to resource allocation in order to optimize results.

\subsection{Suggestion for future research}

In addition to the directions for further research provided at the end of each chapter, this final paragraph indicates some general directions for future research on the service evaluations and the financial consequences.

Previous empirical work demonstrated that the relationships in the SPC may be characterized by lag and carry-over effects (e.g. Bolton and Lemon 1999; Wetzels et al. 1999; Bolton 1998) It would be desirable to test the SPC using longitudinal data for at least three reasons. First, the use of multi-period data would allow us to make stronger causal inferences about the relationship 
proposed in the SPC. Second, a longitudinal analysis is a prerequisite in order to fully appreciate the value of customer evaluative judgments as leading indicator of financial performance (cf. Bernhardt et al. 2000). Third, the use of longitudinal data enriches the possibilities of our optimization model, as it enables us to assess the long-term effects of investment types characterized by varying degrees of persistence.

This dissertation only studies the financial consequences stemming from customer retention. However, financial performance is driven by both customer retention and customer acquisition (Rust et al. 2004; Hogan et al. 2002). In addition, as service companies always loose existing customers for one reason or another, customer acquisition is a prerequisite for survival. Hence, future research should consider the financial consequences of attracting new customers in order to make an economically justified trade-off between retention and acquisition.

Similarly to balancing customer retention and acquisition, service firms are also faced with the challenge to strike the right balance between customer satisfaction and productivity. Although customer satisfaction and productivity are both key drivers of a firm's longevity and financial performance, Anderson et al. (1997) indicate that productivity and customer satisfaction are incompatible goals in most service settings.

Although we found empirical evidence for a significant positive relationship between customer retention and financial performance, much is still to be learned on the processes through which loyalty translates into financial value. Possible ways through which a firm can derive value from current and potential customers include cross-buying and increased usage (Hogan et al. 2002; Verhoef et al. 2001).

The findings in chapter 4 suggest that symmetric linear functional forms are not outperformed by the more complex asymmetric nonlinear functional forms in terms of variance explained. As we only tested our hypothesis using data from low involvement retail-service settings, we at the most established a boundary condition for linear and symmetric relationships among customer evaluative judgments. We therefore recommend extending this research to include other service settings. Furthermore, in line with Singh (1998) and 
Mittal and Kamakura (2001) who propose the presence of nonlinearity in respectively the relationships among employee constructs and the loyaltyrevenues link, a promising avenue of future research could be to test the nonlinearity and asymmetry hypotheses with regard these relationships in order to assess whether nonlinear functional forms indeed explain significantly more variance than linear functional forms.

The significant moderator effects we found in chapter 2 and the need for segmentation illustrated by the results of chapter 5 , underscore the need for additional research focuses on the identification of factors that systematically moderate the relationships put forward in the SPC. Possible relevant moderators include: level of competition (Jones and Sasser 1995), customer characteristics (Mittal and Kamakura 2001), and online vs offline service environments (Shankar et al. 2003).

Finally, as a general conclusion on future research regarding the economic consequences of customer service evaluations, we hope that this dissertation has contributed to more insight and stimulates others to explore this field. In addition, we hope our work inspires companies to view their service employees and customer from this innovative perspective. 


\section{References}


A

Aaker, D.A., (1995). Strategic Market Mamagement. New York: Wiley.

Allen, N.J. and D.B. Grisaffe (2001). Employee commitment to the organization and customer reactions: Mapping the linkages. Human Resoure Management Retrixw, 11(3), 209-236.

Allen, D.G., L.M. Shore, and R.W. Griffeth (2003). The role of perceived organizational support and supportive human resource practices in the turnover process. Journal of Management, 29(1), 99-118.

Anderson, E.W., C. Fornell, and D.R. Lehmann (1994). Customer satisfaction, market share, and profitability: Findings from Sweden. Joumal of Marketing, 58(3), 53-66.

Anderson, E.W., C. Fornell, and R.T. Rust (1997). Customer satisfaction, productivity, and profitability: Differences between goods and services. Marketing Science, 16(2), 129-145.

Anderson, E.W. and V. Mittal (2000). Strengthening the satisfaction-profit chain. Journal of Senvice Researth, 3(2), 107-120.

Anderson, E.W. and M.W. Sullivan (1993). Antecedents and consequences of customer satisfaction for firms. Marketing Sicienc, 12(2), 125-143.

Aryee, S., P.S. Budhwar, and Z.X. Chen (2002). Trust as a mediator of the relationship between organizational justice and work outcomes: Test of a social exchange model. Journal of Onganizational Behavior, 23(3), 267-285.

B

Barney, J. (1991). Firm resources and sustained competitive advantage, Journal of Management, 17(1), $99-120$.

Bell, D., J. Deighton, W.J. Reinartz, R.T. Rust, and G. Schwartz (2002). Seven barriers to customer equity management. Journal of Senvice Researth, 5(1), 77-85.

Bell, S.J. and B.Menguc (2002). The employee-organization relationship, organizational citizenship, and superior service quality. Journal of Retailing, 78(2), 131-146.

Berger, P.D., R.N. Bolton, D. Bowman, E. Briggs, V. Kumar, A. Parasuraman, and C. Terry (2002). Marketing actions and the value of customer assets: A framework for customer asset management. Journal of Senvice Reseant, 5(1), 39-54.

Berger, P.D. and N.I. Nasr (1998). Customer lifetime value: Marketing models and applications. Journal of Interactive Marketing, 12(1), 17-30.

Berger, P.D. and N. Nasr Bechwati (2001). The allocation of promotion budget to maximize customer equity. Omega, 29(1), 49-61

Berkley, B. . and A. Gupta (1995). Identifying the information requirements to deliver service quality. International Journal of Senvice Industry Management, 6(5), 16-35.

Bernhardt, K.L., N. Donthu, and P.A. Kennett (2000). A longitudinal analysis of satisfaction and profitability. Joumal of Business Reseant, 47(2), 161-171.

Bettencourt, L.A and S.W. Brown (1997). Contact employees: Relationships among workplace fairness, job satisfaction and prosocial service behaviors. Journal of Retailing, 73(1), 39-61. 
Bettencourt, L.A. and S.W. Brown (2003). Role stressors and customer-oriented boundary-spanning behaviors in service organizations. Journal of the Arademy of Marketing Science, 31(4), 394-408.

Bitner, M.J. (1990). Evaluating service encounters: The effects of physical surroundings and employee responses. Journal of Marketing, 54(2), 71-84.

Blattberg, R.C. and J. Deighton (1991). Interactive marketing: Exploiting the age of addressability. Sloan Mamagement Review, 33(1), 5-14.

Blattberg, R.C. and J.Deighton (1996). Manage marketing by the customer equity test. Hanuard Business Reriew, 74(4), 136-144.

Blattberg, R.C. and S.J. Hoch (1990). Database models and managerial intuition: $50^{\circ} \%$ model $+50 \%$ manager. Management Science, 36(8), 887-899.

Bock, T. and M. Uncles (2002). A taxonomy of differences between consumers for market segmentation. Intermational Journal of Researb in Marketing, 19(3), 215-224

Bolton, R.N. (1998). A dynamic model of the duration of the customer's relationship with a continuous service provider. The role of satisfaction. Marketing Science, 17(1), 45-65.

Bolton, R.N. and J.H. Drew (1991). A multistage model of customers' assessment of service quality and value. Journal of Consumer Researd, 17(4), 875-884.

Bolton, R.N. and K.N. Lemon (1999). A dynamic model of customers' usage of services: Usage as an antecedent and consequence of satisfaction. Journal of Marketing Researth, 36 (2), 171-186.

Brown, S.P. (1996). A meta-analysis and review of organizarional research on job involvement. Psychalogical Bulletin, 120(2), 235-255.

Brown, S.P., A. L. Ostrom, and S.W. Brown (2003). A meta-analysis of service quality: Relationships, levels, and structure. Working Paper.

Brown, S.P., and R. A. Peterson (1993). Antecedents and consequences of salesperson job satisfaction: A meta-analysis and assessment of causal effects. Joumal of Markecting Researth, $30(1), 63-77$.

C

Cassel, C.M., P. Hackl, and A.H. Westlund (2000). On measurement of intangible assets: A study of robustness of partial least squares. Total Quality Mamagement, 11(7), 897-907.

Churchill, G.A., Jt. (1995). Marketing Researd: Methodologiral Foundations. Fort Worth: The Dryden Press.

Churchill, G.A., Jr., N.M. Ford, and W. Orville Jr. (1976). Organizational climate and job satisfaction in the sales force. Joumal of Marketing Research, 13(4), 323-332.

Churchill, G.A., Jr., N.M. Ford, S.W. Hartley, and O.C. Walker, Jr. (1985). The determinants of salesperson performance: A meta-analysis. Journal of Marketing Research, 22(2), 103-118.

Cohen, Jacob (1988). Statistical Pouer Analysis for the Bebarioral Sciences. Hillsdale: Erlbaum.

Coyne, K.P. (1989), Beyond service fads: Meaningful strategies for the real world. Sloan Management Review, 30(4), 69-76. 
Cronin, J. J., Jr., M.K. Brady, and G.T.M Hult (2000). Assessing the effects of quality, value, and customer satisfaction on consumer behavioral intentions in service environments. Joumal of Retailing, 76(2), 193-218.

Cronin, J.J., Jr. and S.A. Taylor (1992). Measuring service quality: A re-examination and extension. Journal of Marketing, 56(3), 55-68.

Crepiel, J.A. (1990). Service encounters and service relationships: Implications for research. Journal of Business Researb, 20(1), 13-21.

D

Dabholkar, P.A., D.C. Shepherd, and D.I. Thorpe (2000). A comprehensive framework for service quality: An investigation of critical conceptual and measurement issues through a longitudinal study. Journal of Retailing, 76(2), 139-173.

Danaher, P.J. (1998). Customer heterogeneity in service management. Journal of Senvice Researcb, 1(2), 123-139.

DeKimpe, M.G. and D.M. Hanssens (2000). Time-series models in marketing: Past, present, and future. Intemational Journal of Reseanch in Marketing, 17(2/3), 183-193.

De Ruyter, K., J. Bloemer, and P. Peeters (1997). Merging service quality and service sarisfaction: An empirical test of an integrative model. Joumal of Economic Psybology, 18(4), 387-406.

DeSarbo, W.S., L. Huff, M. M. Rolandelli, and J. Choi. (1994). On the measurement of perceived service quality: A conjoint analysis approach. In R.T. Rust and R.L. Oliver (eds.), Service quality: New directions in theory and practice (pp. 201-222). London: Sage.

Divine, R.L. (1995). The influence of price on the relationship between involvement and consideration set size. Marketing Letters, 6(4), 309-319.

Dodds. W. B., K.B. Monroe, and D. Grewal (1991). Effects of price, brand, and store information on buyers' product evaluations. Joumal of Marketing Reseanh, 28(3), 307-319.

Doney, P.M. and J.P. Cannon (1997). An examination of the nature of trust in buyer-seller relationships. Joumal of Marketing, 61(2), 35-51.

Dubinsky, A.J. and S.J. Skinner (1984). Impact of job characteristics on retail salespeople's reactions to their jobs. Joumal of Refailing, 60(2), 35-62.

Dwyer, F.R (1997). Customer lifetime valuation to support marketing decision making. Journal of Dirct Marketing, 8(2), 73-81.

E

Eisenberger, R., R. Huntington, S. Hutchison, and D. Sowa (1986). Perceived organizational support. Journal of Applied Psychology, 71(3), 500-507. 
Fahr, J.L., P.M. Podsakoff, and D.W. Organ (1990). Accounting for organizational citizenship behavior: Leader faimess and task scope versus satisfaction. Journal of Management, 16(4), 705-721.

Fornell, C. and J. Cha. (1994). Partial least squares, In. R.P. Bagozzi (ed.). Adranced Metbods of Marketing Research (pp.52-78). Cambridge: Blackwell.

Fornell, C., M.D. Johnson, E.W. Anderson, J. Cha, and B.E. Bryant (1996). The American customer satisfaction index: Nature, purpose, and findings. Journal of Marketing, 60(4), 7-18.

Fornell, C. and B. Wernerfelt (1987), Defensive marketing strategy by customer complaint management: A theoretical analysis. Journal of Marketing Reseanch, 24(4), 337-346.

Fornell, C. and B. Wernerfelt (1988). A model for customer complaint management. Marketing Saicnce, 7(3), 287-298.

Foster, G., M. Gupta, and L. Sjoblom (1996). Customer profitability analysis: Challenges and new directions. Journal of Cost Management, 10(1), 5-17.

G

Ganesan, S. (1994). Determinants of long-term orientation in buyer-seller relationships. Jourmal of Marketing, 58 (2), 1-19.

Garbarino, E. and M.S. Johnson (1999). The different roles of satisfaction, trust, and commitment in customer relationships. Journal of Marketing, 63(2), 70-87.

Glisson, C. and M. Durick (1988). Predictors of job satisfaction and organizational commitment in human service organizations. Administrative Säence Quarterly, 33(1), 61-81.

Graen, G.B. and T.A. Scandura (1987). Toward a psychology of dyadic organizing. Research in Onganizational Behatior, 9, 175-208.

Graen, G.B. and M. Uhl-Bien (1991). The transformation of professionals into self-managing and partially self-designing contributions: Towards a theory of leader-maker Journal of Management Systems, 3(3), 33-48.

Grant, K., D.W. Cravens, G.S. Low, and W.C. Moncrief (2001). The role of satisfaction with territory design on the motivation, attitudes, and work outcomes of salespeople. Journal of the Academy of Markerting Saience, 29(2), 165-178.

Greenberg, J. (1990). Organizational justice: Yesterday, today, and tomorrow. Jourmal of Management, $16(2), 399-432$

Greising, D. (1994). Quality- How to make it pay. Business IF'cek, 3384, 54-59.

Griffeth, J. (1988). Measurement of group cohesion in U.S. army units. Basic and Applied Psychology, 9(2), 149-171.

Gwinner, K.P., D.D. Gremler, and M.J. Bitner (1998). Relational benefits in services industries: The customer's perspective, Journal of the Academy of Marketing Saincr, 26(2), 101-114. 
Gupta, S. D.R. Lehmann, and J.A. Stuart (2004). Valuing customers. Josmal of Marketing Researt, $41(1), 7-18$.

H

Hackman, J.R. and E.E. Lawler (1971). Employee reactions to job characteristics. Jourmal of Applied Psychology, 55(3), 259-286.

Hackman, J.R and G.R. Oldham (1976). Motivation through the design of work: Test of a theory. Orgamization Bebartor and Human Performance, 16 (x), 250-279.

Hallowell, R. (1996). The relationships of customer satisfaction, customer loyalty, and profitability: An empirical study. The International Joumal of Senvice Industry Management, 7(4), 27-42.

Hamilton, J.D. (1994). Time series analysis, Princeton University Press of New Jersey.

Hampton, R., A.J. Dubinsky, and S.J. Skinner (1986). A model of supervisor leadership behavior and retail salespeople's job-related outcomes. Journal of the Academy of Marketing Science, 14(3), 33-43.

Harker, P.T. (1995). Introduction: Service-sector productivity - The MS/OR challenge. Interface, 25(3), 1-5.

Hartline, M.D. and O.C. Ferrell (1996). The management of customer-contact service employees. Journal of Marketing, 60(4), 52-70.

Hedges, L.V and I. Olkin (1985). Statistical methods for meta-anatysis. Orlando: Academic Press.

Hennig-Thurau, T., K.P. Gwinner, D.D. Gremler (2002). Understanding relationship marketing outcomes: An integration of relational benefits and relationship quality. Journal of Senvice Research, 4(3), 230-247.

Heskett, J.L., T.O. Jones, G.W. Loveman, W. Earl Sasser Jr., and L. Schlesinger (1994). Putting the service profit chain to work. Harrard Business Reriew, 72(2), 164-174.

Hittner, J.B., K. May, and N.C. Silver (2003). A Monte Carlo evaluation of tests for comparing dependent correlations. Journal of General Psychology, 130(2), 149-168.

Hogan, J.E., D.R. Lehmann, M. Merino, R.K. Srivastava, J.S. Thomas, and P.C. Verhoef (2002). Linking customer assets to financial performance. Journal of Senice Research, 5(1), 26-38.

Hogan, J.E., K.N. Lemon, and R.T. Rust (2002). Customer equity management: Charting new directions for the future of marketing. Joumal of Senvice Reseant, 5(1), 4-12.

Horngren, C.T. and G.L. Sundem (1993), Introduction to management accounting. Englewood Cliffs: Prentice-Hall International.

House, R.J. (1971). A path-goal theory of leadership effectiveness. Administrative Science Quarterb, 16 (3), 321-339.

Hunt, S.D. and R.M. Morgan (1995). The comparative advantage theory of competition. Journal of Marketing, 59(2), 1-15.

Hunter, J.E. and F.L. Schmidt (1990). Methods of mela-analysis: Correcting error and hias in research findings. Newbury Park: Sage Publications. 
Inkson, J.H.K. D.S. Pugh, and D.J. Hickson (1970). Organizational context and structure. Administrative Science Quarterly, 15(3), 318-329.

Jackson, S.E. and R.S. Schuler (1985). A meta-analysis and conceptual critique of research on role ambiguity and role conflict in work settings. Organizational Beharyor and Human Deasion Pracesses, 36(1) 16-78.

James, L.R., R.G. Demaree, and G. Wolf (1984). Estimating within-group internater reliability with and without response bias. Journal of Applied Psychology, 69(1), 85-98.

Jimmieson, N.L. and M.A. Griffin (1998). Linking client and employee perceptions of the organization: A study of client satisfaction of health services. Journal of Occupational and Organizational Psychology, 71(1), 81-96.

Johnston, M.W., A. Parasuraman, C.M. Futrell, and W.C. Black (1990). A longitudinal assessment of the impact of selected organizational commitment during early employment. Journal of Marketing Researh, 27 (3), 333-344.

Jones, T.O. and W. Earl Sasser, Jr. (1995). Why satisfied customers defect. Hanvard Business Reriew, $73(6) .88-101$.

$\mathbf{K}$

Kahn, B.E. and R.J. Meyer (1991), Consumer multiattribute judgments under attribute-weight uncertainty. Journal of Consumer Reseant, 17(4), 508-522.

Kahn, R.L., D.M. Wolfe, R.P. Quinn, J.D. Snoek, and R.A. Rosenthal (1964). Organizutional stress: Studies in rale conflict and ambiguity. New York: John Wilcy and Sons.

Kahneman, D. and A. Tversky (1979). Prospect theory: An analysis of decision under risk. Econometrica, 47(2), 263-291.

Kamakura, W.A., V. Mittal, F. de Rosa, and J.A. Mazzon (2002). Assessing the service profit chain Marketing Science, 21 (3), 294-317.

Kekre, S., M.S. Krishnan, K. Srinivasan (1995). Drivers of customer satisfaction for software products: Implications for design and service support. Management Sacnct, 41(9), 1456-1470,

Kelley, S.W. and K.D. Hoffmann (1997). An investigation of positive affect, prosocial behaviors and service quality. Journal of Refailing, 73(3), 407-427.

Kidwell, R.E. Jr., K.W. Mossholder, and N. Bennett (1997). Cohesiveness and organizational citizenship behavior: A multilevel analysis using work groups and individuals. Journal of Management, 23(6), 775-793. 
Ko, J.W., J.L. Price, and C.W. Mueller (1997). Assessment of Meyer and Allen's three-component model of organizational commimnent in South Korea. Joumal of Applied Psychology, 82(6), 961-973.

Kumar, N., L.K. Scheer, and J.B.E.M. Steenkamp (1995). The effects of perceived interdependence on dealer attitudes. Journal of Marketing Research, 32(3), 348-356.

L

Law, K.S. and C.S. Wong (1999). Multidimensional constructs in structural equation analysis: An illustration using the job perception and job satisfaction constructs. Journal of Mamagement, 25(2), 143-160.

Lewis, M. (2003). Simultaneous customer valuation and customer management: An application of dynamic programming to subscriber management. W'arking Paper.

LePine, J.A., A. Erez, and D.E. Johnson (2002). The nature and dimensionality of organizational citizenship behavior: A critical review and meta-analysis. Joumal of Applied Psychology, 87(1), $52-65$.

Libai, B., D. Narayandas, and C. Humby (2002). Toward an individual customer profitability model: A segment-based approach. Journal of Senvice Reseanh, 5(1), 69-76.

Liden, R.C., S.]. Wayne, and R.T. Sparrowe (2000). An examination of the mediating role of psychological empowerment on the relations between job, interpersonal relationships, and work outcomes. Journal of Applied Psychology, 85(3), 407-416.

Lipsey, M.W. and D.B. Wilson (2001), Practical meta-analysis. Thousand Oaks: Sage Publications.

Little, J.D.C. (1970). Models and managers: The concept of a decision calculus Management Science, $16(8), 466-485$

Long. J.S. (1997), Regressian Models for Categorical and Limited Dependent I'ariables. Thousand Oaks: Sage Publications Inc.

Loveman, G.W. (1998). Employee satisfaction, customer loyalty, and financial performance: An empincal examination of the service profit chain in retail banking. Journal of Service Reseanch. $1(1), 18-31$.

M

MacKenzic, S.B., P.M. Podsakoff, and M. Ahearne (1998). Some possible antecedents and consequences of in-role and extra-role salesperson performance. Journat of Marketing, 62(3), 87.98

Mackenzie, S.B., P.M. Podsakoff, and R. Fetter (1993). The impact of organizational citizenship behavior on evaluations of salesperson performance. Journal of Marketing, 57(1), $70-78$.

Mackenzic, S.B. P.M. Podsakoff, and G.A. Rich (2001). Transformational and transactional leadership and salesperson performance. Journal of the Academy of Marketing Science, 29(2), $115-134$. 
Mantrala, M.K., P. Sinha, and A.A. Zoltners (1992). Impact of resource allocation rules on marketing investment-level decisions and profitabiliry. Joumal of Markesting Researh, 29(2), 162175.

Mathieu, J.E. and D.M. Zajac (1990). A review and meta-analysis of the antecedents, correlates, and consequences of organizational commitment. Psychological Bulletin, 108(2), 171-194.

Maxham, J.G., III and R.G. Netemeyer (2003). Firms reap what they sow: The effects of shared values and perceived organizational justice on customers' evaluations of complaint handling. Journal of Marketing, 67(1), 46-62.

Meyer, J.P. and L. Herscovitch (2001). Commitment in the workplace: Toward a general model. Human Resoune Management Rervin, 11(3), 299-326.

Mittal, V. and W.A. Kamakura (2001). Satisfaction, repurchase intent, and repurchase behavior: Investigating the moderating effect of customer characteristics. Journal of Marketing Reseant, $38(1), 131-142$.

Mittal, V., W.T. Ross, and P.M. Baldasare (1998). The asymmetric impact of negative and positive attribute-level performance on overall satisfaction and repurchase intentions. Journal of Marketing, 62(1), 33-47,

Morgan, R.M., and S.D. Hunt (1994). The Commitment-trust theory of relationship marketing. Journal of Marketing, 58(3), 20-38.

Moorman, C., R. Desphandé, and G. Zaltman (1993). Factors affecting trust in market research relationships. Joumal of Marketing, 57(1), 81-101.

Morrison, E.IW. (1994). Role definitions and organizational citizenship behavior: The importance of the employees' perspective. Academy of Management Joumal, 37(6), 1543-1567.

Morrison, E.W. (1996). Organizational citizenship behavior as a critical link between HRM practices and service quality. Human Resoume Management, 35(4), 493-512.

Mowday, R.T. R.M. Steers, and L.W. Porter (1979). The measurement of organizational commitment. Joumal of I ocational Behartor, 14(2), 244-247.

Mowday, R.M. I. IW. Porter, and R.M. Steers (1982). Fimployer-onganization linkages; The psychology of commitment, absenteeism, and turnorer, New York: Academic Press.

Mulhern, F. (1999). Customer profitability analysis: Measurement, concentration, and research directions. Jounual of Intenattive Marketing. 13(1), 25-40.

N

Nelson, E.C., R.R. Rust, A. Zahorik, R.I. Rose, P. Batalden, and B.A. Siemanski (1992), Do patient perceptions of quality relate to hospital financial performance. Journal of Health Care Marketing, 12(4), 1-13.

Netemeyer, R.G., J.S. Boles, D.O. McKee, and R. McMurrian (1997). An investigation into the antecedents of organizational citizenship behaviors in a personal selling context. Journal of Marketing, 61(3), 85-98.

Ngobo, P.V. (1999). Decreasing returns on customer loyalty: Does it really matter to delight the customers?. Adrances in Consunuer Researsh, 26(1), 469-476. 
Nijssen, E, J. Singh, D. Sirdeshmukh, and H. Holzmueller (2003). Investigating industry context effects in consumer-firm relationships: Preliminary results from a dispositional approach. Journal of the Aradeny of Marketing Science, 31(1), 46-60.

Nirai R., M. Gupta, and C. Narasimhan (2001). Customer profitability in a supply chain. Journal of Marketing, 65(3), 1-16.

Nunnally, J.C. and I.H. Bernstein (1994). Psychometric theory. New York: McGraw-Hill.

O

Oliva, T.A., R.L. Oliver, and I.C. Macmillan (1992). A catastrophe model for developing service satisfaction strategies. Journal of Marketing, 56(3), 83-98.

Oliver, R.L. (1997). Satisfaction: A behavional perspective on the consumer. New York: McGraw-Hill.

Oliver, R.L. (1999). Whence customer loyalty. Joumal of Marketing, 63(4), 33.44.

Organ, D.W. (1990), The motivational basis of organizational citizenship behavior. In B.M. Staw and L.L. Cummings (Eds.), Researth in organizational beharior (Vol. 12, pp. 43-72). Greenwich: JAI.

Organ, D.W. and K. Ryan (1995). A meta-analytic review of attitudinal and dispositional predictors of organizational citizenship behavior. Personnel Psychology, 48, 775-802.

Otani, K., R.S. Kurz, T.E. Burroughs, and B. Waterman (2003). Reconsidering models of patient satisfaction and behavioral intentions. Healtb Care Management Review, 28(1), 7-20.

$\mathbf{P}$

Panda, T.K. (20030, Creating customer lifetime value through effective CRM in financial services industry. Joumal of Senrices Research, 2(2), 157-171.

Parker, C.P., R.L. Dipboye, and S.L. Jackson (1995). Perceptions of organizational politics: An investigation of antecedents and consequences. Journal of Mamagement, 21 (5), 891-912.

Patterson, P.G. and R.A. Spreng (1997). Modeling the relationship between perceived value, satisfaction, and repurchase intentions in a business-to-business, services context. The International Journal of Sentice Industry Management. 8(5) 415-432.

Peccei, R. and P. Rosenthal (1997). The antecedents of employee commitment to customer service: Evidence from a UK service context. International Journal of Human Resoure Mamagement, 8(1), 66-86.

Peceei, R and P. Rosenthal (2000). Front-line responses to customer oricntation programmes: A theoretical and empirical analysis. International Joumal of Human Resourne Mamagement, 11(3), 562-590.

Peccei, R. and P. Rosenthal (2001). Delivering customer-oriented behavior through empowerment: An empirical test of HRM assumptions. Journal of Management Studies, 38(6), 831-857.

Pecters, G. and J. Czapinski (1990). Positive-negative asymmetry in evaluations: The distinction between affective and informal negativity effect. In W. Stroebe and M. Hewstone (eds.), Eumpean Reriez of Social Psychology, Volume 1 (pp.425-434). Chicester: John Wiley and Sons. 
Peterson, R.A. and W.R. Wilson (1992). Measuring customer satisfaction: Fact and artufact. Journal of the Acadenty of Marketing Saienc, 20(1), 61-71.

Pillai, R., C.A. Schriesheim, and E.S. Williams (1999). Fairness perceptions and trust as mediators for transformational and transactional leadership: A two-sample study. Jaumal of Management, 25(6), 897-933.

Pitt, L.F., M.T. Ewing, and P. Berthon (2000). Turning competitive advantage into customer equity. Business Horizons, 43(5), 11-18.

Podsakoff, P.M and S.B. MacKenzie (1997), Impact of organizational citizenship behavior on organizational performance. Human Performance, 10(2), 133-151.

Podsakoff, P.M., S.B. MacKenzie, J.B. Paine, and D.G. Bachrach (2000). Organizational citizenship behaviors: A critical review of the theoretical and empirical literature and suggestions for future research. Journal of Managememt, 26(3), 513-564.

Podsakoff, P.M., B.P. Niehoff, S.B. MacKenzie, and M.L. Williams (1993). Do substitutes for leadership really substitute for leadership? An empirical examination of Kerr and Jermier's situational leadership model. Organizational Beharior and Human Derision Processes, 54(1), 1-44.

$\mathbf{R}$

Ramanathan, R. (1998). Introductory econametrics uith applications. Orlando: The Dryden Press.

Rhoades, L. and R. Eisenberger (2002). Perceived organizational support: A review of the literature. Journal of Applied Psychology, 87(4), 698-714.

Rhoades, L., R. Eisenberger, and S. Armeli (2001). Affective commitment to the organization: The contribution of perceived organizational support. Joumal of Applied Pyshology, 86(5), 825. 836.

Rizzo, J.R., R.J. House, and S.I. Lirtzman (1970). Role conflict and ambiguity in complex organizations. Administrative Saience Quarterly, 15(2), 150-163.

Rosenthal, R. (1991), Meta-analytic procedures for social nescarch, Newbury Park: Sage.

Rousseau, D., S.B. Sitkim, R. Burt, and C. Camerer (1998). Not so different after all: A crossdiscipline view of trust. The Academy of Manugement Rerion, 23(3), 393-404.

Rust, R.T. P.J. Danaher, and S. Varki (2000). Using service quality data for competitive marketing decisions. International Journal of Service Industry Management, 11 (5), 438-469.

Rust, R.T., K.N. Lemon, and V.A. Zeithaml (2001). Where should the next marketing dollar go? Marketing Mamagement, 10(3), 25-28.

Rust, R.T., K.N. Lemon, and V.A. Zeithaml (2002). Increasing marketing effectiveness: A decision support system for building customer equity. II'orking Paper.

Rust, R.T., K.N. Lemon, and V.A. Zeithaml (2004). Return on marketing Using customer equity to focus marketing strategy, Journal of Marketing, 68(1), 109-127.

Rust, R.T. and R. Metters (1996). Mathematical models of service. Eumpean Joumal of Openational Research, 91(3), 427-439.

Rust, R.T., C. Moorman, and P.R. Dickson (2002). Getting retums on quality: Revenue expansion, cost reduction, or both? Journal of Marketing, 66(4), 7-24. 
Rust, R T. and R.L. Oliver (1994). Service quality: Insights and managerial implications from the frontier. In R.T. Rust and R.L. Oliver (Eds.), Senve quality: New directions in theory and practice (pp, 1-19) New York: Sage Publications.

Rust, R.T. and A.J. Zahorik (1993). Customer satisfaction, customer retention, and market share. Journal of Retailing, 69(2), 193-215.

Rust, R.T., A.J. Zahorik, T.L. Keiningham (1995). Return on Quality (ROQ); Making service quality financially accountable. Journal of Marketing, 59(2), 58-70.

Rust, R.T., V.A. Zeithaml, and K.N. Lemon (2000). Driving customer equity: How customer lifetime value is reshaping corporate strategy. New York: The Free Press.

Sager, J.K. (1994). A structural model depicting salespeople's job stress. Journal of the Academy of Marketing Saienc, 22(1), 74-84.

Schlesinger, L.A. and J.L. Heskett (1991). The service-driven service company. Hartard Busimess Rerien, 69(5), 71-81.

Schneider, B. (1980). The service organization: Climate is crucial. Organizational Dynamics, 9(2), 52 65.

Schneider, B. (1991). Service quality and profits: Can you have your cake and eat it, too? Human Resource Planning, 14(2), 151-157.

Schneider, B. and D. Bowen (1985). Employee and customer perceptions of service in banks: replication and extension. Journal of Applied Psychology, 70(3), 423-433.

Schneider, B. and D.E. Bowen (1995), Winning the senvice game, Boston: Harvard Business School Press.

Schneider, B., J.K. Wheeler, and J.F. Cox (1992). A passion for service: Using content analysis to explicate service climate themes. Journal of Applied Psychology, 77(5), 705-716.

Selnes, F. (1998). Antecedents and consequences of trust and satisfaction in buyer-seller relationships. European Journal of Markefing, 32(3/4), 305-322.

Shankar, V. A.K. Smith, and A. Rangaswamy (2003). Customer satisfaction and loyalty in online and offline environments. International Joumal of Researth in Marketing, 20(30, 153-175.

Shore, L.M. and S.J. Wayne (1993). Commitment and employee behavior: Comparison of affective commitment and continuance commitment with perceived organizational support. Journal of Applied Psychology, 78(5), 774-780.

Sims, H.P., Jr., A.D. Szilagyi, and R.T. Keller (1976). The measurement of job characteristics. Academy of Management Journal, 19(2), 195-212.

Singh, J. (1993). Boundary role ambiguity: Facets, determinants, and impacts. Journal of Marketing, $57(2), 11-31$.

Singh, J. (1998). Striking a balance in boundary-spanning positions: An investigation of some unconventional influences of role stressors and job characteristics on job outcomes of salespeople. Journal of Marketing, 62(3), 69-86. 
Singh, J. (2000). Performance productivity and quality of frontline employees in service organizations. Journal of Marketing, 64(2), 15-34.

Singh, J. W. Verbeke, and G. Rhoades (1996). Do organizational practices matter in role stress processes? A study of direct and moderating effects for marketing-oriented boundary spanners. Journal of Marketing, 60(3), 69-86.

Singh, J. and D. Sirdeshmukh (2000). Agency and trust mechanisms in consumer satisfaction and loyalty judgments, Journal of the Academy of Marketing Science, 28(1), 150-167.

Sirdeskmukh, D., J. Singh, and B. Sabol (2002). Consumer trust, value, and loyalty in relational exchanges. Journal of Marketing, 66(1), 15-37.

Smith, C.A., D.W. Organ, and J.P. Near (1983). Organizational citizenship behavior: Its nature and antecedents. Journal of -Applied Psychology, 68(4), 653-663.

Sobel, M.E. (1982). Asymptotic intervals for indirect effects in structural equations models. In $\mathrm{S}$. Leinhart (ed.). Sociological Methodology (pp. 290-312). San Francisco: Jossey-Bass.

Spector, P.E. and S.M. Jex (1991). Relations of job characteristics from multiple data sources with employee affect, absence, turnover intentions, and health. Jourmal of Applied Psychology, 76(1), 46-53.

Stamper, C.L. and M.C. Johlke (2003). The impact of perceived organizational support on the relationship between boundary spanner role stress and work outcomes, Journal of Manazement, 29(4), 569-588.

Steenkamp, J.B.E.M. and H.C.M. van Trijp (1991). The use of LISREL in validating marketing constructs, International Joumal of Researth in Marketing, 8(4), 283-299.

Steiger, J.H. (1980). Testing pattern hypotheses on correlation matrices: Alternative statistics and some empincal results, Multinariate Behavioral Researh, 15(3), 335-352.

Steiger, J.H. and M.W. Browne (1984). The comparison of interdependent correlations between optimal linear composites. Psychametrika, 49(1), 11-24.

Streukens, S, and K. de Ruyter (2004): Reconsidering nonlinearity and asymmetry in customer satisfaction and loyalty models: An empirical study in three retail service settings. Marketing Letters, 15(2/3), 99-111.

Swain, G.R., D.B. Schubot, V. Thomas, B.K. Baker, S.L. Foldy, W.W. Graeves, and M. Monteagudo (2004). Three hundred sixty degree feedback: Program implementation in a local health department. Journal of Public Health Mamagement Practice, 10(3), 266-271.

Sweeney, J.C., G.N. Soutar, and L.W. Johnson (1999), The role of perceived risk in the qualityvalue relationship: A study in a retail environment. Journal of Retailing, 75(1), 77-105.

Szymanski, D.M and D.H. Henard (2001). Customer satisfaction: A meta-analysis of the empirical cvidence. Journal of the Academy of Marketing Science, 29(1), 16-35.

$\mathrm{T}$

Tavassoli, N.T. (1998). Language in multimedia: Interaction of spoken and written information. Journal of Consumuer Rescarch, 25(1), 26-43. 
Teas, R.K. (1983). Supervisory behavior, role stress, and the job satisfaction of industrial salespeople. Journal of Marketing Researth, 20(1), 84-91.

Teas, R.K., J.G. Wacker, and R.E. Hughes (1979). A Path analysis of causes and consequences of salespeople's perceptions of role clarity. Journal of Marketing Reseanth, 16(3), 355-369.

Tett, R.P. and J.P. Meyer (1993). Job satisfaction, organizational commitment, turnover intention, and turnover: path analyses based on meta-analytic findings: Personmel Pschology, 46(2), 259 293.

Thompson, JW. (1996). Employee attitudes, organizational performance, and qualitative factors underlying success. Jourmal of Business and Psychology, 11(2), 171-196.

Tubre, T.C. and J.M. Collins (2000). Jackson and Schuler (1985) revisited: A meta-analysis of the relationships between role ambiguity, role conflict, and job performance. Journal of Managememt, 26(1), 155-169.

V

Van Dyne, L., L.L. Cummings, and J.M. Parks (1995). Extra-role behaviors: In pursuit of construct and definitional clarity (A bridge over muddied water). Research in Orgamizational Behatior, 17, 215-286.

Verhoef, P.C. (2003). Understanding the effect of customer relation management efforts on customer retention and customer share development. Journal of Markefing, 67(4), 30-45.

Viswesvaran, C. and D.S. Ones (1995). Theory testing: Combining psychometric meta-analysis and structural equation modeling. Personnel Psychology, 48(4), 865-885.

W

Wayne, S.J. L.M. Shore, and R.C. Liden (1997). Perceived organizational support and leadermember exchange: A social exchange perspective. Academy of Mamagement Journal, 40(1), 82 111.

Wetzels, M. and K. de Ruyter, and J. Lemmink (1999). Role stress in after-sale service management. Journal of Sentice Researib, 2(1), 50-67.

Williams, 1.J. and S.E. Anderson (1991). Job satisfaction and organizational commitment as predictors of organizational citizenship and in-role behaviors. Journal of Mamagement, 17(3). 601-617.

Y

Yi, Y, (1990). A critical review of consumer satisfaction. In V.A. Zeithaml (Ed.), Retrew of marketing (pp. 68-123). Chicago: American Marketing Association.

Yoon, M.H., S.E. Beatty, and J. Suh (2001). The effect of work climate on critical employee and customer outcomes: An employee-level analysis. Intemational Journal of Senvice Industry Mamagement, 12(5), 500-521. 
Yoon, M.H. and J. Suh (2003). Organizational citizenship behaviors and service quality as external effectiveness of contact employees, Joumial of Business Ressunh, 56(8), 597-611.

Z

Zahorik A.J. and R.T. Rust (1992). Modeling the impact of service quality on profitability: A review. In T. Schwart (Ed), Adranes in senice quality and management (Vol 1, pp. 247-276), Greenwich: JAI.

Zeithaml, V.A. (2000). Service quality, profitability and the economic worth of customers: what we know and what we need to learn. Journal of the Acadeny of Marketing Science, 28(1) 67-85.

Zeithaml, V.A., L.L. Berry, and A. Parasuraman (1996). The behavioral consequences of service quality, Journal of Marketing, 60(2), 31-46.

Zeithaml, V.A., R.T. Rust, and K.N. Lemon (2001). The customer pyramid: Creating and serving profitable customers. California Management Retrew, 43(4), 118-142. 

Studies used in meta-analysis 
Aaker, D.A. and R. Jacobson (1994). The financial information content of perceived quality. Journal of Markesting Researh, 31(2), 191-201.

Abelson, M.A. (1983). The impact of goal change on prominent perceptions and behaviors of employees. Journat of Management, 9(1), 65-79.

Adkins, C.L. (1995). Previous work experience and organizational socialization: A longitudinal examination. Acadeny of Management Journal, 38(3), 839-862.

Allen, TD. (2001). Family-supportive work environments: The role of organizational perceptions. Josirnal of L ocational Betharior, 58(3), 414-435.

Allen, D.G., L.M. Shore, and R.W. Griffeth (2003). The role of perceived organizational support and supportive human resource practices in the rurnover process, Journal of Management, 29(10), 99-118.

Ambrose, M.I. and R. Cropanzano (2003). A longitudinal analysis of organizational fairness: An examination of reactions to tenure and promotion decisions. Journal of Applied Psychology, $88(2), 266-275$.

Anderson, S.E., B.S. Coffey, and R.T. Byerly (2002). Formal organizational initiatives and informal workplace practices: Links to work-family conflict and job-related outcomes. Journal of Management, 28(6), 787-810.

Anderson, E.W., C. Fornell, and D.R. Lehmann (1994). Customer satisfaction, market share, and profitability: findings from Sweden. Journal of Marketing, 58(3), 53-66.

Anderson, E.W., C. Fornell, and R.T. Rust (1997). Customer satisfaction, productivity, and profitability: Differences between goods and services. Marketing Scieme, 16(2), 129-145.

Aranya, N. and K.R. Ferris (1983). Organizational-professional conflict among U.S. and Israeli professional accountants. The Journal of Social Psychology, 119(2), 153-161.

Armtrong-Stassen, M. (1998). Downsizing the federal government: A longitudinal study of managers' reactions. Canadian Journal of -Administrative Saiences, 15(4), 310-321.

Amold, H.J. and D.C. Feldman (1982). A multivariate analysis of the determinants of job turnover. Journal of Applicd Psychology, 67(3), 350-360.

Aryec, S., P.S. Budhwar, and Z. X. Chen (2002). Trust as a mediator of the relationship between organizational justice and work outcomes: Test of a social exchange model. Journal of Organizational Beharior, 23(3), 267-285.

Aryee, S., Y.W. Chay, and J. Chew (1994). An investigation of the predictors and outcomes of career commitment in three career stages. Journal of I acational Beharior, 44(1), 1-16.

Athiyaman, A. (1997). Linking student satisfaction and service quality perceptions: The case of university cducation. Limropeun Journul of Markering, 31(7), 528-540. 
Babakus, E., U. Yavas, O.M. Karatepe, and T. Ava (2003). The effect of management commitment to service quality on employees' affective and performance outcomes. Journal of the Academy of Marketing Science, 31(3), 272-286.

Babin, B.J. and J.S. Boles (1996), The effect of perceived co-worker involvement and supervisor support on service provider role stress, performance, and job satisfaction, Joumal of Retailing, 72(1), 57-75.

Babin, B.J. and J.S. Boles (1998). Employee behavior in a service environment: A model and test of potential differences between men and women. Journal of Marketing, 62(2), 77-91.

Bagozzi, R.P. (1978). Salesforce performance and satisfaction as a function of individual difference, interpersonal, and situational factors. Journal of Marketing Reseanth, 15(4), 517-531.

Bateman, T.S. and D.W. Organ (1983). Job satisfaction and the good soldier: The relationship between affect and employee citizenship. Academy of Mamagement Journal, 26(4), 587-595.

Bateman, T.S. and S. Strasser (1984). A longitudinal analysis of the antecedents of organizational commitment. Academy of Management Journal, 27(1), 95-112.

Baugh, S.G., M.J. Lankau, and T.A. Scandura (1996). An investigation of the effects of protégé gender on responses to mentoring. Journal of Vocational Bebatior, 49(3), 309-323.

Bearden, W.O. and J.E. Teel (1983). Selected determinants of consumer satisfaction and complaint reports. Joumal of Marketing Researth, 20(1), 21-28.

Becker, T.E. and R.S. Billings (1993). Profiles of commitment: An empirical test. Journal of Organizational Behavior, 14(2), 177-190.

Bedeian, A.G. and A.A. Armenakis (1981). A path-analytic study of the consequences of role conflict and role ambiguity. Academy of Management Joumal, 24(2), 417-424.

Bedeian, A.G., A.A. Armenakis, and S.M. Curran (1981). The relationship between role stress and job-related, interpersonal, and organizational climate factors. The Journal of Secial Psychology, $113(2), 247-260$.

Bedeian, A.G., K.W. Mossholder, and A.A. Armenakis (1983). Role pereeption-outcome relationships: Moderating effects of situational variables. Human Relations, 36(2), 167-184.

Begley, T.M and J.M. Czajka (1993). Panel analysis of the moderating effects of commitment on job sarisfaction, intent to quit, and health following organizational change. Joumal of Applied Psychology, 78(4), 552-556.

Behson, S.j. (2002). Which dominates? The relative importance of work-family organizational support and general organizational context in employee outcomes. Jaurnal of I ocational Bchatior, 61(3), 53-72.

Bell, S.J. and B. Menguc (2002). The employee-organization relationship, organizational citizenship, and superior service quality. Journal of Retailing, 78(2), 131-146.

Benson, P.G., E.R. Kemery II, W.I. Sauses, Jr. and K.E. Tankesley (1985). Need for clarity as a moderator of the role ambiguity-job satisfaction relationship. Journal of Managemen, 11(3), 125-130. 
Bernardin, H.J. (1979). The predictability of discrepancy measures of role constructs. Personmel Pychology, 32(1), 139-153.

Bernhardt, K.. N. Donthu, and P.A. Kennett (2000). A longitudinal analysis of satisfaction and profitability. Journal of Business Reseanh, 47 (2), 161-171.

Bettencourt, L.A. (1997). Customer voluntary performance: Customers as partners in service delivery, Journal of Retailing, 73(3), 383-406.

Bettencourt, L.A. and S.W. Brown (1997). Contact employees; Relationships among workplace fairness, job satisfaction and prosocial service behaviors. Journal of Retailing, 73(1), 39-61.

Bettencourt, L.A. and S.W. Brown (2003). Role stressors and customer-oriented boundary-spanning behaviors in service organizations. Jaumal of the Academy of Marketing Science, 31(4), $394-408$.

Bettencourt, L.A., K.P. Gwinner, and M.L. Meuter (2001). A comparison of attitude, personality, and knowledge predictors of service-oriented organizational citizenship behaviors. Journal of Applied Psycbology, 86(1), 29-41.

Birnbaum, D, and M.J. Somers (1993). Fitting job performance into turnover models: An examination of the form of the job-performance-turnover relationship and a path model. Joumal of Management, 19(1), 1-11.

Blau, G.J. (1987). Locus of control as a potential moderator of the turnover process. Journal of Ocaupational Psychology, 60(1), 21-29.

Blau, G. (1989). Testing the generalizability of a career commitment measure and its impact on employee turnover. Academy of Management Procedings, 53-57.

Blau, G. and K. Boal (1989). Using job involvement and organizational commitment interactively to predict turnover. Journal of Management, 15(1), 115-127.

Blau, G. (2000). Job, organizational, and professional context antecedents as predictors of intent for interrole work transitions. Journal of L ocational Beharior, 56(3), 330-345.

Bloemer, J. and K. de Ruyter (1995). Integrating service quality and satisfaction: pain in the neck or marketing opportunity. Journal of Consumer Satisfaction, Dissatisfaction, and Complaining Behavior, $8,44-52$.

Boles, J.S: and B.J. Babin (1996). On the front lines: Stress, conflict, and the customer service provider, Journal of Business Research, 37(1), 41-50.

Bollman-Pullins, E, L.M. Fine, and W.L. Warren (1996). Identifying peer mentors in the sales force: An exploratory investigation of willingness and ability, Joumal of the Academy of Marketing Saience, 24(2), 125-136.

Brady, M.K. and J.J. Cronin Jr. (2001). Customer orientation effects on customer service perceptions and outcome behaviors. Journal of Senvice Research, 3(3), 241-251.

Brady, M.K. and C.J. Robertson (1999). An exploratory study of service value in the USA and Ecuador. International Journal of Senvice Industry Management, 10(5), 469-486.

Brashaer, T.G., J.S. Boles, D.N. Bellenger, and C.M. Brooks (2003). An empirical test of trust building processes and outcomes in sales manager-salesperson relationships. Journal of the Academy of Marketing Sriena, 31 (2), 189-200.

Brown, S.P and R.A. Peterson (1994). The effect of effort on sales performance and job satisfaction. Journal of Markerting, 58(2), 70-80. 
Cable, D.M. and D.S. DeRue (2002). The convergent and discriminant validity of subjective fit perceptions. Journal of Applied Psychology, 87 (5), 875-884.

Capon, N., J.U. Farley, and S. Hoenig (1990). Determinants of financial performance: A metaanalysis. Management Scienc, 36(10), 1143-1159.

Chebat, J.C. and P. Kollias (2000). The impact of empowerment on customer contact employees' roles in service organizations. Joumal of Sentice Researth, 3(1), 66-81.

Chen, X.P., C. Hui, and D.J. Sego (1998). The role of organizational citizenship behavior in turnover: Conceptualization and preliminary tests of key hypotheses. Journal of Applied Psychology, 83(6), 922-931.

Churchill, G.A., Jr., N.M. Ford, and O.C. Walker Jr. (1976). Organizational climate and job satisfaction in the salesforce. Joumal of Marketing Rescanch, 13(4), 323-332.

Cleveland, J.N. and L.M. Shore (1992). Self- and supervisory perspectives on age and work attitudes and performance. Journal of Applied Psychology, 77(4), 469-484.

Clugston, M. (2000). The mediating effects of multidimensional commitment on job satisfaction and intent to leave, Journal of Organizational Behatior, 21 (4), 477-486.

Colarelli, S.M., R.A. Dean, and C. Konstans (1987). Comparative effects of personal and situational influences on job outcomes of new professionals. Journal of Applied Psychalogy, 72(4), 558566.

Conway, N. and R.B. Briner (2001). Full-time versus part-time employees: Understanding the links berween work status, the psychological contract, and attitudes. Journal of I ocational Beharvor, 61(2), 279-301.

Cronin, J.. Jr., M.K. Brady, and G.T.M. Hult (2000), Assessing the effects of quality, valuc, and customer satisfaction on consumer behaviotal intentions in service environments. Journal of Retailing, 76(2), 193-218.

Cronin, J.J., Jr. and S.A. Taylor (1992). Measuring service quality: A reexamination and extension. Journal of Markcting, 56(3), 55-68.

Cropanzano, R., J.C. Howes, A.A. Grandey, and P. Toth (1997). The relationship of organizational politics and support to work behaviors, atritudes, and stress. Journal of Organizational Behavior, 18(2), 159-180.

Cropanzano, R., K. James, and M.A. Konovsky (1993). Dispositional affectivity as a predictor of work attitudes and job performance. Journal of Onyamizational Behartior, 14(6), 595-606.

Cropanzano, R. D.E. Rupp, and Z.S. Byme (2003). The relationship of emotional exhaustion to work attitudes, job performance, and organizational citizenship behaviors. Joumal of -Applied Psychology, 88(1), 160-169.

\section{D}

Dabholkar, P.A., C.D. Shepherd, and D.I, Thorpe (2000). A comprehensive framework for service quality: An investigation of critical conceptual and measurement issues through a longitudinal study. Journal of Retailing, 76(2), 139-173. 
Dalton, D.R. and D.J. Mesch (1991), On the extent and reduction of avoidable absenteeism: An assessment of absence policy provisions. Journal of Applied Psychology, 76(6), 810-817.

Danaher, P.J. and V. Haddrell (1996). A comparison of question scales used for measuring customer satisfaction. International Joumal of Senvice Industry Management, 7(4), 4-26.

Darden, W.R., R. Hampton, and R.D. Howell (1989). Career versus organizational commitment: Antecedents and consequences of retail salespeoples' commitment. Journal of Retailing, 65(1), 80-106.

Day, N.E. and P. Schoenrade (1997). Staying in the closet versus coming out: Relationships between communication about sexual orientation and work attitudes. Personnel Psychology, $50(1), 147-163$.

DeCotiis, T.A and T.P. Summers (1987). A path analysis of a model of the antecedents and consequences of organizational commitment. Human Relations, 40(7), 445-470.

De Ruyter, K. and J. Bloemer (1999), Customer loyalty in extended service settings: The interaction between satisfaction, value attainment, and positive mood. International Journal of Sentice Industry Management, 10(3), 320-336.

De Ruyter, K., J. Bloemer, and P. Peeters (1997). Merging service quality and service satisfaction: An empirical test of an integrative model. Journal of Economic Psychology, 18(4), 387-406.

De Ruyter, $\mathrm{K}$ and M. Wetzels (1998). On the complex nature of patient evaluations of general practice service. Journal of Esonomic Psychology, 19(5), 565-590.

DeWitt, R., L. Klebe Trevino, and K.A. Mollica (1998). The influence of eligibility on employees' reactions to voluntary workforce reductions. Joumal of Mandgement, 24(5), 593-613.

De Wulf, K, G. Odekerken-Schröder, and D. Iacobucci (2001). Investments in consumer relationships: A cross-country and cross-industry explonation. Journal of Marketing, 65(4), 33 50.

Dunham, R.B. (1977). Reactions to job characteristics: Moderating effects of the organization. Academy of Management Journal, 20(1), 42-65.

Dubinsky A.J. and S.W. Hartley (1986), A path-analytic study of a model of salesperson performance. Joumal of the Academy of Marketing Science, 14(1), 36-46.

Dubinsky, A.L. and B.E. Mattson (1979). Consequences of role conflict and ambiguity experienced by retail salespeople. Jourmal of Retuiling, 55(4), 70-86.

Dubinsky, A.J. and S.J. Skinner (1984). Impact of job characteristics on retail salespeople's reactions to their jobs. Journal of Retailing, 60(2), 35-62.

Dubinsky, A.J. and F. Y. Yammarino (1984). Differential impact of role conflict and ambiguity on selected correlates: A two-sample test, Psychological Reports, 55(3), 699-707.

Dunham, R.B. (1976). The measurement and dimensionality of job characteristics. Journal of Applied Psychology, 61(4), 404-409.

Duxbury, L.E., C.A. Higgins, and D.R. Thomas (1996). Work and family environments and the adoption of computer-supported supplemental work-at-home. Journal of V ocational Behatior, 49 (1), 1-23. 
Eisenberger, R., J. Cummings, S. Armeli, and P. Lynch (1997). Perceived organizational support, discretionary treatment, and job satisfaction. Journal of Appliced Psychology, 82(5), 812-820.

F

Fahr, J.L., P.M. Podsakoff, and D.W. Organ (1990). Accounting for organizational citizenship behavior: Leader fairness and task scope versus satisfaction. Journal of Management, 16(4), 705-721.

Fisher, C.D. (1985). Social support and adjustment to work: A longitudinal study. Jourmal of Management, 11(3), 39-53.

Fry, L.W., C.M. Futrell, A. Parasuraman, and M.A. Chmiclewski (1986). An analysis of alternative causal models of salesperson role perceptions and work-related attitudes. Journal of Marketting Researhh, 23(2), 153-163.

Futrell, C.M. and A. Parasuraman (1984). The relationship of satisfaction and performance to salesforce turnover. Journal of Marketing, 48(4), 33-40.

G

Gakovic, A and L.E. Tetrick (2003). Perceived organizational support and work status: A comparison of the employment relationships of part-time and full-time employees attending university classes. Journal of Organizational Behatior, 24(5), 649-666.

Ganesh, J., M.J. Amold, and K.E. Reynolds (2000). Understanding the customer base of service providers: An examination of the differences between switchers and stayers. Joumal of Marketing, 64(3), 65-87.

George, J.M. (1991), State or trait: Effects of positive mood on prosocial behaviors at work. Journal of Applied Psychology, 76(2), 299-307.

George, J.M. and K. Bettenhausen (1990). Understanding prosocial behavior, sales performance. and rurnover: A group-level analysis in a service context. Journal of Applied Psychology, 75(6). 698-709.

George, J.M. and G.R. Jones (1996). The experience of work and tumover intentions: Interactive effects of value attainment, job satisfaction, and positive mood. Joumul of Applied Psychology. 81(3), 318-325.

Glisson, C. and M. Durick (1988). Predictors of job satisfaction and organizational commitment in human service organizations. Administrative Science Quarterly, 33(1), 61-81.

González-Romá, V., J.M. Peiro, and N. Tordera (2002). An examination of the antecedents and moderator influences of climate strength. Journal of Applied Psychology, 87(3), 465-473.

Good, L.K., G.F. Sisler, and J.W. Gentry (1988). Antecedents of tumover intentions among retail management personnel. Joumal of Retailing, 64(3), 295-314. 
Gotheb, J.B., D. Grewal, and S.W. Brown (1994), Consumer satisfaction and perceived quality: Complementary or divergent constructs?. Joumal of Applied Psychology, 79(6), 875-885.

Goulet, L.R and P. Singh (2002). Career commiment: A reexamination and an extension. Journal of Vocational Behatior, 61(1), 73-91.

Grant, K. D.W. Cravens, G.S. Low, and W.C. Moncrief (2001). The role of satisfaction with territory design on the motivation, attitudes, and work outcomes of salespeople. Journal of the Academy of Marketing Science, 29(2), 165-178.

Gremler, D.D. and K.P. Gwinner (2000). Customer-employee rapport in service relationships. Joumal of Serrice Ressanth, 3(1), 82-104.

$\mathbf{H}$

Hallowell, R. (1996). The relationship of customer satisfaction, customer loyalty, and profitability: An empirical study. International Joumal of Senvice Industry Mamagement, 7(4), 27-42.

Hampton, R., A.J. Dubinsky, and S.J. Skinner (1986). A model of supervisor leadership behavior and retail salespeople's job-related outcomes. Journal of the Academy of Marketing Saicnce, 14(3), 33-43.

Hartline, M.D. and K.C. Jones (1996). Employee performance cues in a hotel service environment: Influence on perceived service quality, value, and word-of-mouth intentions. Joumal of Business Reseanh, 35(3), 207-215.

Hartline, M.D., J.G. Maxham III, and D.O. McKee (2000). Corridors of influence in the dissemination of customer-oriented strategy to customer contact service employees. Journal of Marketing, 64(2), 35-50.

Hattrup, K., M.S. O'Connell, and P.H. Wingate (1998). Prediction of multidimensional criteria: Distinguishing task and contextual performance. Human Performance, 11(4), 305-319.

Hennig-Thurau, T., K.P. Gwinner, D.D. Gremler (2002). Understanding relationship marketing outcomes: An integration of relational benefits and relationship quality. Journal of Sentice Reseanch, 4(3), 230-247.

Hochwarter, W.A., P.L. Perrewé, G.R. Ferris, and R. Guercio (1999). Commitment as an antidote to the tension and rumover consequences of organizational politics. Journal of Vocational Beharior, 55(3), 277-297.

Hollenbeck, J.R. (1989). Control theory and the pereeption of work environments: The effects of focus of attention on affective and behavioral reactions to work. Orgamizational Beharior and Human Decision Processes, 43(3), 406-430.

Hollon, C.J. (1983). Machiavellianism and managerial work attitudes and perceptions. Psychological Reports, 52, 432-434.

Holtom, B.C., T.W. Lee, and S.T. Tidd (2002). The relationship between work status congruence and work-related attitudes and bchaviors. Journal of Applied Psychology, 87(5), 903-915.

Howell, J.P and P.W. Dorfman (1981). Substitutes for leadership: Test of a construct. Academy of Mamugement Joumal, 24(4), 714-728. 
Huselid, M.A. and N.E. Day (1991). Organizational commitment, job involvement, and turnover: A substantive and methodological analysis. Journal of Applied Psychology, 76(3), 380-391.

Hutchison, S. and M.L. Garstka (1996). Sources of perceived organizational support: Goal setting and feedback. Joumal of Applied Social Psybology, 26(15), 1351-1366.

Hutchison, S., K.E. Valentino, and S.L. Kirkner (1998). What works for the gander does not work as well for the goose: The effect of leader behavior. Journal of . Applied Social Psychology, 28(2), $171-182$.

I

Irving, P.G., D.F. Coleman, and C.L. Cooper (1997). Further assessment of a three-component model of occupational commitment: Generalizability and differences among occupations. Journal of Applied Psychology, 82(3), 444-452.

Ittner, C.D. and D.F. Larcker (1999). Are nonfinancial measures leading indicators of financial performance? An analysis of customer satisfaction. Journal of Accounting Reseant, 36(3), 1-35.

Jauch, L.R. and U. Sekaran (1978). Employee orientation and job satisfaction among professional employees in hospitals. Journal of Management, 4(1), 43-56.

Jamal, M. (1990). Relationship of job stress and type-A behavior to employees' job satisfaction, organizational commitment, psychosomatic health problems, and turnover motivation. Human Relations, 43(8), 727-738.

Johlke, M.C., D.F. Duhan, R.D. Howell, and R.W. Wilkes (2000). An integrated model of sales managers' communication practices. Journal of the Academy of Marketing Science, 28(2), 263. 277.

Jones, G.R. (1986). Socialization tactics, self-efficacy, and newcomers' adjustments to organizations. Academy of Management Journal, 29(2), 262-279.

Jamal, M. (1981). Shift work related to job attitudes, social participation and withdrawal behavior: A study of nurses and industrial workers. Personnel Psychology, 34(3), 535-547.

Jamal, M. (1984). Job stress and job performance controversy: An empirical assessment. Orgamizational Behatior and Human Performame, 33(1), 1-21.

Johlke, M.C. and D.F. Duhan (2000). Supervisor communication practices and service employee job outcomes, Joumal of Sentice Research, 3(2), 154-165.

Johnson, J.W. (1996). Linking employee perceptions of service climate to customer satisfaction. Personnel Psychalogy, 49(4), 831-851.

Johnson, J.L. and A.M. O'Leary-Kelly (2003). The effects of psychological contract breach and organizational cynicism: Not all social exchange violations are created equal. Journal of Organizational Beharyor, 24(5), 627-647. 
Jones, E., P. Busch, and P. Dacin (2003). Firm market otientation and salesperson customer orientation: Interpersonal and intrapersonal influences on customer service and retention in business-to-business buyer-seller relationships. Journal of Business Reseanch, 56(4), 323-340.

Joshi, A.W. and S. Randall (2001). The indirect effects of organizational controls on salesperson performance and customer orientation. Joumal of Business Rescanth, 54(1), 1-9.

Judge, T.A. (1993). Does affective disposition moderate the relationship between job satisfaction and voluntary turnover?. Joumal of Applied Psychology, 78(3), 395-401.

K

Kalliath, T.J., A.C. Bluedorn, and M.J. Strube (1999). A test of value congruence effects. Journal of Organizational Beharior, 20(7), 1175-1198.

Kamakura, W.A., V. Mittal, R. de Rosa, and J.A. Mazzon (2002). Assessing the service-profit chain. Marketing Saiene, 21(3), 294-317.

Katz, R. (1978). Job longevity as a situational factor in job satisfaction. Administrative Saience Quarterty, 23(2), 204-223.

Katz, R. (1978). The influence of job longevity on employee reactions to task characteristics, Human Relations, 31(8), 703-725.

Keller, R.T. (1975). Role conflict and ambiguity: Correlates with job satisfaction and values. Personnel Psychology, 28(1), 27-64.

Kelly, J.P., M. Gable, and R.T. Hise (1981). Conflict, clarity, tension, and satisfaction in chain store manager roles. Journal of Retailing, 57(1), 27-42.

Kelly, J.P and R.T. Hise (1980). Role conflict, role clarity, job tension and job satisfaction in the brand manager position. Joumal of the Academy of Marketing Science, 8(2), 120-137.

Kickul, J., S.C. Lester, and J. Finkl (2002). Promise breaking during radical organizational change: Do justice interventions make a difference? Joumal of Organizational Behatior, 23(4), 469-488.

Kidder, D.1. (2002). The influence of gender on the performance of organizational citizenship behaviors. Journal of Mamagement, 28(5), 629-648.

Kidwell, Jr., R.E., K.W. Mossholder, and Nathan Bennett (1997). Cohesiveness and organizational citizenship behavior: A multilevel analysis using workgroups and individuals. Joumal of Management, 23(6), 775-793.

Kimes, S.E. (1999). The relationship between product quality and revenue per avalable room at Holiday Inn. Journal of Senvice Rescarch, 2(2), 138-144.

Kirchmeyer, C. (1995). Demographic similarity to the work group: A longitudinal study of managers at the early career stage. Journal of Organizational Beharior, 16(1), 67-83.

Kirchmeyer, C. and C. Bullin (1997). Gender roles in a traditionally female occupation: A study of emergency, operating, intensive care, and psychiatric nurses. Journal of I ocational Beharior, 50(1), 78-95.

Ko. J. J.1. Price, and C.W. Mueller (1997). Assessment of Meyer and Allen's three-component model of organizational commitment in South Korea. Journal of Applied Psycholog, 82(6), 961.973 
Koh, W.L., R.M. Steers, and J.R. Terborg (1995). The Effects of transformational leadership on teacher attitudes and student performance in Singapore. Journal of Organizational Becharior. 16(4), 319-333.

Kohli, A.K. (1985). Some unexplored supervisory behaviors and their influence on salespeople's role clarity, specific self-esteem, job satisfaction, and motivation. Joumal of Marketing Researt, 22(4), 424-433.

Konovsky, M.A and R. Cropanzano (1991). Perceived fairness of employee drug testing as a predictor of employec attitudes and job performance. Journal of Applied Psychology, 76(5), 698-707,

Konovsky, M.A. and S.D. Pugh (1994). Citizenship behavior and social exchange. Academy of Management Journal, 37(3), 656-669.

Kordupleski, R.E., R.T. Rust, and A.J. Zahorik (1993). Why improving quality doesn't improve quality (Or whatever happened to marketing?). Califormia Management Review, 35(3), 82-95.

Koys, D.J. (2001). The effects of employee satisfaction, organizational citizenship behavior, and turnover on organizational effectiveness: A unit-level, longitudinal study. Personme/ Psychology, 54(1), 101-114.

Krausz, M., A. Sagie, and Y. Bidermann (2000). Actual and preferred work schedules and scheduling control as determinants of job-related attitudes. Journal of Vocational Beharior, $56(1), 1-11$.

L

Lagace, R.R (1988). Role-stress differences between salesmen and saleswomen: Effect of job satisfaction and performance. Psychological Reports, 62(3), 815-825.

Lai, M. and R. Widdows (1993). Determinants of consumers' satisfaction with service: A preliminary study, Joumal of Consumer Sattisfaction, Dissatisfaction, and Complaining Behatror, 6, $166-174$.

Lam, S.S.K., J. Schaubroeck, and S. Aryee (2002). Relationship between organizational justice and employee work outcomes: A cross-national study. Journal of Organizational Bebartor, 23(1), 1 18.

Landau, J. and T.H. Hammer (1986). Clerical employees' perceptions of intraorganizational career opportunities. Academy of Mamagement Journal, 29(2), 385-404.

Lankau, M.J. and T.A. Scandura (2002). An investigation of personal learning in mentoring relationships: Content, antecedents, and consequences. Academy of Management Journal, 45(4), 779-790.

Law, K.S. and C. Wong (1999). Multidimensional constructs in structural equation analysis: An illustration using the job perception and job satisfaction constructs. Joumal of Management, 25(2), 143-160.

Lee, C. and R.S. Schuler (1980). Goal specificity and difficulty and leader initiating structure as strategies for managing role stress. Joumal of Management, 6(2), 177-187. 
Lee, T.W. and R.T. Mowday (1987), Voluntarly leaving an organization: An empirical investigation of Stecrs and Mowday's model of turnover. Academy of Management Journal, 30(4), 721-743.

Leiter, M.P. and C. Maslach (1988). The impact of interpersonal environment on burnout and organizational commitment. Joumal Organizational Behavior, 9(4), 297-308.

Levy, P.E. and J.R. Williams (1998). The role of perceived system knowledge in predicting appraisal reactions, job satisfaction, and organizational commitment. Journal of Organizational Bebatior, 19(1), 53-65.

Liden, R.C., S.J. Wayne, M.L. Kraimer, and R.T. Sparrowe (2003). The dual commitments of contingent workers: An examination of contingents' commitment to the agency and the organization. Journal of Organizational Beharior, 24(5), 609-625.

Liden, R.C., S.J. Wayne, and R.T. Sparrowe (2000). An examination of the mediaring role of psychological empowerment on the relations between job, interpersonal relationships, and work outcomes. Journal of Applied Psychology, 85(3), 407-416.

Liljander, V. (1994). Modeling perceived service quality using different comparison standards. Journal of Consumer Satisfaction, Dissatisfaction, and Complaining Beharior, 7, 126-142.

Liljander, V. and T. Strandvik (1997). Emotions in service satisfaction. Intemational Journal of Senvice Industry Management, 8(2), 148-169.

Loveman, G.W. (1998). Employee satisfaction, customer loyalty, and financial performance: An empirical examination of the service profit chain in retail banking. Journal of Senrice Research, 1(1), 18-31.

Lucas, G.H., Jr. (1985). The relationship between job attitudes, personal characteristics, and job outcomes: A study of retail store managers. Joumal of Retailing, 61(1), 35-62.

Lynch, P.D., R. Eisenberger, and S. Armeli (1999). Perceived organizational support: Inferior versus superior performance by wary employees. Joumal of Applied Psychology, 84(4), 467-483.

Lyness, K.S. and D.E. Thompson (1997). Above the glass ceiling? A comparison of matched samples of female and male executives. Journal of Applied Psychology, 82(3), 359-375.

M

MacKenzic, S.B., P.M. Podsakoff, and M. Ahearne (1998). Some possible antecedents and consequences of in-role and extra-role salesperson performance. Journal of Marketing, 62(3), $87-98$.

MacKenzic, S.B, P.M. Podsakoff, and G.A. Rich (2001). Transformational and transactional leadership and salesperson performance. Joumal of the Academy of Marketing Science, 29(2), 115-134.

Mägi, A, W. (2003). Share of wallet in retailing: The effects of customer satisfaction, loyalty cards, and shopper characteristics. Journal of Retailing, 79(2), 97-106.

Maier, G.W and J.C. Brunstein (2001). The role of personal work goals in newcomers' job satisfaction and organizational commitment: A longitudinal analysis. Journal of Applied Psychology, 86(5), 1034-1042. 
Maignan, I., O.C. Ferrell, and G.T.M. Hult (1999). Corporate citizenship: Cultural antecedents and business benefits. Josumal of the Acadenny of Marketing Saience, 27(4), 455-469.

Martin. T.N. and J.C. Hafer (1995). The multiplicative interaction effects of job involvement and organizational commitment on the turnover intentions of full- and part-time employees. Josurnal of V ocational Behavior, 46(3), 310-331.

Maslyn, J.M and D.B. Fedor (1998). Perceptions of politics: Does measuring different foci matter. Journal of Applied Psychology, 84(4), 645-653.

Masterson, S.S., K. Lewis, B.M. Goldman, and M.S. Taylor (2000). Integrating justice and social exchange: The differing effects of fair procedures and treatment on work relationships. Acadeny of Mamagement Journal, 43(4), 738-748.

Mathieu, J.E. (1991). A cross-level nonrecursive model of the antecedents of organizational commitment and satisfaction. Journal of Applied Psycbology, 76(5), 607-618.

Mathieu, J.E. and J.L. Farr (1991). Further evidence for the discriminant validity of measures of organizational commiment, job involvement, and job satisfaction. Journal of Applied Psychology, 76(1), 127-133.

Maxham, J.G., III and R.G. Netemeyer (2002). Modeling customer perceptions of compliant handling over time: The effects of perceived justice on satisfaction and intent Jourmal of Business Researhh, 78(4), 239-252.

Maxham, J.G., III and R.G. Netemeyer (2003). Firms reap what they sow: The effects of shared values and perceived organizational justice on customers' evaluations of complaint handling. Journal of Marketing, 67(1), 46-62.

Mayes, B.T. and D.C. Ganster (1988). Exit and voice: A test of hypotheses based on fight/flight responses to job stress. Journal of Onganizational Beharior, 9(3), 199-216.

McFarlin, D.B. and P.D. Sweeney (1992). Distributive and procedural justice as predictors of satisfaction with personal and organizational outcomes. Academy of Management Journal, 35(3), 626-637.

McNeely, B.L. and B.M. Meglino (1994). The role of dispositional and situational antecedents in prosocial organizational behavior: An examination of the intended beneficianies of prosocial behavior. Journal of -Applied Psychology, 79(6), 836-844.

Menguc, B. (1995). Evidence for Turkish industrial salespeople: Testing the applicability of a conceptual model for the effect of effort on sales performance and job satisfaction. European Journal of Marketing, 30(1), 33-51.

Mentzer, J.T., D.J. Flint, and T.M. Hult (2001), Logistics service quality as a segment-customized process. Jourmal of Markerting, 65(4), 82-104.

Meyer, J.P., S.V. Paunonen. I.R. Gellatly, R.D. Goffin, and D.N. Jackson (1989). Organizational commitment and job performance: It's the nature of commitment that counts, Journal of Applied Psychology, 74(1), 152-156.

Micelli, M.P. and P.W. Mulvey (2000). Consequences of satisfaction with pay systems: Two field studies. Industrial Relations, 39(1), 62-87. 
Michaeis, R.E., W.L. Cron, A.J. Dubinsky, and E.A. Joachimsthaler (1988). Influence of formalization on the organizational commitment and work alienation of salespeople and industrial buyers. Journal of Marketing Researth, 25(4), 376-383.

Michaels, R.E, and A.L. Dixon (1994), Sellers and buyers on the boundary: Potential moderators of role-stress-job outcome relationships. Joumal of the Academy of Marketing Saience, 22(1), $62-73$.

Miles, R.H. (1975). An empirical test of causal inference between role perceptions of conflict and ambiguity and various personal outcomes. Journal of . Applied Psychology, 60(3), 334-339.

Miles, R.H. (1976). A comparison of the relative impacts of role perceptions of ambiguity and conflict by role. Academy of Management Journal, 19(1), 25-35.

Miller, H.E., R. Katerberg, and C.L. Hulin (1979). Evaluation of the Mobley, Horner, and Hollingsworth model of employee turnover, Journal of Applied Psychology, 64(5), 509-517.

Mitchell, T.R., B.C. Holtom, T.W. Lee, C.J. Sablynski, and M. Erez (2001). Why people stay: Using job embeddedness to predict voluntary turnover. Academy of Management Journal, 44(6), 1102-1121.

Mobley, W.H., S.O. Horner, and A.T. Hollingsworth (1978). An evaluation of precursors of hospital employee turnover. Journal of Applied Psychology, 63(4), 408-414.

Moorman, R.H., G.L. Blakely, and B.P. Niehoff (1998). Does perceived organizational support mediate the relationship between procedural justice and organizational citizenship behavior. Acudemy of Management Journal, 41(3), 351-357.

Morris, J.H. and R.A. Snyder (1979). A second look at need for achievement and need for Autonomy as Moderators of Role Perception-Outcome Relationships, Joumal of Applied Psychology, 64(2), 173-178.

Morrison, E.W. (1994). Role definitions and organizational citizenship behavior: The importance of the employees perspective. Academy of Management Journal, 37(6), 1543-1567.

Moshavi, D. and J.R. Terborg (2002). The job satisfaction and performance of contingent and regular customer service representatives: A human capital perspective. International Journal of Senvice Industry Mamagement, 13(4), 333-347.

Mossholder, K.W., A.G Bedeian, and A.A. Armenakis (1981). Role perceptions, satisfaction, and performance: Moderating effects of self-esteem and organizational level. Organizational Beharior and Human Performance, 28(2), 224-234.

$\mathrm{N}$

Nelson, E.C., R.R. Rust, A. Zahorik, R.L. Rose, P. Batalden, and B.A. Siemanski (1992), Do patient perceptions of quality relate to hospital financial performance. Journal of Health Care Marketing, 12(4), 1-13.

Netemeyer, R.G., J.S. Boles, D.O. McKee, and R. MeMurrian (1997). An investigation into the antecedents of organizational citizenship behaviors in a personal selling context. Journal of Marketing, 61(3), 85-98. 
Netemeyer, R.G., S. Burton, M.W. Johnston (1995). A nested comparison of four models of the consequences of role perception variables: Omanizational Beharvor and Human Deasion Processes, 61(1), 77-93.

Netemeyer, R.G., M.W. Johnson, and S.Burton (1990). Analysis of role conflict and role ambiguity in a structural equations framework. Jourmal of Applied Psychology, 75(2), 148-157.

Nijssen, E., J. Singh, D. Sirdeshmukh, and H. Holzmueller (2003). Investigating industry context effects in consumer-firm relationships: Preliminary results from a dispositional approach. Journal of the Academy of Marketing Sciencr, 31(1), 46-60.

Nye, L.G. and A. Witt (1993). Dimensionality and construct validity of the perceptions of organizational politics scale (POPS). Educational and Psychological Mcasurement, 53(3), 821-829.

Nygaard, A. and R. Dahlstrom (2002). Role stress and effectiveness in horizontal alliances. Joumal of Marketing, 66(2), 61-82.

\section{O}

O'Connell, C.E. and K. Korabik (2000). Sexual harassment: The relationship of personal vulnerability, work context, perpetrator status, and type of harassment to outcomes. Journal of Vocational Behatior, 56(3), 299-329.

Oliver, R.L and A.P. Brief (1977), Determinants and consequences of role conflict and ambiguity among retail sales managers. Journal of Retailing, 53(4), 47-90.

Oliver, R.L., R.T. Rust, and S. Varki (1997). Customer delight: Foundations, findings, and managerial insight. Joumal of Retailing, 73(3), 311-336.

Oliver, R.L. and J.E. Swan (1989). Equity and disconfirmation perceptions as influences on merchant and product satisfaction. Journal of Consumer Research, 16(3), 372-383.

O'Neill, B.S. and M.A. Mone (1998). Investigating equity sensitivity as a moderator of relations between self-efficacy and workplace attitudes. Joumal of Applied Psychology, 83(5), 805-816.

O'Reilly III, C.A., G.N. Parlette, and J.R. Bloom (1980). Perceptual measures of task characteristics: The biasing effects of differing frames of reference and job attitudes. Academy of Management Journal, 23(1), 118-131.

Organ, D.W and M. Konovsky (1989). Cognitive versus affective determinants of organizational citizenship behavior. Journat of Applied Psychalogy, 74(1), 157-164.

Ostroff, C. (1992). The relationship between satisfaction, attitudes, and performance: An organizational level analysis. Journal of Applied Psychology, 77(6), 963-974.

$\mathbf{P}$

Parker, C.P., R.L. Dipboye, and S.L. Jackson (1995). Perceptions of organizational politics: An investigation of antecedents and consequences. Joumal of Managemem, 21(5), 891-912

Patterson, P.G., L.W. Johnson, and R.A. Spreng (1997). Modeling the determinants of customer satisfaction for business-to-business professional services. Joumal of the Acadeny of Marketing Sairnce, 25(1), 4-17. 
Parterson, P.G. and T. Smith (2003). A cross-cultural study of switching barriers and propensity to stay with service providers, Journal of Refailing, 79(2), 107-120.

Patterson, P.G. and R.A. Spreng (1997). Modeling the relationship between perceived value, satisfaction, and repurchase intentions in a business-to-business, services context: An empirical examination. Intemational Journal of Senvice Industry Management, 8(5), 414-434.

Pickle, H., R. Abrahamson, and A. Porter (1970). Customer satisfaction and profit in small business, Journal of Refailing, 46(4), 38-49.

Pierce, J.L. (1979). Employee affective responses to work unit structure and job design: A test of an intervening variable. Journal of Management, 5(2), 193-211.

Pillai, R., C.A. Schriesheim, and E.S. Williams (1999). Fairness perceptions and trust as mediators for transformational and transactional leadership: A two-sample study. Joumal of Management, 25(6), 897-933.

Prakash, V. and J.W. Lounsbury (1984). The role of expectations in the determination of consumer satisfaction. Journal of the Acadenry of Marketing Science, 12(3), 1-17.

Podsakoff, P.M., S.B. MacKenzie, W.H. Bommer (1996). Transformational leader behaviors and substitutes for leadership as determinants of employee satisfaction, commitment, trust, and organizational citizenship behaviors. Journal of Management, 22(2), 259-298.

Podsakoff, P.M., B.P. Nichoff, S.B. MacKenzic, and M.L. Williams (1993). Do substitutes for leadership really substitute for leadership? An empirical examination of Kerr and Jermier's situational leadership model. Organizational Beharior and Human Decision Processes, 54(1), 1-44.

Pond, S.B., R.W. Nacoste, M.F. Mohr, and C.M. Rodriguez (1997). The measurement of organizational citizenship behavior. Are we assuming too much? Joumal of Applied Social Pychology, 27(17), 1527-1544.

Posner, B.Z. and A.W. Randolph (1980). Moderators of role stress among hospital personnel. The Journal of Psychology, 105(2), 215-244.

Price, J.L. and C.W. Mueller (1981). A causal model of turnover for nurses. Academy of Management Journal, 24(3), 513-565.

\section{$\mathbf{R}$}

Reichers, A.E. (1986). Conflict and organizational commitments. Journal of Applied Psychology, 71(3), 508-514.

Rhoades, L., R. Eisenberger, and S. Armeli (2001). Affective commitment to the organization: The contribution of perceived organizational support. Journal of Applied Psychology, 86(5), 825. 836.

Rioux, S.M. and L.A. Penner (2001), The causes of organizational citizenship behavior: A motivational analysis. Joumal of .Applied Psychology, 86(6), 1306-1314.

Rogg, K.1., D.B. Schmidt, C. Shull, and N. Schmitt (2001). Human resource practices, organizational climate, and customer satisfaction. Journal of Management, 27(4), 431-449.

Rosin, $\mathrm{H}$ and $\mathrm{K}$ Korabik (1995), Organizational experience and propensity to leave: A multivariate investigation of men and women managers. Joumal of I ocational Beharior, 46(1), 1-16. 
Rothausen, T.J. (1994), Job satisfaction and the parent worker: The role of flexibility and reward. Journal of L ocational Behatvor, 44(3), 317-336.

Ryan, A.M., M.J. Schmit, and R. Johnson (1996). Attutudes and effectiveness: Examining relations at an organizational level. Personmel Psychology, 49(4), 853-882.

Sadler-Smith, E., G. El-Kot, and M. Leat (2003). Differentiating work autonomy facets in a NonWestern context. Journal of Organizational Behatvor, 24(6), 709-731.

Sager, J.K. (1991). A longitudinal assessment of change in sales force turnover. Journal of the Academy of Marketing Science, 19(1), 25-36.

Sager, J.K. (1994). A structural model depicting salespeople's job stress. Journal of the Academy of Marketing Science, 22(1), 74-84.

Sager, J.K and A. Menon (1994). The role of behavioral intentions in turnover of salespeople. Journal of Business Reseant, 29(3), 179-188.

Saks, A.M. and B.E. Ashforth (1997). A longitudinal investigation of the relationship between job information sources, applicant perceptions of fit, and work outcomes. Personnel Psychology. $50(2), 395-423$.

Saks, A.M. and B.E. Ashforth (2000). The role of dispositions, entry stress, and behavional plasticity theory in predicting newcomers' adjustment to work. Journal of Ongamizational Beharior, 21(1), 43-62.

Sawyer, J.E. (1992). Goal and process clarity: Specification of multiple constructs of role ambiguity and a structural equation model of their antecedents and consequence. Joumal of Applied Psychology, 77(2), 130-142.

Schappe, S.P. (1998). The influence of job satisfaction, organizational commitment, and fairness perceptions on organizational citizenship behavior. The Journal of Psychology, 132(3), 277-290.

Schaubroeck, J. and L.S. Fink (1998). Facilitating and inhibiting effects of job control and social support on stress outcomes and role behavior: A contingency model. Journal of Organizational Beharior, 19(2), 167-195.

Schriesheim, C. A., S.L. Castro, and F.J. Yammarino (2000). Investigating contingencies: An examination of the impact of span of supervision and upward controllingness on leadermember exchange using traditional and multivariate within- and between-entities analysis. Joumal of Applied Psychology, 85(5), 659-677.

Schriesheim, C.A. and C.J. Murphy (1976). Relationships between leader behavior and subordinate satisfaction and performance: A test of some situational moderators. Journal of Applied Psychology, 61(5), 634-641.

Selnes, F. (1998). Antecedents and consequences of trust and satisfaction in buyer-seller relationships. European Journal of Markefing, 32(3/4), 305-322.

Shaffer, M.A. J.R.W. Joplin, M.P. Bell, T. Lau, and C. Oguz (2000). Gender discrimination and jobrelated outcomes: A cross-cultural comparison of working women in the United States and China. Jourmal of I ocational Behartor, 57(3), 395-427. 
Shore, L.M. and K. Barksdale (1998). Examining degree of balance and level of obligation in the employment relationship: A social exchange approach. Joumal of Onganizational Behatior, $19(7), 731-744$.

Shore, L.M., L.E. Tetrick, and T.H. Shore, and K. Barksdale (2000). Construct validity of measures of Becker's side bet theory. Journal of V'orational Behatior, 57(3), 428-444.

Shore, L.M. and L.E. Tetrick (1991). A construct validity study of the survey of perceived organizational support. Joumal of Applied Psychology, 76(5), 637-643.

Shore, L.M. and S.J. Wayne (1993). Commitment and employee behavior: Comparison of affective commitment and continuance commitment with perceived organizational support. Journal of Applied Psychology, 78(5), 774-780.

Schwepker Jr, C.H. (2001), Ethical climate's relationship to job satisfaction, organizational commitment, and turnover intentions in the salesforce. Journal of Busimess Research, 54(1), 3952.

Sergeant, A. and S. Frenkel (2000). When do customer contact employees satisfy customers?. Journal of Senvice Research, 3(1), 18-34.

Settoon, R.P., N. Bennett, and R.C. Liden (1996). Social exchange in organizations: Perceived organizational support, leader-member exchange, and employee reciprocity. Journal of Applied Psychology, 81(3), 219-227.

Shankar, V., A.K. Smith, and A. Rangaswamy (2003). Customer satisfaction and loyalty in online and offline environments. International Journal of Research in Marketing, 20(2), 153-175.

Shaw, J.D., M.K. Duffy, G.D. Jenkins Jr., and N. Gupta (1999). Positive and negative affect, signal sensitivity, and pay satisfaction, Journal of Management, 25(2), 189-206.

Siguaw, J.A., G. Brown, and R.E. Widing II (1994). The influence of the market orientation of the firm on sales force behavior and attitudes. Journal of Marketing Research, 31(1), 106-116.

Simons, T. and Q. Roberson (2003). Why managers should care about fairness: The effect of aggregate justice perceptions on organizational outcomes. Journal of Applied Psychology, 88(3), $432-443$.

Singh, J. (1998). Striking a balance in boundary-spanning positions: An investigation of some unconventional influences of role stressors and job characteristics on job outcomes of salespeople. Joumal of Marketing, 62(3), 69-86.

Singh, J. (2000). Performance productivity and quality of frontline employees in service organizations. Journal of Marketing, 64(2), 15-34.

Soderlund, M. (1998), Customer satisfaction and its consequences on customer behavior revisited: The impact of different levels of satisfaction on word of mouth, feedback to the supplier and loyalty. Intemational Journal of Senvice Industry Management, 9(2), 169-188.

Smart, R.M. (1998). Career stages in Australian professional women: A test of Super's model. Joumal of L ocatiomal Bebarior, 52(3), 379-395.

Smith, C.A., D.W. Organ, and J.P. Near (1983). Organizational citizenship behavior: Its nature and antecedents. Journal of Applied Psychology, 68(4), 653-663.

Sohi, R.S., D.C. Smith, and N.M. Ford (1996). How does sharing sales force between multiple divisions affect salespeople?. Journal of the Acadeny of Marketing Science, 24(3), 195-207. 
Somers, M.J. (1995), Organizational commitment, turnover and absentecism: An examination of direct and interaction effects. Joumal of Organizational Beharior, 16(1), 49-58.

Somers, M.J. (1999). Application of two neural network paradigms to the study of voluntary employee turnover. Journal of Applied Psychology, 84(2), 177-185.

Spector, P.E. and S.M. Jex (1991). Relations of job characteristics from multiple data sources with employee affect, absence, turnover intentions, and health. Journal of Applied Psychology, 76(1), 46-53.

Spencer, D.G., R.M. Steers, and R.T. Mowday (1983). An empirical test of the inclusion of job search linkages into Mobley's model of turnover decision process, Journal of Occupational Psychology, 56(2), 137-144.

Spreng, R.A. and R.D. MacKoy (1996). An empirical examination of a model of perceived service quality and satisfaction. Joumal of Retuiling, 72(2), 201-214.

Stamper, C.L. and M.C. Johlke (2003). The impact of perceived organizational support on the relationship between boundary spanner role stress and work outcomes. Journal of Management, 29(4), 569-588.

Steers, R.M. (1977). Antecedents and outcomes of organizational commitment. Administrative Science Quarterly, 22(1), 46-56.

Stinglhamber, F. and C. Vandenberghe (2003). Organizations and supervisors as sources of support and targets of commitment: A longitudinal study. Joumal of Orgamizational Behavior, 24(3), 251-270.

Streukens, S and K. de Ruyter (2004). Reconsidering nonlinearity and asymmetry in customer satisfaction and loyalty models: An empirical study in three retail service settings. Marketing Letters, 15(2/3), 99-111.

Stumpf, S.A. and S. Rabinowitz (1981). Career stage as a moderator of performance relationships with facets of job satisfaction and role perceptions. Joumal of I ocational Betiatior, 18(2), 202 218.

Susskind, A.M., K.M. Kacmar, and C.P. Borchgrevink (2003). Customer service providers' attitudes relating to customer service and customer satisfaction in the customer-server exchange. Journal of Applied Psychology, 88(1), 179-187.

Szilagyi, A.D. (1977), An empirical test of causal inference between role perceptions, satisfaction with work, performance and organizational level. Personnel Psychology, 30(3), 375-388.

Szilagyi, A.D. and H.P. Sims, Jr. (1974). An exploration of the path-goal theory of leadership in a health care environment. Academy of Management Joumal, 17(4), 622-634.

$\mathbf{T}$

Taylor, S.A. (1996). Consumer satisfaction with marketing education: Extending services theory to academic practice. Joumal of Consumer Satisfaction, Dissatisfaction, and Complaining Beharvor, 9, 207-220. 
Taylor, S.A. and T.L. Baker (1994). An assessment of the relationship between service quality and customer satisfaction in the formation of consumers' purchase intentions. Journal of Retailing, 70(2), 163-178.

Taylor, S.A and G.L. Hunter (2002). The impact of loyalty with E-CRM software and E-services. International Journal of Senvice Industry Management, 13(5), 452-474.

Teas, R.K. (1983). Supervisory behavior, role stress, and the job satisfaction of industrial salespeople, Journal of Marketing Researh, 20(1), 84-91.

Tiegs, R.B., L.E. Tetrick, and Y. Fried (1992). Growth need strength and context satisfactions as moderators of the relations of the job characteristics model. Journal of Management, 18(3), 575-593.

Tierney, P. and T.N. Bauer (1996). A longitudinal assessment of LMX on extra-role behavior. Acadeny of Management Procedings, 298-302.

Tompson, H.B. and J.M. Werner (1997). The impact of role conflict/facilitation on core and discretionary behaviors: Testing a mediated model. Journal of Management, 23(4), 583-601.

Tosi, H. (1971). Organization stress as a moderator of the relationship between influence and role response, Acadeny of Management Joumal, 14(1), 7-20.

Turnley, W.H., M.C. Bolino, S.W. Lester, and J.M. Bloodgood (2003). The impact of psychological contract fulfillment on the performance of in-role and organizational citizenship behaviors. Journal of Management, 29(2), 187-206.

Tyagi, P.K. and T.R. Wotruba (1993). An exploratory study of reverse causality relationships among sales force turnover variables, Joumal of the Academy of Marketing Sicnce, 21(2), 143-153.

Uhl-Bien, M. and J.M. Maslyn (2003). Reciprocity in manager-subordinate relationships: Components, configurations, and outcomes. Joumal of Manugement, 29(4), 511-532.

V

Van Birgelen, M., K. de Ruyter, A. de Jong, and M. Wetzels (2002). Customer evaluations of aftersales service contact modes: An empirical analysis of national culture's consequences. Intemational Journal of Reseanth in Marketing, 19(1), 43-64.

Van Birgelen, M., K. de Ruyter, and M. Wetzels (2001). What makes service research centers effective? Joumal of Sentice Researih, 3(3), 265-273.

Vancouver, J.B., R.E. Millsap, and P.A. Peters (1994). Multilevel analysis of organizational goal congruence. Journal of Applied Psychology, 79(5), 666-679.

Vandenberg, R.J. and C.E. Lance (1992). Examining the causal order of job satisfaction and organizational commitment. Journal of Management, 18(1), 183-167.

Vandenberg, R.J. and V. Scarpello (1990). The matching model: An examination of the processes underlying realistic job previews. Journal of . Applied Psychology, 75(1), 60-67. 
Vandenberg, R.J., R.M. Self, and J.H. Seo (1994). A critical examination of the internalization, identification, and compliance commitment measures. Josimal of Management, 20(1), 123-140.

Van Dolen, W.. J. Lemmink, K. de Ruyter, and A. de Jong (2002). Customet-sales employees encounters: $A$ dyadic perspective. Journal of Retuiling, 78(4), 265-279.

Van Riel, A.C.R., V. Liljander, and P. Jurriéns (2001). Exploring consumer evaluations of Eservices: A portal site. International Joumal of Senvice Industry Mamagement, 12(4), 359-377.

Verhoef, P.C. (2003). Understanding the effect of customer relationship management efforts on customer retention and customer share development. Journal of Marketing, 67(4), 30-45.

Verhoef, P.C., P.H. Franses, and J.C. Hoekstra (2002). The effect of relational constructs on customer referrals and number of services purchased from a multiservice provider. Does age of relationship matter?. Journal of the Acadeny of Marketing Science, 30(3), 202-216.

Vigoda, E. (2000). Organizational politics, job attitudes, and work outcomes: Exploration and implications for the public sector. Journal of V ocational Beharior, 57(3), 326-347.

W

Wagner, S.L. and M.C. Rush (2000). Altruistic organizational citizenship behavior: Context, disposition, and age. Journal of Social Psychology, 140(3), 379-391.

Wayne, S.J., L.M. Shore, and R.C. Liden (1997). Perceived organizational support and leadermember exchange: A social exchange perspective. Academy of Management Journal, 40(1), 82 111.

Webb, D. and A. Jagun (1997). Customer care, customer satisfaction, value, and loyalty and complaining behavior: Validation in a UK university setting. Journal of Consumer Satisfaction, Dissatisfaction, and Complaining Behavior, 10, 139-151.

Wetzels, M. and K. de Ruyter, and J. Lemmink (1999), Role stress in after-sale service management. Journal of Serrice Researith, 2(1), 50-67.

Whitener, E.M. (2001). Do "high commitment" human resource practices affect employec commitment? A cross-level analysis using hierarchical linear modeling. Journal of Management, 27(5), 515-535.

Whitener, E.M. and P.M. Walz (1993). Exchange theory determinants of affective and continuance commitment and turnover. Journal of I ocational Beharior, 42(3), 265-281.

Wiley, D.L. (1987). The relationship berween work/nonwork role conflict and job related outcomes: Some anticipated findings. Journal of Management, 13(3), 467-472.

Williams, L.J and S.E. Anderson (1991). Job satisfaction and organizational commitment as predictors of organizational citizenship and in-role behaviors. Journal of Management, 17(3), 601-617.

Williams. L.J., M.B. Gavin, and M.L. Williams (1996). Measurement and nonmeasurement processes with negative affectivity and employee attitudes. Journal of Applied Psychology, 81(1), 88-101. 
$\mathbf{Y}$

Yoon, M.H., S.E. Beatty, and J. Suh (2001). The effect of work climate on critical employee and customer outcomes: An employee-level analysis. International Journal of Service Industry Management, 12(5), 500-521.

Yoon, M.H. and J, Suh (2003). Organizational citizenship behaviors and service quality as external effectiveness of contact employees. Joumal of Business Researb, 56(8), 597-611.

Yu, Y. and A. Dean (2001). The contribution of emotional satisfaction to consumer loyalty. International Journal of Senvice Industry Management, 12(3), 234-250.

\section{$\mathbf{Z}$}

Zhu, F.X., W. Wymer, Jr. and I. Chen (2002). IT-based services and service quality in consumer banking. International Journal of Senvice Industry Management, 13(1), 69-90. 
Nederlandse samenvatting 


\section{Inleiding}

Recent onderzoek toont aan dat er een positief verband bestaat tussen klantevaluaties zoals tevredenheid en loyaliteit enerzijds en de financiële prestatie van dienstverlenende bedrijven anderzijds. Hierdoor zijn steeds meer bedrijven erin geinteresseerd om klantevaluaties te gebruiken als indicatoren voor financiële prestatie. Effectief gebruik van klantevaluaties als voorspeller van financiële prestatie is gebonden aan de volgende twee voorwaarden. Ten eerste, inspanningen die gericht zijn op het verbeteren van klantevaluaties moeten financieel te verantwoorden zijn. Ten tweede is het noodzakelijk inzicht te krijgen in de complete set van verbanden tussen klantevaluaties en financiële prestatie en moet men deze verbanden kunnen kwantificeren.

Drie concepten uit de wetenschappelijke literatuur zijn essentieel om een diepgaand en volledig inzicht te krijgen in de complexe verbanden tussen klantevaluaties en financiële prestatie. Ten eerste, de Return on Services benadering, welke stelt dat investeringen in klantevaluaties behandeld moeten worden als reguliere investeringen. Dat wil zeggen, er moet een duidelijke en formele afweging worden gemaakt tussen kosten en opbrengsten die gemoeid zijn met dergelijke initiatieven. Het tweede theoretische concept dat een sleutelrol vervult in dit proefschrift is de Service Profit Chain. Dit model veronderstelt dat opbrengsten die voorvloeien uit commerciële dienstverlening het gevolg zijn van een verscheidenheid aan klantevaluaties, welke op hun beurt weer het product zijn van attitudes en gedragingen van de werknemer die de klant de daadwerkelijke dienst verleent. Op grond van de relaties in de senvice profit chain kan gesteld worden dat het aangaan en onderhouden van sterke klantrelaties een belangrijke bron van financieel gewin vormt. Uit deze veronderstellingen, komt het derde theoretische concept voort, customer equity. Onder customer equity verstaat men de collectieve financiële waarde van de klanten van een onderneming. Financiële klantwaarde is gedefinieerd als de contante waarde van opbrengsten die gegenereerd worden door een individuele klant minus de kosten om de klantrelatie te onderhouden. Uit eerder onderzoek blijkt dat customer equity een goede indicator is van de financiële waarde van een bedrijf en dat het een belangrijk en effectief criterium is bij het nemen van strategische beslissingen. 


\section{Motivatie}

Vanuit een theoretisch perspectief onderstrepen de volgende vijf lacunes in de empirische literatuur het belang van dit promotieonderzoek. Ten eerste, weinig studies richten zich op een integrale test van de Service Profit Chain, wat als gevolg heeft dat relevante causale en mediërende verbanden wellicht niet onderkend worden. Ten tweede, de Service Profit Chain verondersteld dat klantloyaliteit slechts wordt gevormd door klanttevredenheid. Echter, om klantloyaliteit zo goed en nauwkeurig mogelijk te voorspellen is het van belang om meerdere relevante antecedenten zoals perceived value en customer relationship perceptions te onderzoeken. Ten derde, hoewel onderzoekers het er over eens zijn dat dienstverlenende werknemers een belangrijke factor zijn in het vormen van klantevaluaties, is er slechts weinig bekend over de precieze mechanismen die werknemer percepties / gedragingen en klantevaluaties koppelen. Ten vierde resteert er nog veel onduidelijkheid over de exacte functionele vorm van de onderlinge relaties tussen klantevaluaties. Tot slot vormt het gebrek aan formele wiskundige modellen die klantevaluaties aan financiële prestatie koppelen een vijfde motief voor het onderzoek in dit proefschrift. Het ontwikkelen en implementeren van eerder genoemde wiskundige modellen vormt een noodzakelijke voorwaarde om op basis van klantevaluaties effectieve strategische beslissingen te kunnen nemen.

Naast de vijf genoemde theoretische drijfveren zijn er ook nog vier ontwikkelingen in de dienstverlenende sector te onderscheiden die het belang van dit promotieonderzoek accentueren. Allereerst moeten dienstverlenende bedrijven steeds meer resultaatgericht zijn om te kunnen overleven in een omgeving die gekenmerkt wordt door een steeds intensere nationale en internationale concurrentie. Ten tweede, geconfronteerd met een immense hoeveelheid klantinformatie over tevredenheid en (aankoop)gedrag zijn nieuwe benaderingen om op basis hiervan effectieve strategische beslissingen te nemen zowel wenselijk als noodzakelijk de concurrentie het hoofd te kunnen bieden. Ten derde, als gevolg van de recente boekhoudschandalen zijn ook dienstverlenende bedrijven steeds meer gedwongen openheid van zaken te geven over hun uitgaven en de financiële consequenties daarvan. Ten vierde, in de meeste ontwikkelde door diensten genomineerde economieën is 
er sprake van weinig groei en volwassen markten zijn trouwe klanten verworden tot een schaars goed dat agressief wordt nagejaagd door een groeiend aantal aanbieders.

\section{Doelstellingen en Studies \\ De centrale doelstelling van deze dissertatie is:}

Te onderzoeken hoe klantenevaluaties in de dienstensector effectief te managen in termen van financiële gevolgen

Om deze doelstelling te kunnen beantwoorden zijn de volgende onderzoeksdoelen geformuleerd.

1. Het integraal testen van de relaties die verondersteld worden in de Service Profit Chain

2. Het verkrijgen van inzicht in de relaties tussen enerzijds percepties, attitudes, gedrag van de dienstverlener en anderzijds klantevaluaties

3. Welke klantenevaluaties dragen bij aan de vorming van klantloyaliteit en hoe deze evaluaties aan elkaar en aan klantloyaliteit gerelateerd zijn.

4. Het empirisch testen van de functionele vorm van de verbanden tussen klant evaluaties in termen van nonlineariteit en asymmetrie.

5. Het opstellen van wiskundige optimalisatie modellen om hiermee de financiële gevolgen van verbeteringen in klantevaluaties formeel te evalueren en te optimaliseren.

De vijf bovengenoemde onderzoeksdoelstellingen vormen de leidraad voor de vier empirische studies van dit proefschrift. Deze vier empirische onderzoeksprojecten kunnen als volgt kort worden samengevat. In hoofdstuk 2 wordt de literatuur besproken met betrekking tot de verbanden die verondersteld worden in de Service Profit Chain. Ook wordt een meta-analyse 
uitgevoerd om al het beschikbare empirische bewijs met betrekking tot de Service Profit Chain te integreren. In hoofdstuk 3 wordt het complete Service Profit Chain onderworpen aan een integrale empirische test. Daarnaast wordt in hoofdstuk 3 een wiskundig model ontwikkeld en geschat dat voorvloeit uit een samensmelting van Serrice Profit Chain en de Retum on Services benadering. Het doel van dit wiskundige model is het anbieden van een methode die gebruikt kan worden voor een formele en economisch verantwoorde evaluatie en optimalisatie van de financiële consequenties voortvloeiend uit investeringen gericht op het verbeteren van klantevaluaties. In hoofdstuk 4 wordt dieper ingegaan op de werkelijke vorm van de relaties tussen verschillende relevante typen klantevaluaties. Zo zal in hoofdstuk 4 empirisch getest worden of de verbanden tussen verschillende soorten klantevaluaties gekenmerkt worden door asymmetrie en / of nonlineariteit. Het laatste onderzoeksproject, beschreven in hoofdstuk 5 van deze dissertatie, richt zich op het verschaffen van inzicht in en het optimaliseren van klant relaties gezien vanuit een customer equity perspectief.

\section{Resultaten en conclusies}

Deze paragraaf beschrijft de belangrijkste resultaten en conclusie van de vier studies opgenomen in deze dissertatie

Allereerst worden de resultaten besproken die betrekking hebben op de werknemers en de werknemer-klant relatie. Uit onze resultaten blijkt dat organizational citizenship behavior een significante directe invloed heeft op de gepercipieerde dienstenkwaliteit door de klant. Verder hebben ook job satisfaction en affective commitment invloed op de vorming van de door klanten gepercipieerde dienstenkwaliteit, echter dit effect is indirect en wordt volledig gemedieerd door organizational citizenship bebavior. Gezien de belangrijke rol die het gedrag van de dienstverlener vervult in het vormen van klantevaluaties, is het van het grootste belang dat managers het juiste gedrag van hun dienstverlenende medewerkers weten te stimuleren. Uit de resultaten van het onderzoek blijkt dat in het bijzonder de percepties die werknemers hebben met betrekking tot de organisatie waarvoor ze werken van invloed zijn op de mate waarin ze gedrag vertonen dat een positieve invloed heeft op 
klantevaluaties. Verder blijken taak gerelateerde factoren een belangrijke invloed te hebben op het gedrag van dienstverleners. Tot slot suggereren de resultaten dat het patroon van relaties dat de verschillende dienstlener percepties, attitudes, en gedrag aan elkaar koppelt, verschilt per dienstensector. Samengevat geven de gedetailleerde empirische resultaten dus richtlijnen voor het management van dienstverlenende werknemers, met als doel klantevaluaties, en uiteindelijk de financiële prestatie van het organisatie, positief te beïnvloeden.

Met betrekking tot de klantenzijde van de Service Profit Chain laten onze resultaten zien dat de relaties tussen klantevaluaties op zijn minst even goed worden beschreven door symmetrische lineaire functies dan door de meer complexe asymmetrische nonlineaire functies. Deze bevindingen impliceren dat zogenaamde specification errors door het gebruik van symmetrische lineaire verbanden onwaarschijnlijk zijn. Verder laten onze resultaten zien dat naast kwaliteit en tevredenheid, ook perceived value en trust een cruciale rol vervullen in het vormen van klantloyaliteit. Het meenemen van perceived value in modellen die klantloyaliteit trachten te voorspellen zorgt ervoor dat de afwegingen die klanten maken tussen de gepercipieerde kosten en baten in hun relatie met de dienstverlener expliciet worden meegenomen. De belangrijke rol die trust speelt in het vormen van klantloyaliteit benadrukt het relatiemarketing paradigma wat veronderstelt dat het ontwikkelen en onderhouden van sterke klantrelaties een zinvolle strategie lijkt te zijn in het verbeteren van klantloyaliteit en de daarmee samenhangende financiële gevolgen.

De resultaten van hoofdstuk 2 wijzen verder uit, dat verschillende factoren de relaties tussen klant evaluaties modereren. Zo blijken allereerst de onderlinge effecten tussen klant evaluaties voor pure diensten hoger te zijn dan voor product gerelateerde diensten. Verder blijkt dat het gebruik van zogenaamde single-item measures de grootte van de effecten tussen klant relaties kunstmatig verhoogt. Dit verschijnsel komt waarschijnlijk voort uit een gebrek aan discriminant validity van de single item measures in het meten van verschillende klantevaluaties. Het gebruiken van schalen die gekenmerkt worden door een 
hoge mate van construct validity is derhalve noodzakelijk indien men een realistische schatting wil maken omtrent de onderlinge effecten van klant evaluaties en hun uiteindelijke invloed op de financiële prestatie van een bedrijf. Tot slot blijkt uit de resultaten dat zowel de sterkte als de grootte van de relaties tussen klant evaluaties verschillen per klant segment. Dit resultaat impliceert dat het onderkennen van verschillende klantsegmenten een noodzakelijke voorwaarde is voor het effectief managen van klant evaluaties en de bijbehorende financiële consequenties..

Uit de resultaten van hoofdstukken 2 en 3 blijkt dat klantevaluaties inderdaad gerelateerd zijn aan financial performance. Deze bevindingen zijn van cruciaal belang daar zij de voornaamste aanname staven van de Service Profit Chain en de Return on Services benadering. Verder benadrukken deze resultaten de notie klantevaluaties te gebruiken als indicator van financiële prestatie.

Om initiatieven die gericht zijn om klantevaluaties te verbeteren respectievelijk te optimaliseren is het noodzakelijk de beoogde acties ook vanuit financieel oogpunt verantwoordelijk te maken voor de resultaten. Om dit te bereiken is er een wiskundig optimalisatie model ontwikkeld. Dit model bouwt voort op de Return on Services benadering, en heeft als belangrijkste voordeel dat de verbanden tussen acties, klantevaluaties, en de financiële gevolgen expliciet worden geformaliseerd en gekwantificeerd. Binnen het optimalisatie model wordt de Service Profit Chain gebruikt om de opbrengsten die voortkomen uit initiatieven ter verbetering van klantevaluaties te beschrijven. De kracht van het ontwikkelde optimalisatie model ligt in de veelzijdigheid aan beslissingsmogelijkheden waarvoor het model gebruikt kan worden. Voorbeelden van deze veelzijdigheid zijn: de mogelijkheid vast te stellen welke investeringsgrootte nodig is om een bepaald doel te bereiken, het bepalen van het rendement die een bepaalde investering met zich meebrengt, en het bepalen van de meest optimale allocatie van middelen bij een bepaalde investeringsgrootte. 
Curriculum Vitae 

Sandra Streukens was born on August 8, 1975 in Heerlen, the Netherlands. After completion of the secondary school at RKSG Serviam in Sittard, she studied at the Faculty of Economics and Business Administration at Maastricht University, The Netherlands. She specialized in Marketing and Marketing Research as well as Quantitative Economics and obtained her Master's degree in 1999. As of September 1999, she became a Ph.D. candidate at the department of Marketing and Marketing Research at the Faculty of Economics and Business Administration at Maastricht University. Her main research interests include: marketing research methods, customer service evaluations, customer value, service management and relationship marketing. Her work has been published in Marketing Letters, Journal of Economic Psychology, Journal of Business Research, International Journal of Service Industry Management, and International Journal of Internet Marketing and Advertising. 


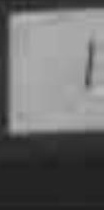

